\title{
Reclaiming Memories
}

\section{An Atlas of Palestinian Diaspora in Canada}

\author{
by \\ Pouian Delfanazari
}

\begin{abstract}
A thesis submitted to the Faculty of Graduate and Postdoctoral Affairs in partial fulfillment of the requirements for the degree of

Master of Architecture

in
\end{abstract}

Azrieli School of Architecture \& Urbanism

\author{
Carleton University \\ Ottawa, Ontario
}

(C) 2021

Pouian Delfanazari 


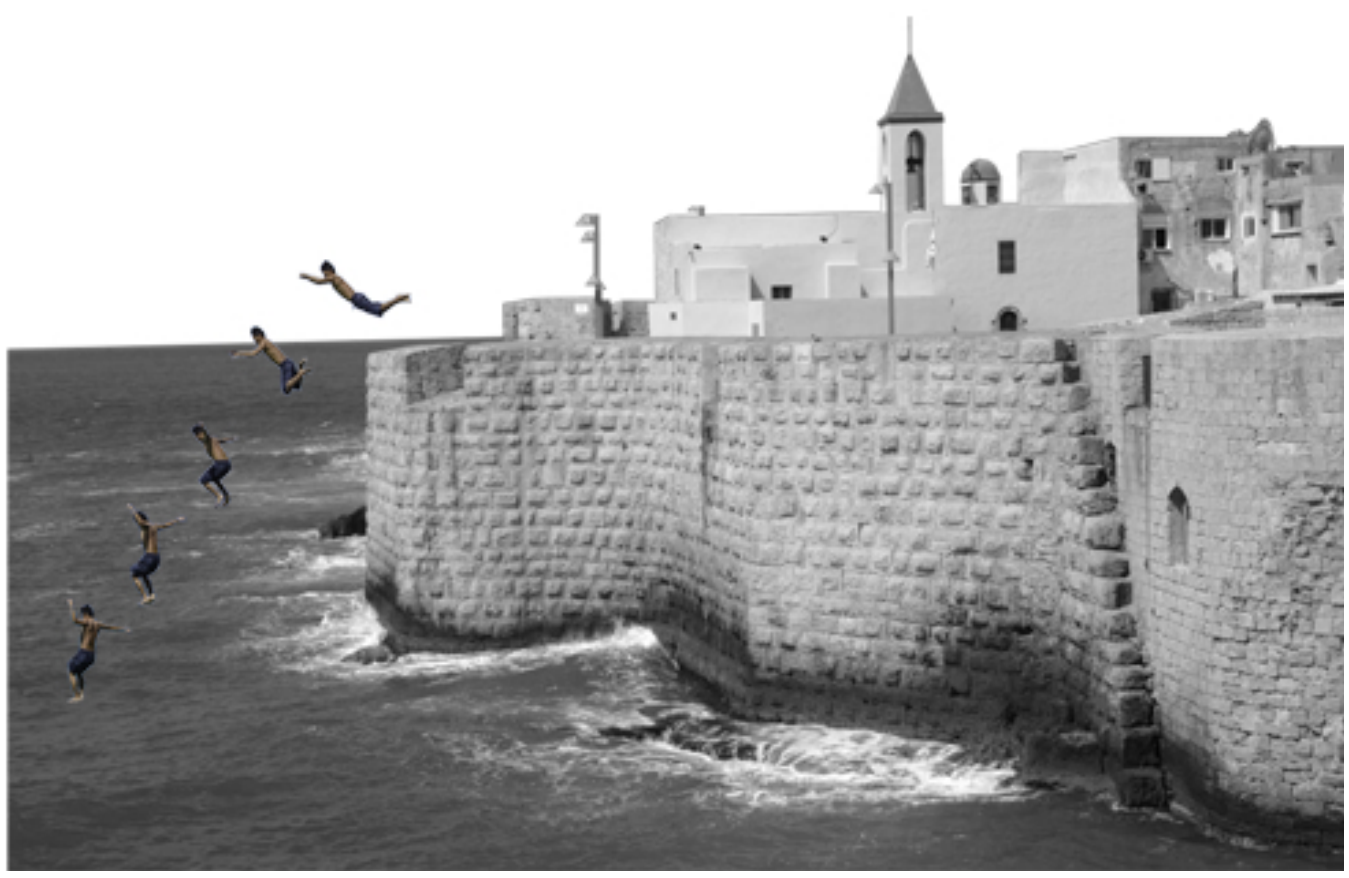




\section{Abstract}

Some 5 million people live in the Palestinian diaspora today, including over 50,000 individuals in Canada, as the prospects of a possible return to their ancestral homeland become ever more complicated with the realities of protracted occupation and exile. This thesis envisions a diasporic space for Palestinians in Canada. The aim is not to target a fixed reality towards specific architectural solutions, but rather to put forward speculations that would illuminate the diasporic identity of Palestinians living in Canada. The process of propositional space-making is underpinned by core concepts of oral history and collective identity, spatialization and reterritorialization, belonging and geography, as well as transnational and intercultural solidarity and memory. The intent of this thesis is to utilize architecture as a form of spatial agency for Palestinians, an apparatus for engaging diaspora as an operative process of common memory production and as the site of remote resistance and cultural preservation. Building on existing literature and case studies, as well as firsthand Canadian fieldwork and interviews, with a focus on community infrastructure and its associated social impacts, this thesis explores a series of interventions to interrogate the network of relations that would construct a space of diasporic connectivity. 


\section{Acknowledgements}

First, I would like to express my sincere gratitude to my thesis supervisor, Professor Suzanne Harris-Brandts, for her support and contribution to my project. This thesis would not be possible without her deliberate efforts to improve my work through edits, insightful suggestions, and words of encouragement. I am deeply grateful to have had the opportunity to spend an entire year engaging in conversations and exchanging thoughts with her. Along the same lines, I owe the completion of this book to those members of the Palestinian-Canadian community who participated in the interviews and whose contribution was critical to the development of the conceptual and spatial thinking behind this thesis. It is important to note that every single individual who contributed to the production of the atlas has a share in this process and an equal right to its conceptual and intellectual ownership. At last, I will leave an empty spot for colleagues and peers whom I wished to see and collaborate with in person, as a deprived opportunity due to the COVID-19 pandemic. 


\section{Table of Contents}

3

4

5

7

12

15
1.2 Methodological Reflections

1.1 Reclaiming Memories

24
3 Palestinian Diaspora
3.1 Diaspora in Palestine
3.2 Palestinian Diaspora in Canada

PART I - ATLAS

524 Diasporic Experiences

4.1 Narratives

4.2 Recalling the Unvisited

4.3 Family Home in Akka

4.4 Al Jazzar Mosque

4.5 The Seawall Jump

4.6 The Guest House

4.7 Gaza, an Internal Separation

4.8 Spatial Signals

4.9 Permitted views 


\section{PART II - INTERVENTION}

96

5 Conceptual Framework

5.1 Spatial Agency

5.2 The Guest House

1056 Revisiting the Madafah

6.1 An Interpretation

6.2 Mobile Madafah

6.3 Living Room

6.4 Tatreez

6.5 Screening

6.6 Recipe Sharing

1407 Conclusion

7.1 Permanent Temporariness

7.2 Concluding Remarks

146 Bibliography 


\section{List of Figures}

Figure 1.0 1984, Amman. Memories from Jerusalem

Source: Said, Edward Wadie, and Jean Mohr. After the Last Sky: Palestinian Lives. New York: Columbia University Press., 1999.

Figure 2.0 A village between Ramallah and Nablus, 1979

Source: Said, Edward Wadie, and Jean Mohr. After the Last Sky: Palestinian Lives. New York: Columbia University Press., 1999.

Figure 2.1 Amman 1981. The former mayor of Jerusalem and his wife in exile.

Source: Said, Edward Wadie, and Jean Mohr. After the Last Sky: Palestinian Lives. New York: Columbia University Press., 1999.

Figure 2.2 Jenin, 1984. Preparing for a feast.

Source: Said, Edward Wadie, and Jean Mohr. After the Last Sky: Palestinian Lives. New York: Columbia University Press., 1999.

Figure 2.3 Figure 3.0 - May 1983, Tripoli, Lebanon. A Palestinian wedding in exile.

Source: Said, Edward Wadie, and Jean Mohr. After the Last Sky: Palestinian Lives. New York: Columbia University Press., 1999.

Figure 3.0 Gaza, 1979. Farm using refugee labor.

Source: Said, Edward Wadie, and Jean Mohr. After the Last Sky: Palestinian Lives. New York: Columbia University Press., 1999.

Figure 3.1 Map of Palestinian Diaspora

Source: by Author

Figure 3.2 Jordan, 1984. Palestinian students at Baqa'a Camp.

Source: Said, Edward Wadie, and Jean Mohr. After the Last Sky: Palestinian Lives. New York: Columbia University Press., 1999.

Figure 3.3 Village of Senjel, near Ramallah, 1979. Rescued Bird.

Source: Said, Edward Wadie, and Jean Mohr. After the Last Sky: Palestinian Lives. New York: Columbia University Press., 1999.

Figure 3.4 Gaza, 1979.

Source: Said, Edward Wadie, and Jean Mohr. After the Last Sky: Palestinian Lives. New York: Columbia University Press., 1999.

Figure 3.5 Tyre, South Lebanon, 1983. A local official collects letters from the relatives of Palestinian refugees.

Source: Said, Edward Wadie, and Jean Mohr. After the Last Sky: Palestinian Lives. New York: Columbia University Press., 1999.

Figure 3.6 Palestinian Organizations in Canada

Source: by Author 
Figure 4.0 Geo-located Map of Interviewees

Source: by Author

Figure 4.1 Geo-located Map of Interviewee 1

Source: by Author

Figure 4.2 An Imaginary Dichotomy of Haifa (above) and Latakia (below)

Source: by Author

Figure 4.3 Geo-located Map of Interviewee 2

Source: by Author

Figure 4.4 Kheirullah Jarrah (front) with King Hussein (back)

Source: Jarrah, Maya. (2021, January 18). Personal Interview.

Figure 4.5 Issam Jarrah in Akka (Acre)

Source: Jarrah, Maya. (2021, January 18). Personal Interview.

Figure 4.6 Husni Jarrah's House in Akka, 1996.

Source: Jarrah, Maya. (2021, January 18). Personal Interview.

Figure 4.7 Moied Jarrah's House in Akka

Source: Jarrah, Maya. (2021, January 18). Personal Interview.

Figure 4.8 Fawzi Jarrah's House in Akka

Source: Jarrah, Maya. (2021, January 18). Personal Interview.

Figure 4.9 Anis Jarrah's House in Akka, 1996.

Source: Jarrah, Maya. (2021, January 18). Personal Interview.

Figure 4.10 Issam Jarrah's high school in Akka, 1996.

Source: Jarrah, Maya. (2021, January 18). Personal Interview.

Figure 4.11 The Jarrah Shop, 1996. (Interior)

Source: Jarrah, Maya. (2021, January 18). Personal Interview.

Figure 4.12 The Jarrah Shop, 1996. (Exterior)

Source: Jarrah, Maya. (2021, January 18). Personal Interview.

Figure 4.13 Masjid Al-Jazzar, Akka (Acre)

Source: Jarrah, Maya. (2021, January 18). Personal Interview.

Figure 4.14 Masjid Al-Jazzar (Exterior)

Source: Jarrah, Maya. (2021, January 18). Personal Interview.

Figure 4.15 Masjid Al-Jazzar, 1996. (Interior)

Source: Jarrah, Maya. (2021, January 18). Personal Interview. 
Figure 4.16 The sea wall jump

Source: Jarrah, Maya. (2021, January 18). Personal Interview.

Figure 4.17 The village of Biddya viewed from a family house

Source: Audeh, Rifat. (2021, January 19). Personal Interview.

Figure 4.18 The Audeh Family Madafah, Biddya

Source: Audeh, Rifat. (2021, January 19). Personal Interview.

Figure 4.19 Madafah (Axonometric)

Source: by Author

Figure 4.20 Madafah, a place to eat

Source: by Author

Figure 4.21 Madafah, a place to sleep

Source: by Author

Figure 4.22 Geo-located Map of Interviewee 4

Source: by Author

Figure 4.23 Selective Domains

Source: by Author

Figure 4.24 Pre-Radio Perception

Source: by Author

Figure 4.25 Post-Radio Perception

Source: by Author

Figure 4.26 Geo-Located Map of Interviewee 5

Source: by Author

Figure 4.27 Visual Route to the Mediterranean

Source: by Author

Figure 4.28 View of the Mediterranean from Ramallah, 2020

Source: Interviewee 5. (2021, February 12). Personal Interview.

Figure 4.29 Visual Route to Jerusalem

Source: by Author

Figure 4.30 The Dome of the Rock, 2018

Source: Interviewee 5. (2021, February 12). Personal Interview.

Figure 4.31 View of the Dome of the Rock from Ubeidiya, 2018

Source: Interviewee 5. (2021, February 12). Personal Interview. 
Figure 5.0 Conceptual Framework

Source: by Author

Figure 5.1 The Madafah of Al-Madi family in ljzim, near Haifa.

Source: Benvenisti, Meron. Sacred Landscape: The Buried History of the Holy Land since 1948. Berkeley: California University Press, 2002.

Figure 5.2 An Arab Feast

Source: http://factsanddetails.com/world/cat55/sub359/entry-5907.html

Figure 5.3 Sandi Hilal's living room used as a community hub

Source: https://www.visibleproject.org/blog/project/al-madhafah-the-living-room/

Figure 6.0 A mobile Madafah

Source: by Author

Figure 6.1 Madafah no.1, Exploded Axonometric

Source: by Author

Figure 6.2 Madafah no.2, Exploded Axonometric

Source: by Author

Figure 6.3 Living Room, Interior

Source: by Author

Figure 6.4 Living Room Plan, Selkirk Street

Source: by Author

Figure 6.5 The Living Room

Source: by Author

Figure 6.6 A Nocturnal Visit to the Homeland

Source: by Author

Figure 6.7 Tatreez, Interior

Source: by Author

Figure 6.8 Tatreez Casual Plan, McLeod Street

Source: by Author

Figure 6.9 Tatreez Event Plan, Ottawa Canal

Source: by Author

Figure 6.10 An Instruction Guide on Tatreez

Source: by Author

Figure 6.11 Tatreez by the Canal, Ottawa

Source: by Author

Figure 6.12 Tatreez Showroom

Source: by Author

Figure 6.13 Indoor Screening Plan, Selkirk Street

Source: by Author 
Figure 6.14 Indoor Screening, Axonometric

Source: by Author

Figure 6.15 Outdoor Screening Plan, Vancouver Art Gallery

Source: by Author

Figure 6.16 Outdoor Screening, Axonometric

Source: by Author

Figure 6.17 Screening Detail, Exploded Axonometric

Source: by Author

Figure 6.18 Documentary Screening, Vancouver Art Gallery

Source: by Author

Figure 6.19 Kitchen, Interior

Source: by Author

Figure 6.20 Recipe Sharing Event Plan, Stanley Park

Source: by Author

Figure 6.21 Recipe Collection

Source: by Author

Figure 6.22 Ingredient Repository

Source: by Author

Figure 6.23 Recipe Sharing Event Plan, Stanley Park

Source: by Author

Figure 6.24 Recipe Sharing Event, Axonometric

Source: by Author

Figure 6.25 Recipe Sharing Event, Stanley Park

Source: by Author

Figure 6.26 Recipe Sharing and Memories

Source: by Author

Figure 7.0 Acre, 1979. A Café at the port.

Source: Said, Edward Wadie, and Jean Mohr. After the Last Sky: Palestinian Lives. New York: Columbia University Press., 1999. 


\section{Prologue}

The question of Palestine as a much discussed topic in the global context resonates with my childhood spent in the Middle East, with the news I often overheard heavily depicting the ongoing conflict of occupation. This presence remained a silent part of my life until a few years into my undergraduate degree in Canada, where I became acquainted with a collective house consisting of Arab and Iranian communities in Vancouver. It was during the act of rebuilding my own social circle as an immigrant that I made direct contact with Palestinians living in Canada. While such interactions were solely situated around excuses for gatherings tied to music or food, it was the conversations that accompanied them, or rather that were generated during the course of the events, that struck me the most. In essence, this was my initial step towards identifying a prodigious personal appetite for the exchange of collective and individual memories, something that helped shape the theoretical framework of this thesis.

I clearly remember how the translation of a traditional song's lyrics from Arabic to English entailed uncovering its deeper story, for which only one person from the audience was aware-an individual whose knowledge was entirely backed by narratives and stories passed on from the older generation, rather than from official textbooks or documents. In this manner, I have similarly relied on what I think can justly be called the Palestinian experience in diaspora within Canadian borders. Over the course of 8 weeks, I engaged myself in conducting interviews with members of 
the Palestinian community in Canada, where I had the exceptional opportunity to become exposed to a wide range of narratives. I was able to discover the irreducible robustness of memories, not only pertaining to auditory or visual elements, but also to a sort of tactile imprint that concedes nothing to time.

During the process of documentation, there I had a relentless desire to put into practice the randomness by which these memories and narratives would often be shared-a distinct feature I had for long witnessed in my own interactions with people during gatherings at the collective house. I had observed, for instance, how taking a bite from a dish at a dinner party would open up a lively discussion over various recipes owned by several nationalities, or how a small variation in the dialect of a person singing in Arabic would be followed by endless discussions reciting narratives that explained the way such variation had taken shape. In line with this, it is important to note that the design process was as much influenced by the narratives from the interviews as from observing various ways through which they would circulate. The recognition of the complexities of individual experiences is rather central to becoming familiar with the Palestinian community and forming solidarity-a community whose image has often been overlooked, if not distorted in the West, and particularly in Canada. 
Forgotten, as if you never were.

Like a bird's violent death

like an abandoned church you'll be forgotten,

like a passing love

and a rose in the night... forgotten

Palestinian poet and author Mahmoud Darwish 


\section{Introduction}

\section{"The fish, even in the fisherman's net, still carries the smell of the sea."}

Mourid Barghouti, I Saw Ramallah (1997)

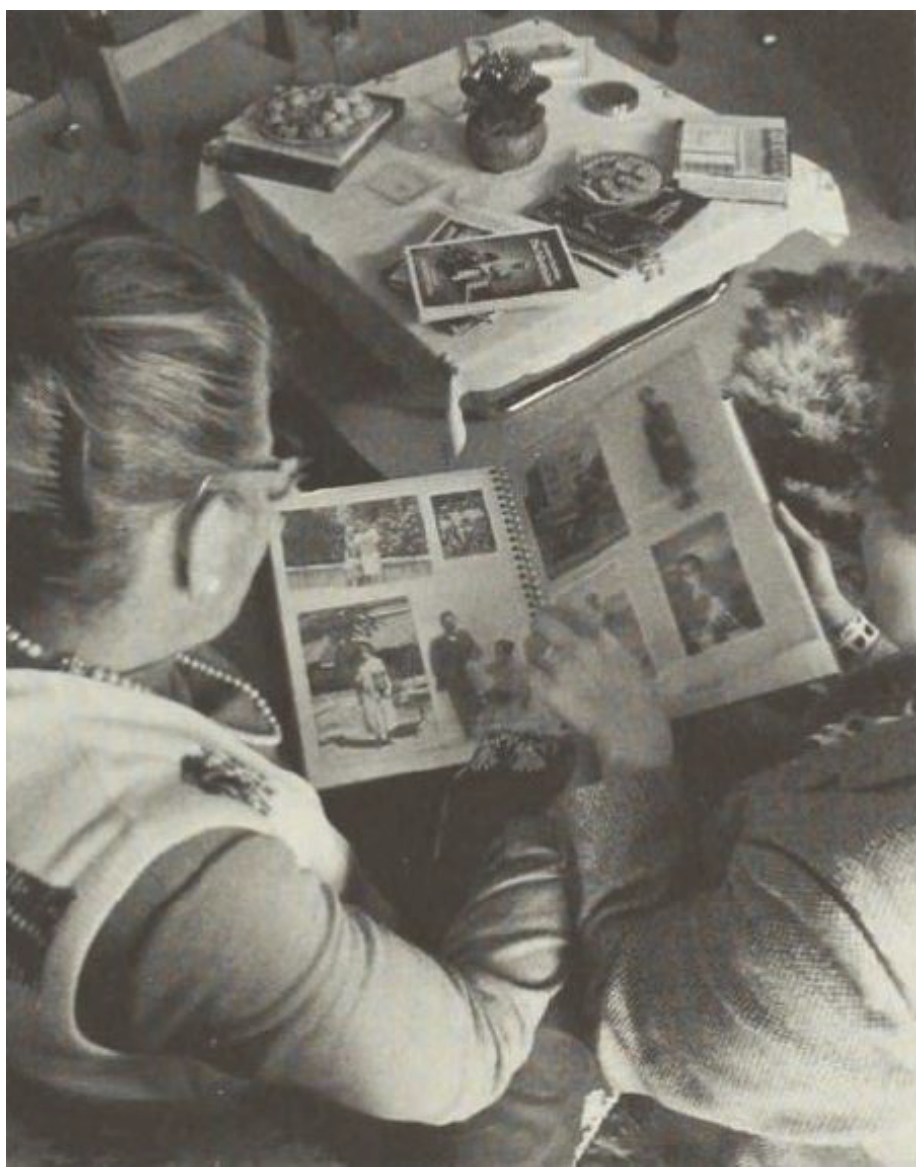

Figure 1.0 - Amman, 1984. Memories of Jerusalem 


\subsection{Reclaiming Memories}

Memory formation is a critical feature of life in diaspora. The irreducible durability of memories shapes the present as much as the past and is polished with the passage of time. An essential component of diaspora is the persistent simultaneity across place and time. The Palestinian diasporic community of Canada is defined by such rich and complex layers of shifting memories, resulting in identities that have defined a hybridized notion of citizenship. The magnitude and the range of discontinuities to Palestine among those who identify themselves as Palestinians in Canada is a key factor in establishing various levels of connection to the place of origin. Diaspora in its simplest form resembles life in two places within a shared and inseparable timeframe. The mere impossibility for some to visit the Occupied West Bank and the Gaza Stripdue to the ongoing restrictions and infringements on Palestinian rights to visit their homeland-has added an additional layer of complexity to such diasporic identity. However, the vision of Palestine as a homeland remains as the common denominator for those who identify themselves as members of the Canadian Palestinian community. As the research of this thesis will demonstrate, such self-identification occurs overwhelmingly among Palestinian Canadians, whether that person was born and raised in Palestine, or has never been able to visit their national homeland.

In order to unpack these narratives of Canadian-Palestinian identity and to consider design agency within them, this thesis is comprised of two parallel, nonsequential sections. Both sections are complimentary in terms of putting forward memory production as the main mode of connection to a sense of homeland within the Palestinian diasporic community in Canada. The first section serves as a visual 'atlas,' a series of narrative documentations which aim to collect not only shared memories but also individual experiences of Palestinian-Canadians in diaspora. This was accomplished 
through conducting five semi-structured interviews with members of Palestinian communities located across Canada, then sharing the completed visualizations back with community members. The atlas provides a layered and visualized way of understanding Palestinian cultural identity in Canada, mapping continuity to the place of origin and the various ways that one experiences being in two places simultaneously. As a formal document, this work brings together community stories that have yet to be compiled or officially written, with a clear emphasis on the spatial qualities of diasporic experiences.

The 'atlas' is comprised of image collages, architectural drawings, regional-scaled maps of the Palestinian diaspora (from official statistics), and spatial diagrams (for example, of existing community gathering spaces, like diving cliffs). The interviews conducted with members of the Palestinian diaspora in Canada provide a better sense of the type of spaces this community considers useful for gathering. In turn, the atlas informed my design process and the creation of spaces that can allow for common memory formation and community knowledge production. It is hoped that the work's engagement of this public and the documentation of their unique experiences will provide an opportunity to create further community solidarity.

The creation of the atlas is accompanied by designing mobile pavilions that could be shared by members of this community. The aim is to foster deeper connections and solidarity. The practice of memory formation that is central to the design is highly stressed in order to explore ways to facilitate solidarity as an ongoing performative and spatial practice. The designed pavilions would ultimately function as an architectural response supporting the subversion of existing power dynamics for a diasporic community, and showcasing the agency of Palestinians ultimately not as guests, but as hosts in Canada. The act of hosting would illuminate the cultural dimension of the 
project in addition to the political one. The mobile pavilions are designed as spaces to collect experiences, narratives, and various forms of knowledge from community members through a range of communal activities that they host. The design also aims to generate the contextual basis for an exchange of the collected information that engages a cross-cultural domain.

This thesis acknowledges architecture as an arena and medium for political violence and resistance in Palestine. There is a deliberate consideration of these political actions as important and necessary forces against the catastrophic nature of the Israeli occupation. However, its aim is instead to look at a parallel condition of diasporic life 'in the meantime'; and to complement these political tactical works by zooming in to see how solidarity might be fostered in a more banal day-to-day manner in diasporic communities. Taking the destructive impact of the occupation into account, the thesis investigates what spatial practices outside the occupied territories deserve attention. 


\subsection{Methodological Reflections}

This thesis employs a qualitative mixed methods approach, including document and media analysis, semi-structured interviews, mappings, and propositional design. The visual documentation of diasporic experiences is its primary research method. Such is achieved through conducting five semi-structured interviews with members of the Palestinian diaspora across Canada and then visualizing aspects of their oral histories. Building on the work of scholars such as Jens Haendeler and Vivien Sansour who propose community-based atlases, this thesis collects the narratives of Palestinians living in Canada. Haendeler's "Atlas al-'Ain" was a critical influence for the thesis to incorporate an atlas, examining how common memory production mobilizes return as a performative practice against the dispossession of Palestinians. The visual documentation component of the thesis draws heavily upon various mapping exercises and narrative collection techniques that the "Atlas al-'Ain" uses. Haendeler relies on an atlas in order to shed light on the ongoing nature of the Palestinian dispossession in the case of the al-Walaja springs, which were bisected across two territories when the present-day Green Line was put in place through the Israeli act of state-formation in 1949. ${ }^{1}$ The Palestine Heirloom Seed Library by Vivien Sansour likewise played a significant role in shaping the thesis's archival premise. Sansour's work involves exploring, sharing, and growing seeds of the ancient Palestinian landscape through a repository of first-hand knowledge and narratives from Palestinian farmers. ${ }^{2}$

Narrative of Place, a term introduced by the urban cultural geographer Jack Jen Gieseking (2013), provides a further lens to explain how a physical, remembered,

1 "Atlas Al-'Ain: The Performativity of "return" and Common ..." Accessed September 20, 2020. http://parsejournal.com/article/ atlas-al-ain/.

2 "Palestine Heirloom Seed Library." Visibleproject. Accessed October 21, 2020. https://www.visibleproject.org/blog/project/ palestine-heirloom-seed-library/. 
and imagined space (particularly a 'campus' in Gieseking's research) overlaps with the creation of a place where it is perceived and lived. Based on his findings, it is argued that asking participants to walk through their experience of a space helps relive and recall the embodied experiences of a place. The mapping exercise can also be viewed as an effective and efficient tool for helping participants recover memories that they do not usually have access to in their daily lives. Gieseking's study implied that reliving past experiences inspired most people to recall forgotten names of places, or experiences linked with those places that had not been remembered for years. ${ }^{1}$ Mapping techniques deployed in Gieseking's study are meant to define the relationship between the individual and place from the individual's point of view, as the lead agent who produces spaces, societies, cultures, and politics. However, this notion can also be explored in the opposite way, by examining how places live and produce people, subverting the power of place to an actor in the memory of the individual.

Drawing from Gieseking's approaches of accessing narratives of place, this thesis's research relies heavily on oral histories of spatial memory. Oral history as a method utilizes memory activation towards the way people actively generate and experience space. While each participant acts as a spatial agent in the process of spatial production, their active involvement sheds light on various types of spatial intelligence, and dynamics of human relationships with their surrounding environments. The visual recording of diasporic narratives as a research exercise can be considered a powerful alternative to research interviews that rely entirely on verbal exchange. Visual methods allow for oral sources or written narratives of places to be comprehended within a completely different medium. The research is, therefore, not only intended to incorporate drawing and mapping as a mere documentation technique, but also aims to offer a deeper understanding of how the visual representation of memories

1 Gieseking, Jack Jen. "Where We Go From Here." Qualitative Inquiry 19, no. 9 (2013): 712-24. doi:10.1177/1077800413500926. 
can inform qualitative analyses of diasporic subjects, experiences, and spaces. The inclusion of visualized histories in the interviews thus unites the physical world with the imagined one.

The interview process involved recording and analyzing personal narratives and experiences, as well as physical artifacts such as photographs or keepsakes, that shape each person's identity in diaspora. Participants were chosen from the adult Palestinian community of Canada, with no preferred gender, education, religion, geographic location, or socio-economic status. The only inclusion criteria considered was for participants to be of self-identified Palestinian ancestry and living or having lived in Canada. Participants were asked to provide personal insights on their life in diaspora, and to share personal experiences and oral histories of their communities. Interviews were each approximately one hour and semi-structured, guided largely by the topics the interviewees wished to discuss. Depending on interviewee consent, they were or were not audio recorded. Those who wished to remain anonymous also had that option. In addition to interviews, the thesis included images linked to the diasporic community, such as public gatherings in Canada and keepsakes from overseas. Participants were recruited through contacting non-profit solidarity for Palestinian human rights organizations at multiple Canadian universities and through individuals referred by them. Others were recruited through sharing posters with Palestinian community groups on social media. Due to restrictions imposed by COVID-19, interviews took place online via the Zoom platform. Participants were asked to reflect on their lived experience as a Palestinian in diaspora and to help examine aspects of such that could be visualized or spatialized. These key elements of diasporic life helped me as a researcher to document and elaborate on discontinuities between one's place of origin and a secondary home. 
Each interview deeply engaged the interviewee, with them providing personal insights into their life in diaspora in Canada, sharing unique experiences and narratives of everyday life in their community. The interviews included posing questions regarding the typical place of gathering as a community and the type of architecture/spaces that support their encounters. The resultant data included interview recordings, notes and transcripts, photographs, maps and the collection of artifacts and their images. It is important to note that the intent of the research was not to be representative of the diasporic population, but to understand and document individual diasporic experiences on a case-by-case basis. The thesis represents the diverse voices of multi-positioned participants through narratives, quotations, images, maps, and drawings. As an atlas of diaspora, this thesis is, therefore, on its own a process of knowledge production and diasporic content, in addition to the spatial intervention that it aims to introduce. The creation of such an atlas involves a rigorous investigation into diasporic acts that are particularly borne out of the Palestinian situation. The examination and documentation of such experiences were parallel to the creation of a spatial intervention, in order to directly fold their feedback into the design.

Each interviewee participated in a total of two sessions. The first meeting served as an introductory point for becoming familiarized with the participant's background and perspectives before formally asking for the specifics of their personal narrative. The latter involved analyzing and discussing images and drawings that reflected each person's story. For each interview raw images and personal narratives were collected from participants in the first interview. Then, the collaged aspects of their stories were provided to participants during the next interview to carry forward the conversation. Given the spatial nature of each story told over the course of the interview, the collages and drawings produced helped accentuate particularities of such spatial dimension. Indeed, the second round of discussion provided an opportunity for in- 
terpretation.

Textual sources collected and documented as a part of this thesis include notes, maps, and manuscripts. Creative sources, such as music notes, novels, poems, films, and photos, were intended to be complimentary, but, in some instances, became even more valuable in terms of data significance. Oral sources can be divided into two categories, one that consists of first-hand personal narratives and another that consists of oral stories passed down from one generation to another. At a deeper level of analysis, oral sources concern local dialects and slangs that are inevitable parts of the oral transfer of knowledge. Key elements of the diasporic life would help document and elaborate on discontinuities between one's place of origin and home in Canada.

The structural formation of the interviews as a repository of individual and collective experiences was inspired by the idea of the Madafah, as a digital gathering during the COVID-19 pandemic. While the design intervention envisions a physical space of interaction for the passage of narratives, the online process of memory collection is itself a virtual Madafah space. The serial order of interviews also played a part with subverting the guest/host dynamics between me and the interviewees. From the first session to the latter, my role as a host researcher shifted towards being a guest listener. Some participants managed to take hold of the conversation and allow for a dialogue to take place over the course of the interview. The thesis rather explores these various arenas of diasporic conversation virtually and through a spatial intervention. 


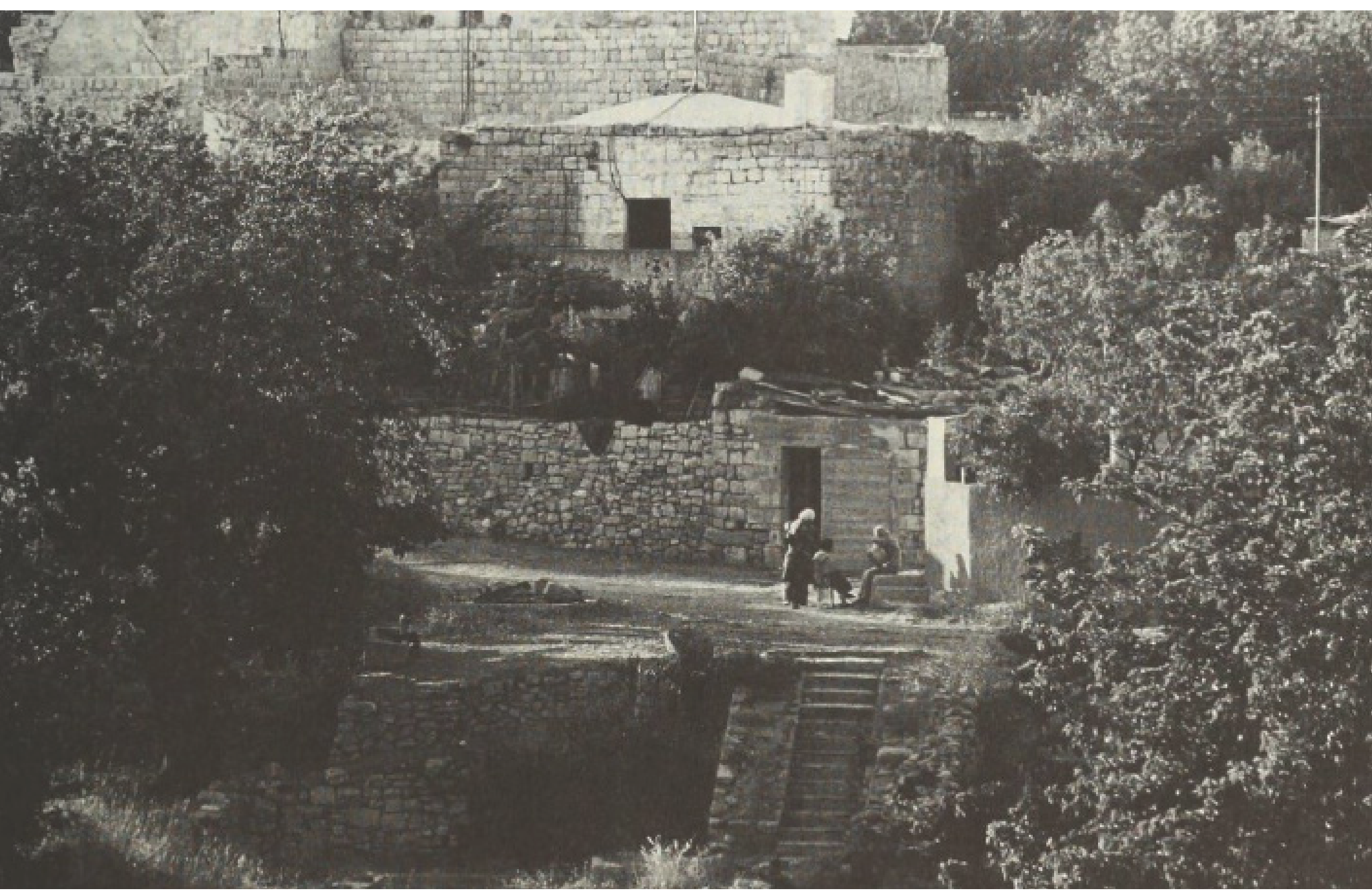

2 Diaspora

Figure 2.0 - A village between Ramallah and Nablus, 1979
"Whereas nostalgia is the desire to return home, to remember is to bring to mind or think of again, to be mindful of, to recollect. Both remembering and re-collecting, suggest a connecting, assembling, a bringing together of things in relation to one another."

Sinead McDermott, Memory, Nostalgia, and Gender in A Thousand Acres (2002) 


\subsection{Diaspora and Memory}

Memories are tactile. The past, like the present, offers events that define hybridized identities in a new setting, yet with their own socio-political domains. The established connection between individual and collective pasts are essentially established through memories, whether directly encountered or inherited from the experiences of others. Thus, the past is, indeed, an active production of a continuous present. ${ }^{1}$ To understand the dynamic interaction between the past and the present, there needs to be a rigorous investigation of the boundaries and meanings of such relationships with time, place, and social context. Life in diaspora and the communities in which diasporic subjects are born pertain to the same complex web of extraterritorial transitions. The transition between different socio-cultural domains is confronted with a hybridization of identity, rather than a mere transformation of an 'old' state of life into a 'new' physical location. The overlap of memories of places of origin, as well as entanglements with places of residence, produces such hybrid identification.

The original use of the word diaspora was intended to serve as a description for the forced displacement of the Jewish, Armenian, and Greek peoples. ${ }^{2}$ The key defining components of diaspora can be expressed to elucidate the diverse qualities of what essentially constitutes the phenomenon. In his seminal essay, "Diasporas in Modern Societies: Myths of Homeland and Return", political Scientist William Safran provides a diverse range of collective experiences that shape the term diaspora in similar and different ways. He outlines the main features of diaspora in terms of expatriate minority communities that are dispersed from a place of origin or hold a memory of that original center. He also includes those alienated in their host country, or those

1 Hirsch, Marianne, and Valerie Smith. 2002. Feminism and Cultural Memory: An Introduction. Signs: Journal of Women in Culture and Society, 28(1): 9

2 Clifford, James. 1994. Diasporas. Cultural Anthropology 9(3): 305. 
who view their ancestral home with a desire for eventual return when times allow. Safran describes the latter group as those who share the following characteristics:

"They continue to relate, personally or vicariously, to that homeland in one way or another, and their ethno-communal consciousness and solidarity are importantly defined by the existence of such a relationship."3

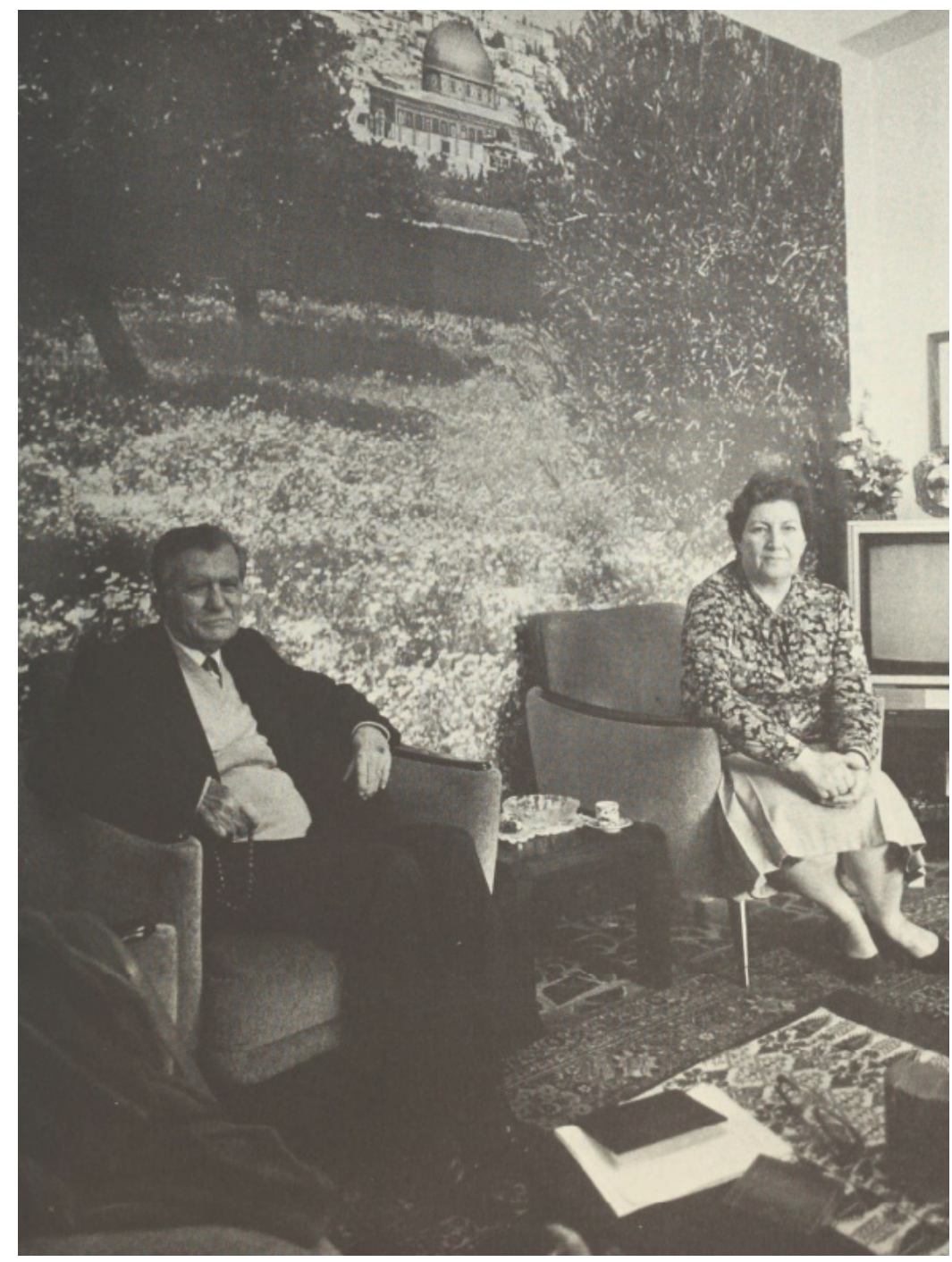

Figure 2.1 - Amman 1981. The former mayor of Jerusalem and his wife in exile.

3 Safran, William. "Diasporas in Modern Societies: Myths of Homeland and Return." Diaspora: A Journal of Transnational Studies 1, no. 1 (1991): 83-84 
Safran's perspective elucidates a complex discursive field for understanding diaspora as a multi-dimensional topic. Hence, the notion of diaspora is defined far beyond a dislocation from an original center. The multiplicity of diasporic qualities offers a variety of perspectives from which diaspora is lived and experienced over time. The temporal aspect of diaspora has a lasting impact on shaping diasporic communities. For example, the transition from a first generation that is directly relocated from an ancestral homeland into a guest country, to a latter generation whose only point of connection is perhaps the memories and the lived experiences of the former entails the continuity of shifting identities in diaspora. Nevertheless, for the coming generations, social and physical boundaries still influence the connection to their place of origin. The ever-present tension between being 'here' and recalling 'there' frames diaspora as a double presence across two places at once. In the book, "Diaspora, Memory and Identity: A Search for Home," Vijay Agnew elaborates on the historical dimension of diasporas in relation to memory, which is clearly discussed in the following passage:

"Diasporas are grounded in historical and cultural specificity that are heterogeneous and contested sites differentiated by gender, class, sexual orientation, generational difference, language access, historical experiences, and geographical locations. Diasporas are fluid, changing with history, not fixed or pre-given. Scholars who study diasporas have documented how cultural memory can be negotiated, claimed, and invented. Diasporic writers, poets, and artists have deployed collective memory to document the traditions, rituals, and history of their communities and groups."1

Individual and collective memories need to be differentiated in order to trace qualities that belong to a group of people as a whole against individual experiences. Individual memory stands for the memory of a single person, maintained within a lifetime, that is developed and enriched by direct experience. Collective memory, by contrast, that

1 Agnew, Vijay. Diaspora, Memory and Identity: A Search for Home. Toronto: University of Toronto Press, 2013: 204 
also has a cultural dimension in essence, represents the collective memory of multiple generations of the same roots. ${ }^{2}$ Memory constructs the past rather than reviving it. Collective memories are retained by members of a group and can be represented in various forms, from oral and written histories to cultural practices. In fact, collective memories only come after individual memories are constructed, with enough repetitions and occurrences that allows for certain events to be engraved in people's minds.

2 Bertman, Stephen. Cultural Amnesia: Americas Future and the Crisis of Memory. Westport, CT: Praeger, 2000: 31 


\subsection{Diasporic Boundaries}

"A second implication is that every society - and hence every mode of production with its subvariants (I.e. all those societies which exemplify the general concept - produces a space, its own space."1

- Henri Lefebvre

To define the boundaries and borders of diaspora, it is important to stress how common territory and time are traversed simultaneously. An essential quality of diaspora is the pure experience of being at two places at the same time. Although diasporic and immigrant populations are commonly defined against the norms of their nation states, James Clifford argues that people in diaspora do not fully integrate to the new host country like most immigrants. Clifford states that loss and nostalgia are a shared ground for both groups, although for the immigrant population these are challenges faced during a transition to a whole new home. By contrast, the diasporic identity is essentially determined by mutual displacement and a sense of loss that is not able to be remedied by integrating into a new society. ${ }^{2}$ The disparities of uneven and unequal memories and loss in relation to a place of origin establish a constant 'reterritorialization' of the diasporic space.

Along similar lines, in his seminal article "Culture's In-Between" Indian-English scholar and critical theorist, Homi Bhabha, discusses the notion of 'unhomely' and the emergence of in-between culture. Bhabha states that the migrations of modern times develop a 'partial' culture in the new context that is both analogous and dissimilar from the parent culture. In fact, the individual setting foot on new soil bring with them only a part of the total culture. ${ }^{3}$ The concept of hybridity here aims to describe an intersti-

1 Lefebvre, Henri. The Production of Space. Malden, MA: Blackwell, 2016: 31

2 Clifford, James. 1994. Diasporas. Cultural Anthropology 9(3): 307

3 Bhabha, Homi K. "Culture's In-Between." Questions of Cultural Identity Stuart Hall and Paul du Gay. London: Sage, 1996: 54 
tial agency that does not seek a binary representation of social antagonism. Instead, hybrid agencies establish the partial culture that they develop in the new setting in order to create visions of community, and forms of historic memory. ${ }^{4}$ Hybrid identity is indeed shaped by background, through everyday experiences and essentially specified across differences. In "Nation and Narration", Bhabha clearly states that hybridity is not simply the combination of pre-given identities. It is rather expressed by the bafflement of the living as it disrupts the fullness of life in the way it is represented. ${ }^{5}$ The essence of such perplexity could be identified not only in terms of cultural differences one faces upon entering a new environment, but also by the complimentary role of cultural identity formation and reterritorialization.

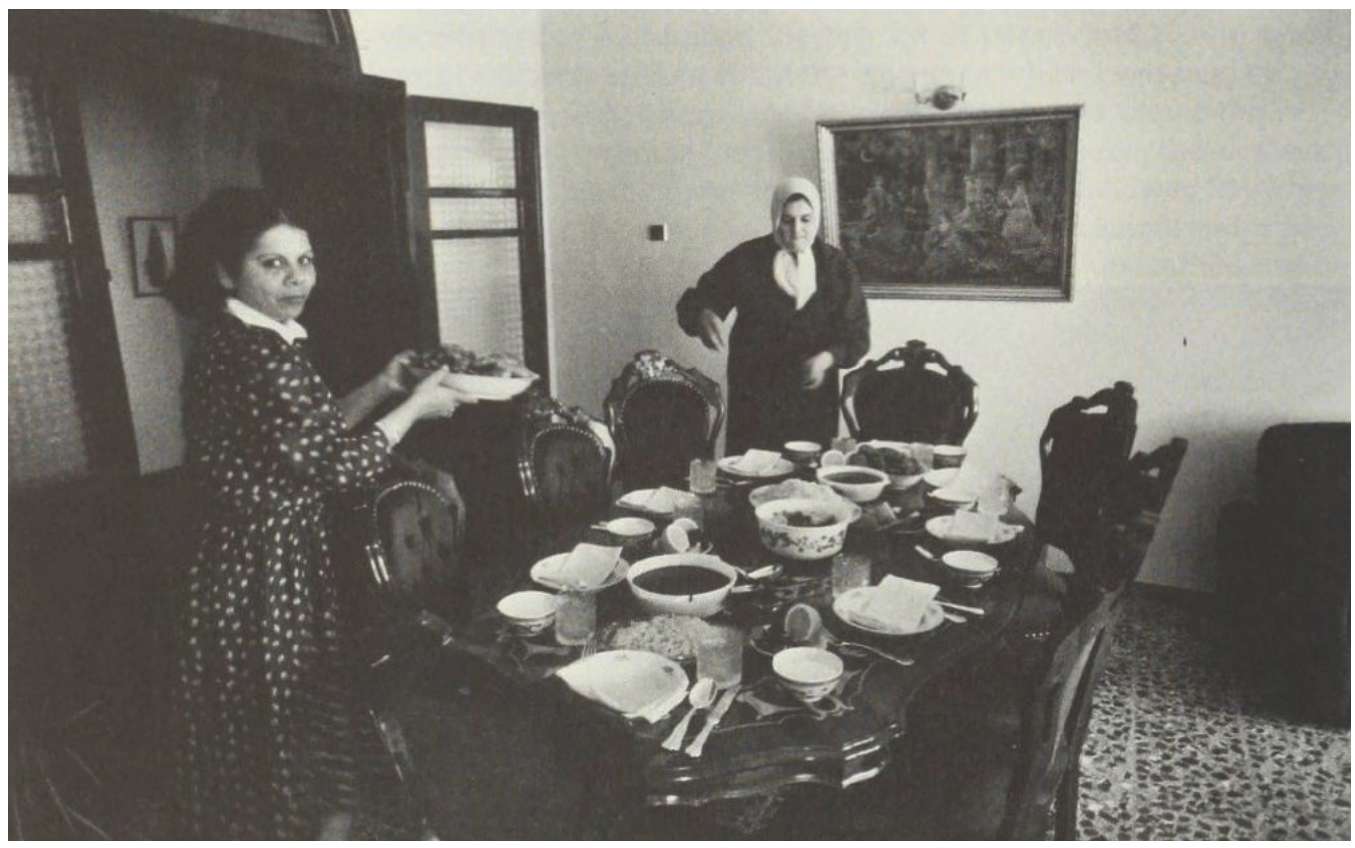

Figure 2.2 - Jenin, 1984. Preparing for a feast. 
We see these notions of hybridity in many diasporic communities, including their crucial links to the built environment. For example, in her dissertation, "Diasporic Agencies,", architect Nishat Awan explores fragmented notions of belonging experienced by diasporic Kurds in East London and the role of politics, subjectivity, and co-production of space in understanding their diasporic inhabitations. Awan argues that the consequent reterritorialization of space by the diasporic subject that comes after displacement can be utilized as a mode of thinking and doing. The diasporic condition is discovered through everyday practices in diaspora, as a basis for a new form of urbanism. ${ }^{1}$ The process of reterritorialization here reflects on the hybridity of diasporic identity, which is formed though the dialogue between the individual and their new environment. In this sense, diaspora is given meaning in terms of the 'production of subjectivities,' rather than fixed identities. This conception of identity is defined through the difference encountered in a new setting, in other words by hybridity. Indeed, it is through difference and transformation that diasporic identities constantly produce and reproduce themselves in new ways. ${ }^{2}$ Awan expands on 'deterritorialization' and 'reterritorialization', a concept borrowed from Deluze and Guattari, which describes the ways diasporas define and transform space. ${ }^{3}$ From a diasporic standpoint, Awan describes the concept of 'reterritorialization' as follows:

"...the adapting and adopting of various cultural and bodily practices, and enacting these performatively to produce specific inhabitations of space." ${ }^{4}$

The fundamental principle behind marking new territories concerning diasporas, is the autonomy of the individual to be under the influence of being 'here' and 'there'. This influence refers to the tension between two places that are considered home to

1 Awan, Nishat. "Diasporic Urbanism: Concepts, Agencies \& Mapping Otherwise." PhD Dissertation: 9

2 lbid: 18-19

3 Ibid: $20-21$

4 lbid: 45 
the diasporic citizen. The tension is essentially rooted in the dual belonging of being half-here and half-there. Such demarcation is beyond the physical boundaries of the subject's new place of residence, constantly affected by the ceaseless flow of memories and cultural influences rooted in the place of origin. The diasporic space can exemplify these aspects through a strong emphasis on notions of difference and the ways they take place in daily life. The concerns of 'elsewhere' reactivate attributes that are collectively shared amongst members of the diasporic community. The nature of space concerning diasporic communities, therefore, does not bear a fixed character or placement within a physical setting. Rather, a diasporic space can exist and survive through temporary gestures of remembering and re-enacting activities that are embedded within the culture of origin. The contextual ground for these practices to live and survive can bear the same level of temporariness. We see a supporting argument for this provided by Arjun Appadurai in his book "Modernity at Large", where he cites examples such as Turkish guest workers watching Turkish films in Germany, and Pakistani cab drivers listening to sermons recorded in mosques in Pakistan or Iran. Appadurai stresses the role of globalization and modernity on the production of these spheres, that allow for intimate access to two coexisting worlds. ${ }^{5}$

The important aspect in the simultaneity of diasporic spatial production discussed above is the adaptability of this act of creation, which can be implemented within any space. The domestic realm offers a cultural stronghold to activate and generate points of connection to the place of origin, in forms and ways that are particularly borne out of a diasporic condition. For example, a Pakistani cab driver listening to a locally recorded sermon in Pakistan does not experience the same sense of homeland connection as a Pakistani driver who lives in a foreign country. Physical detachment,

5 Arjun Appadurai, Modernity at large: Cultural dimensions of globalisation (Minneapolis: University of Minnesota Press, (1996): 24 
therefore, paradoxically makes the sense of loss and separation bolder. It even triggers psychological and emotional conditions that owe their existence to longing for an original 'home'. The everyday practices that take place in a 'secondary home' can drastically differ from the customs and cultural attributes of the first domestic home, which is related to the evident differences between the two worlds.

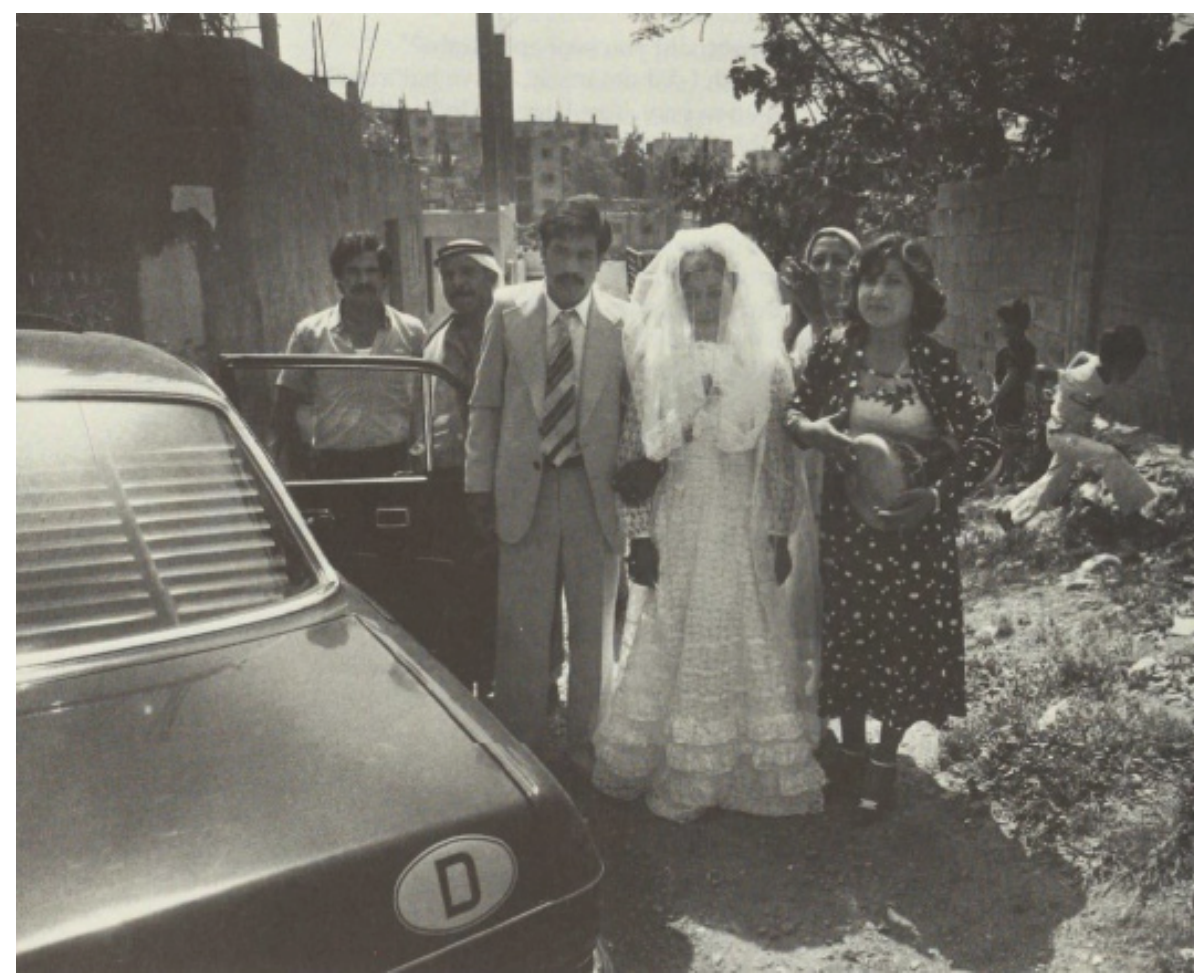

Figure 2.3 - May 1983, Tripoli, Lebanon. A Palestinian wedding in exile. 
Similar arguments are made by architect Nezar AlSayyad, who builds on Bhabha and Appadurai's work, folding in a deeper understanding of the built environment's relationships to such hybrid identities. Sayyad examines identity in relation to notions of hybridity, difference, and place. ${ }^{1}$ He notes that hybridity is not a third notion that settles the tension between two cultures. In other words, according to Bhabha's Lacanian formulation, hybridity cannot be simply viewed as the synthesis of $X$ and $Y$; instead, identified as X and . $^{2}$ Bhabha's conception of "third space" seeks to explain the emergence of hybridity in terms of an "in-between" space where elements transform and interact with each other. ${ }^{3}$ AlSayyad refers to a series of cases to elucidate multiple dimensions of hybridity. One such case is the story of Dr. Ahmad Tibi, an Israeli Arab lawmaker, where Tibi remains silent while others sing at the swearing in of members of the Israeli parliament. Tibi here faces a great contradiction between his twin identities, given that the rights of the Arabs to their own state are not recognized by Israel. ${ }^{4}$ The following passage describes the logic of hybridity in Tibi's case:

"Tibi has attempted to reverse his status as an individual from a deprived national minority with no influence on national decision making ... What maybe be observed briefly in these articles are situations in which assumed dualities are torn open and the logic of hybridity is introduced. The process does not simply involve the combination or merger of incompatible elements, but instead the insertion of a third possibility connecting originally incommensurable terms and irreconcilable realities." 5

1 AlSayyad, Nezar. Hybrid Urbanism: On the Identity Discourse and the Built Environment. Westport, CT: Praeger, 2001: 5 2 Ibid: 6

3 Ibid: 7

4 lbid: 3

5 Ibid: 3 


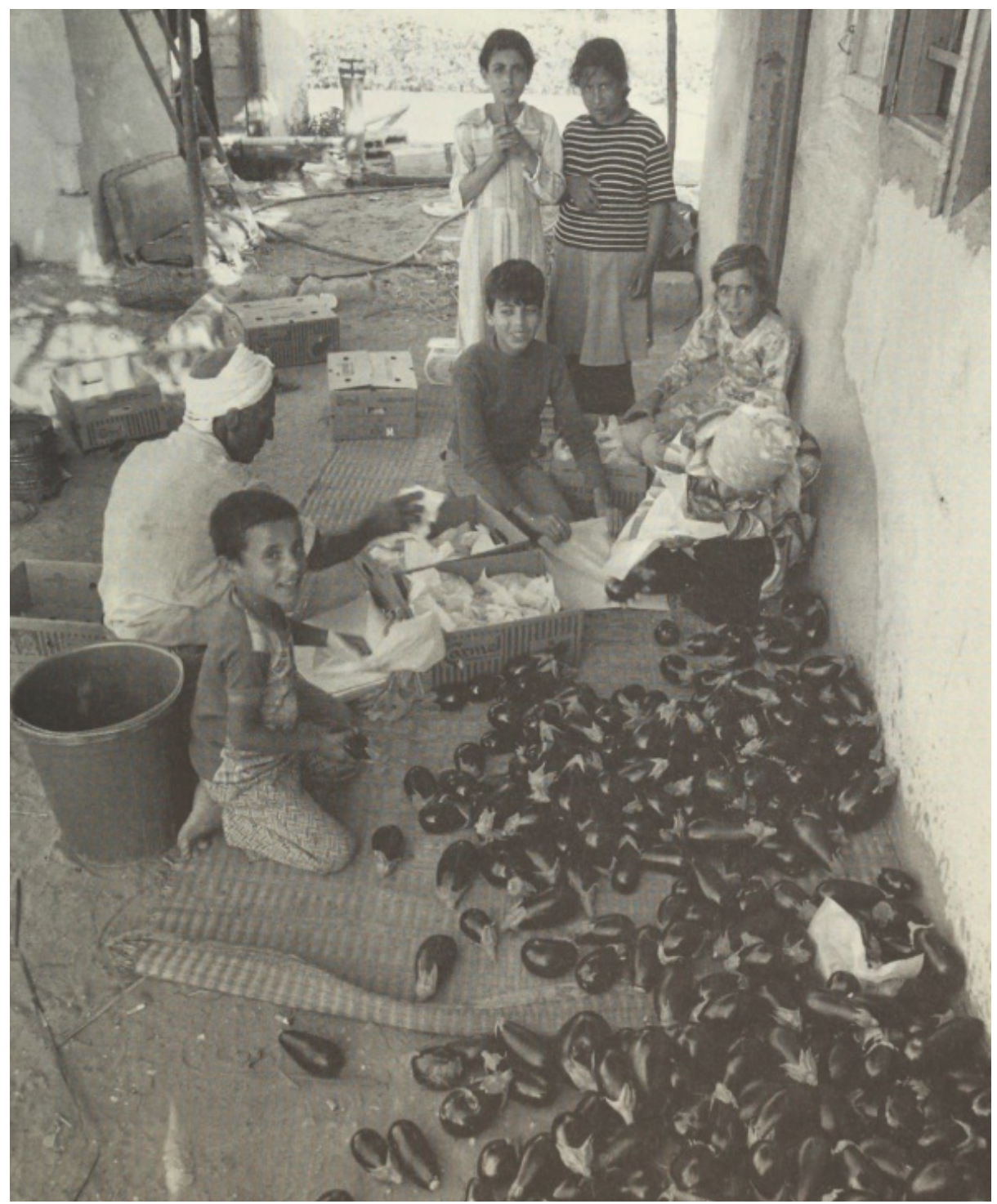

Figure 3.0 - Gaza, 1979. Farm using refugee labor.

\section{Palestinian Diaspora}

"Exile is strangely compelling to think about but terrible to experience. It is the unhealable rift forced between a human being and a native place, between the self and its true home: its essential sadness can never be surmounted."

Edward Said, Reflections on Exile and Other Essays (2012) 


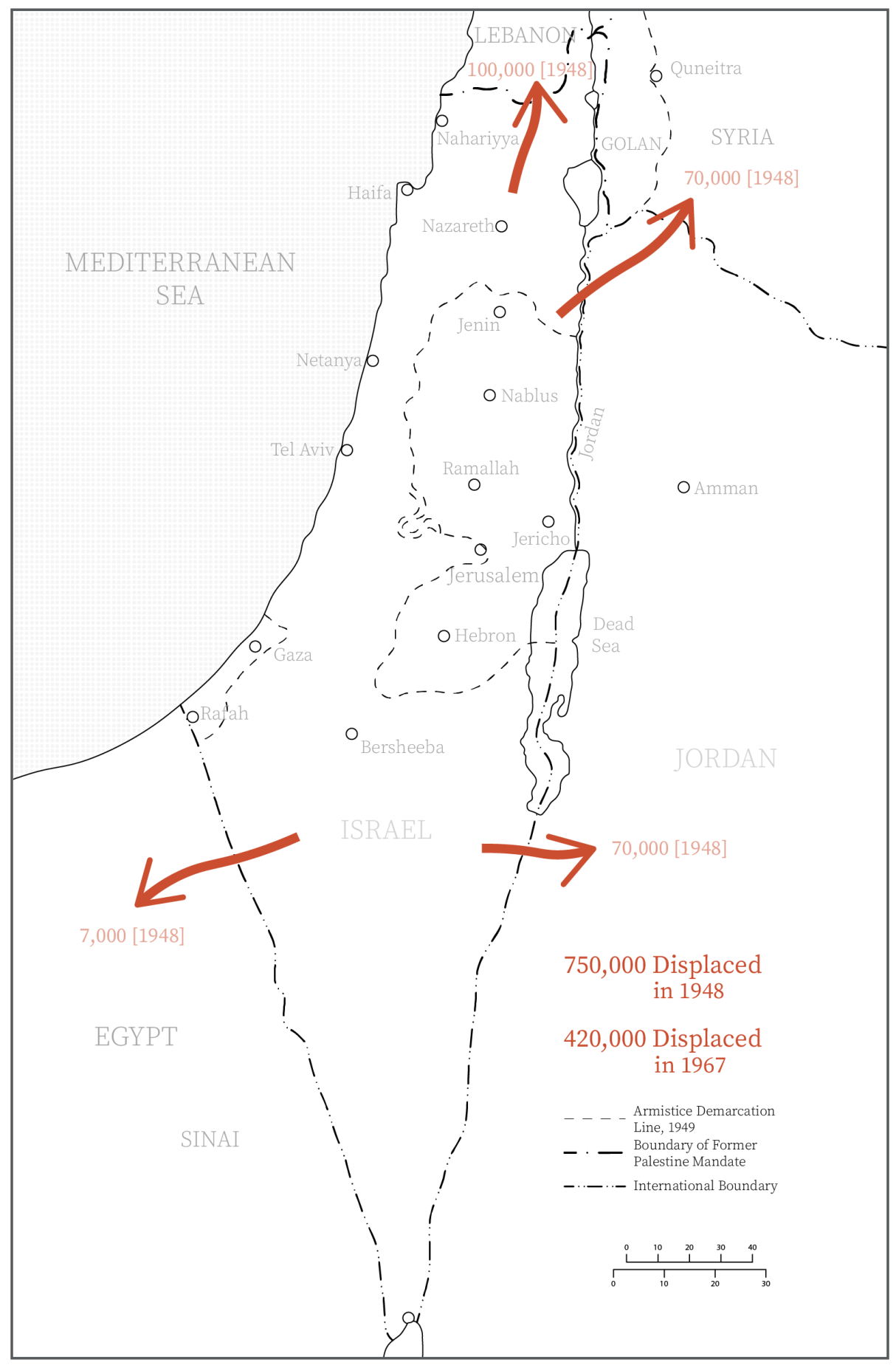

Figure 3.1 - Map of Palestinian Diaspora 


\subsection{Diaspora in Palestine}

"...There is a great deal of disagreement about the exact territorial dimensions of the Palestinian homeland. Regardless of these uncertainties, both the physical fact of a growing Palestinian diaspora and a collective diaspora consciousness cannot be denied; and while that consciousness may be diluted in the case of relatively prosperous Palestinians who have settled in Western countries, it is strongly perpetuated among the children of refugees and expellees."1

Palestinian diaspora is distinct in its duality of an internal geopolitical separation that involves the physical disconnection between the West Bank, Gaza Strip, and pre1948 Palestine (present-day Israel), and an external discontinuity between an ancestral home and the foreign country of residence. The devastating consequences of the 1948 war were the forced displacement and fragmentation of the indigenous Palestinian community. The term 'Nakba', meaning 'catastrophe' in Arabic, refers to the expulsion of Palestinian Arabs from their towns and villages. ${ }^{2}$ In her book "Erased from Space and Consciousness", Noga Kadman expands on the status of national identity with respect to notions of conflict, space, and memory. Kadman states that the primary objective of destruction is to prevent the physical return of the expelled population. However, it also intends to erase the history, memories, and identity of the architecture and the place. ${ }^{3}$

Urban tactics have played a crucial role in Israel's decision-making towards rapid urban development in order to gain control of Palestinian land. The blurring of the 1949 Armistice Green Line has led to continuous land seizure and the unilateral construction of Israeli-only settlements in strategic zones of occupied Palestinian territory.

1 Safran, William. "Diasporas in Modern Societies: Myths of Homeland and Return." Diaspora: A Journal of Transnational Studies 1, no. 1 (1991): 88

2 Molavi, Shourideh C. Stateless Citizenship: The Palestinian-Arab Citizens of Israel. Chicago, II.: Haymarket Books, 2014: 7 3 Kadman, Noga, and Dimi Reider. Erased from Space and Consciousness: Israel and the Depopulated Palestinian Villages of 1948. Bloomington, IN: Indiana University Press, 2015: 35 
These contested lands once enjoyed a diversity of ownership (agricultural, nomadic, religious) tied to communal forms of living. Such multiplicity of land use designations has been flattened into an Israeli-Palestinian binary over the years of endless intrusion of Palestinian life. What Palestinians have been gifted by the Oslo Accord are a number of broken promises and increasingly partitioned areas encapsulated in cells, surrounded by the growing numbers of Israeli settlements and bypass roads. The strategy of control and division by Israel is still under execution today. Israel has for long invested upon the language of security; to create strategic depth in the Occupied Territories.

Yet, Palestinians remain outside the legal structures governing their lives. The limited scope of the international concern regarding the Israeli Occupation has deflected the attention from a systemic phenomenon to a number of events that are its byproducts. The lens has been focused on individual humanitarian disasters as opposed to the system responsible for such outcomes that seem indefinite and unavoidable. Hence, the occupation must be seen as a pervasive phenomenon, retaining the character of a mechanism that generates temporary and permanent destructive marks on all aspects of Palestinian life. Israel's national policy of maintaining 'demographic balance' aims to stabilize a proportion that favors a Jewish majority over an Arab minority. ${ }^{4}$ Palestinian demographic growth has not only been confined within Israel but has also been disrupted by illegal settlement construction within Occupied West Bank.

The distinct feature of the Palestinian diaspora is the internal displacement and separation of Palestinians. Internally displaced Palestinians can be divided into two groups. The first consists of people who were displaced in the territories that became the state of Israel in 1948. This includes Palestinians who were expelled during the mass exodus of the Nakba in 1948, and those subsequently displaced by the Israeli 4 Weizman, Eyal. Hollow Land: Israel's Architecture of Occupation. London: Verso, 2007, 48 
State after its creation. Only 160,000 Palestinians managed to stay on the land, and about one million of Palestine's indigenous population were expelled to the West Bank and the Gaza Strip. Others moved to Lebanon, Syria, and Jordan. ${ }^{5}$ The second group consists of those displaced within the Occupied Palestinian Territories (OPT) since 1967, following the 1967 Six-Day War and as a result of the occupying Israeli regime's protracted colonization and subjugation of the Gaza Strip and the West Bank. ${ }^{6}$ For these two groups, the permanent impact of forced displacement is juxtaposed with the temporariness of an ongoing life under protracted military occupation; The marginalization and separation of the West Bank and Gaza from one another, as well as the pre-1948 territories, further ruptures the Palestinian community. An additional layer of complexity concerning detachment is the alienation of Palestinians with regard to reclaiming their original status as residents of their ancestral homeland. While Israel's Law of Return (1950) and Citizenship Law (1952) unconditionally grant Israeli citizenship to Jewish immigrants, Palestinian-Arabs are given no equivalent chance to regain their local status or connection to land they once owned and inhabited. Today, Palestinians that are not citizens of Israel continue to face extensive legal procedures in order to obtain temporary status, something that very few are eligible to do so. In her critical study on the oppression and separation of Palestinians living in the region, Shourideh Molavi describes the daily challenges:

"Evidently, these same two laws, each of which is both ideologically and historically foundational to the State of Israel, privilege Jews by systematically excluding Palestinian-Arabs who were compelled to flee their villages and homes between 1947-1952, deny them their indigenous status, strip them of their right to their land and directly contradict the internationally-recognized Palestinian right of return as affirmed in UN Resolution 194."7

5 Pappé, Ilan. A History of Modern Palestine One Land, Two Peoples. Cambridge: Cambridge University Press, 2014: 141 6 Badil Resource Center for Palestinian Residency and Refugee Rights. Survey on Palestinian Refugees and Internally Displaced Persons 2008-2009. Bethlehem: Badil Resource Center for Palestinian Residency and Refugee Rights, 2009: 57-59

7 Molavi, Shourideh C. Stateless Citizenship: The Palestinian-Arab Citizens of Israel. Chicago, II.: Haymarket Books, $2014: 62$ 
Scholars such as Makdisi ${ }^{8}$, Khalidi ${ }^{9}$, Hanafi' ${ }^{10}$ and Weizman ${ }^{11}$ have similarly all described the challenges facing Palestinians living locally in exile. Internal displacement thus accounts for the double meaning of diaspora for Palestinians, whether situated within the borders of their homeland, or in a foreign country. The residents of the West Bank and Gaza make up the first group of those experiencing internal exile, joined by a second group which includes those who live outside these areas. For Palestinians in diaspora, whose identity formation is heavily influenced by displacement; space and time are often overlapped through living between places. Space is more than a static, physical phenomenon. The passing of time is folded since one's interaction with the past and the present is not linear but cyclical. In other words, the subject's lived experience and the folding of time establishes a connection to space founded on the basis of longing and physical separation from one's place of origin. The dynamic tension caused by the double presence of being here and there lives at different magnitudes, based on each individual's specific way of connection to their place of origin. The aim of this thesis is, therefore, to capture the diversity of these experiences on a case-by-case basis through the visual documentation of the spatio-temporal aspects of diasporic living.

In "Children of the Idea of Palestine," Victoria Mason explores the shifting concepts of identity and attachment to home for successive generations of Palestinians who live in diaspora. Palestine, as a homeland, has remained central to notions of identity, home and belonging. However, the vast majority of the generations who were born in exile and did not encounter the Nakba directly, have no lived experience of Palestine. Instead, their familiarity and point of connection to their ancestral homeland has been passed on to a great degree through shared memory. ${ }^{12}$ Mason describes

8 Makdisi, Saree. Palestine inside Out: An Everyday Occupation. New York: W.W. Norton, 2010.

9 Khalidi, Rashid. Palestinian Identity. Columbia University Press, 1997.

10 Knudsen, Are J., and Sari Hanafi. Palestinian Refugees: Identity, Space and Place in the Levant. London: Routledge, 2011.

11 Weizman, Eyal. Hollow Land Israels Architecture of Occupation. London: Verso, 2017.

12 Mason, Victoria. "Children of the "Idea of Palestine"1: Negotiating Identity, Belonging and Home in the Palestinian Diaspo-

ra." Journal of Intercultural Studies 28, no. 3 (2007): 272. 
the diasporic community in a hierarchical manner and in terms of three generations. The first generation is comprised of those who experienced the Nakba directly. The second is the first generation born into exile (first exilic generation), and the third is the second generation born into exile (second exilic generation). Despite maintaining a strong link to Palestine, each generation finds their own meaning around notions of identity and belonging. Those who directly experienced dispossession and the first exilic generation both are believed to be influenced by what is known in Arabic as ghurbah, or 'estrangement,' 'homesickness,' and lack of belonging. The second exilic generation is defined by the notion of 'hybridity,' where the individual maintains a strong connection to the place of residence yet is constructing new and dynamic points of connection to the place of origin through transnational technologies. ${ }^{13}$

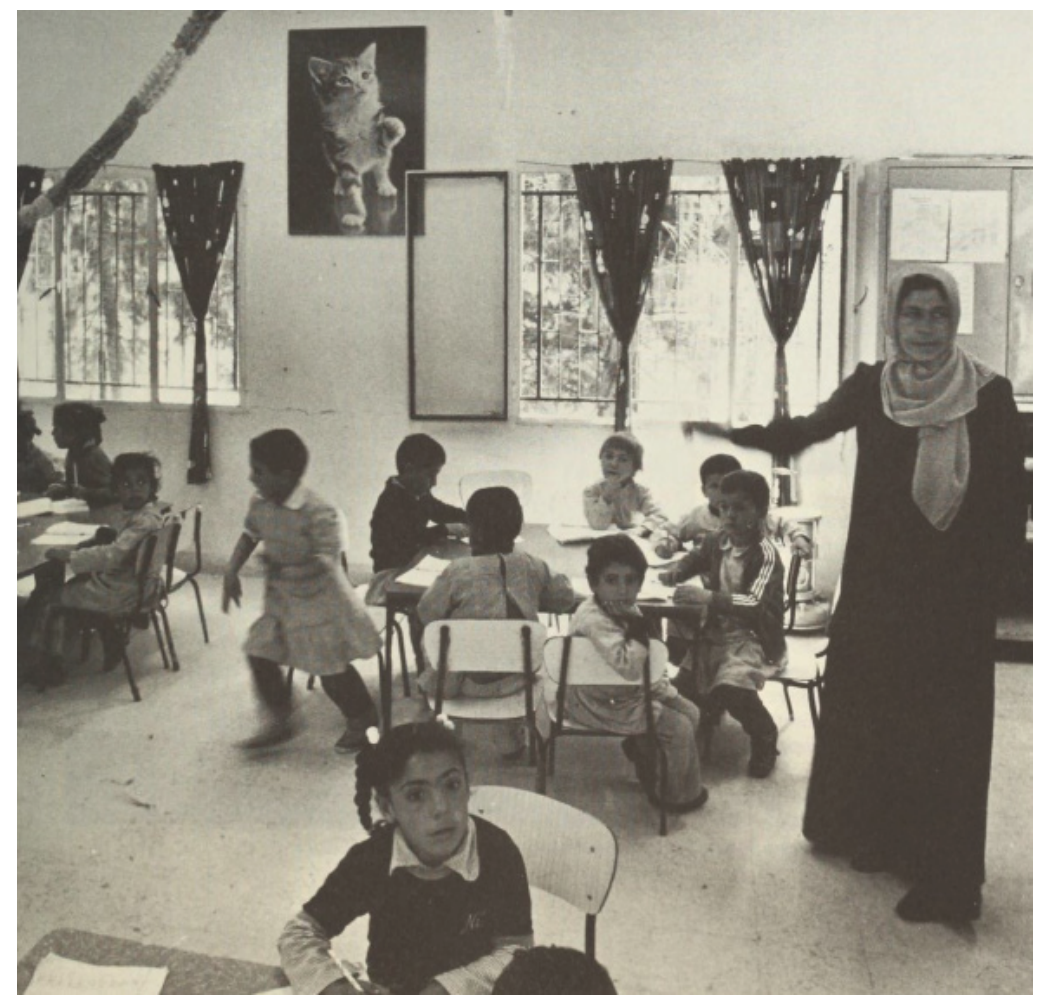

Figure 3.2 - Jordan, 1984. Palestinian students at Baqa'a Camp.

13 Ibid: $272-273$ 
The scope of this thesis is focused on the experiences of the first and the second exilic generations whose connection to the home of the homeland and the home of the lived reality is crucial to their diasporic identity. The hybridity of such identity emerges out of recreating and reiterating the experience of Palestine through memory, where one's understanding of the homeland has been primarily passed down and not directly experienced. In other words, as the lived experience of the homeland diminishes through the first and the second exilic generations, Palestine as a lived reality gives way to the 'idea of Palestine'.14 Mureed Barghouti, a prominent Palestinian poet and writer, expands on this concept in the following passage:

"The occupation has created generations of Palestinians who are strangers to Palestine, generations who are familiar with every alleyway of their places of exile, but who are ignorant of their homeland [. . .] These generations are condemned to love an unseen lover, a distant, difficult lover separated from them by guards and fences and sleek terror. The [Israeli] occupation has transformed us from the sons of Palestine into the sons of the idea of Palestine."15

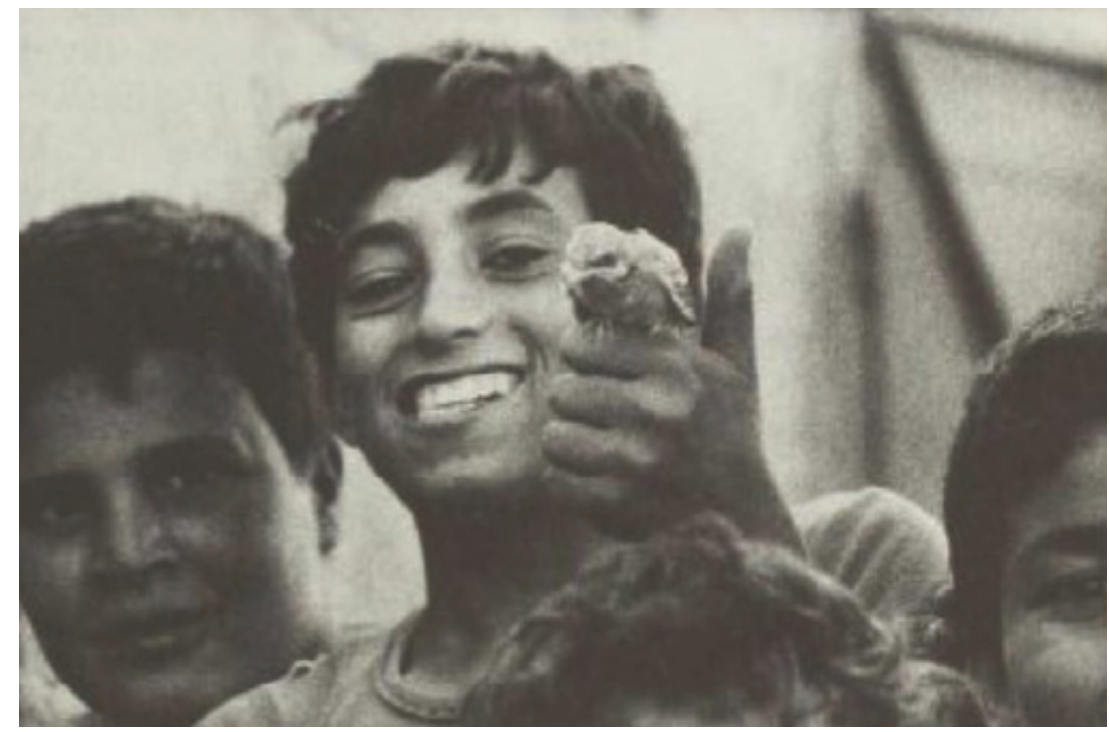

Figure 3.3 - Village of Senjel, near Ramallah, 1979. Rescued Bird.

14 Ibid: 275

15 Al-Barghouti, Mureed. "Songs for a Country No Longer Known." Journal of Palestine Studies 27.2 (Winter 1998): 60-61 
In their seminal 'Oral History of the Palestinian Nakba,' Abdo and Masalha elucidate the vigorous and lively disposition of oral history telling, and the role that it plays in retaining information from the past. They mention how the passing of the names of depopulated and destroyed Palestinian towns and villages down through generations helped keep alive knowledge that could have been otherwise easily erased from memory. ${ }^{16}$ The retention and transfer of the pre-Nakba and post-Nakba narratives play a significant role in the reconstruction of Palestinian identity. The importance of knowledge production and memory formation is thus manifested within an ontological framework for integrating and conceptualizing diverse forms of human experience, where information from the past shapes the present and the future.

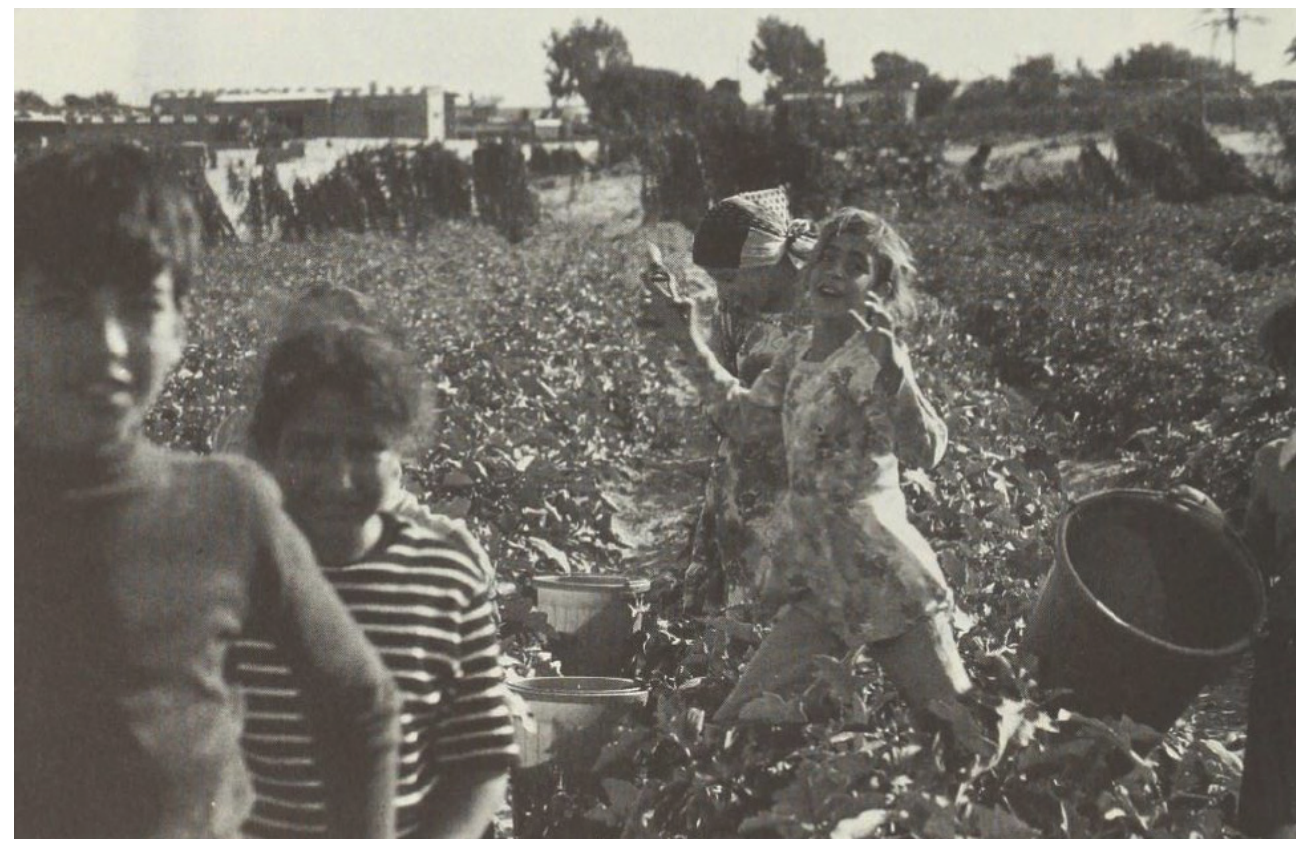

Figure 3.4 - Gaza, 1979. 
Sandi Hilal and Alessandro Petti of the West Bank-based collective Decolonizing Architecture Art Research (DAAR) describe return as a notion which has shaped the diasporic and extraterritorial aspect of Palestinian life, both in a cultural and a political sense, since the Nakba. ${ }^{17}$ Hence, return can be defined beyond the physical relocation to the place of origin. The scope of their work is mainly focused on return as a cultural practice of common memory formation within a spatial platform. Spatial and cultural practices are complimentary to one another, where the creation of space opens the way for communal exchange of thoughts and memory production.

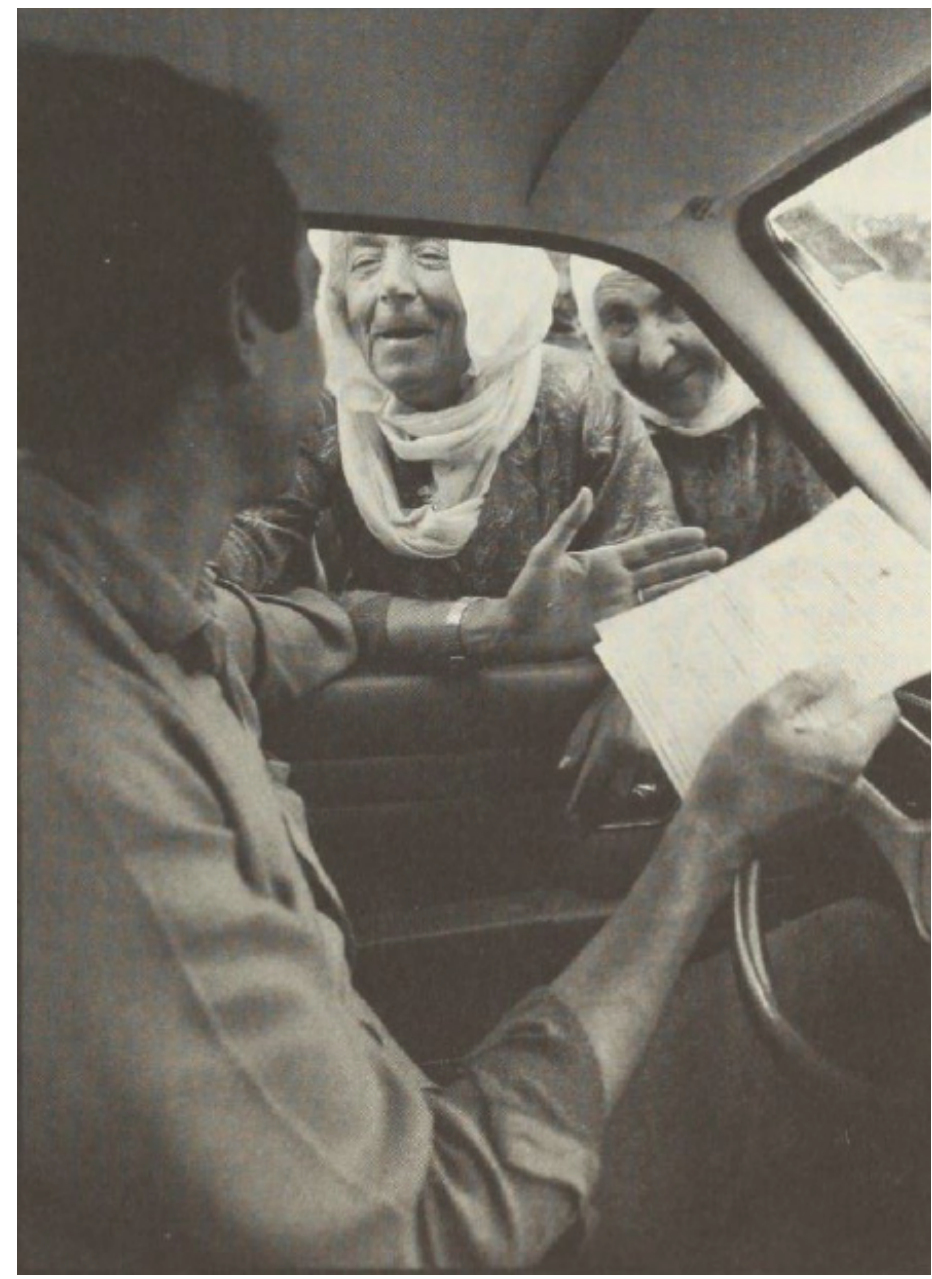

Figure 3.5 - Tyre, South Lebanon, 1983. A local official collects letters from the relatives of Palestinian refugees.

17 "Introduction." DAAR, 25 Jan. 2016, www.decolonizing.ps/site/site3-returns/. 
To capture the experiences of the Palestinian diasporic community in Canada, this thesis examines a combination of individual experiences inside Palestine, as well as in the secondary country, together with the geo-political conditions and policies of the host. In the case of Palestinians living in the Occupied territories and Gaza Strip, there is an emphasis on living conditions under occupation that shape the diaspora within their homeland. An internal discontinuity which speaks of the separation between Gazans and the residents of the West bank thus alludes to the double meaning of diaspora in the Palestinian case. The diasporic sphere outside these territories is also constructed by generations of Palestinians, which refers to individuals who live in different parts of the world but who identify collectively with one another, with Palestine, and with the society in which they currently reside. The thesis therefore involves the collection and analysis of descriptive socio-cultural information about the way of life in diaspora from the Palestinian community in Canada.

The scope of the research zooms into a distinct local condition of diasporic life. The ideas of the thesis still exist with an understanding of the tremendous pain and loss of the Nakba and the continuation of Israeli settler-colonialism today. The thesis takes into consideration the ongoing impact of the Israeli occupation and mass displacement of Palestinians as a driving force that directly affects life in diaspora. The thesis owes a debt to scholars such as Weizman, Said, and Abdo that have deeply covered the lives of Palestinians under occupation in Palestine. However, it also shifts the lens to parallel events occurring in Canada's diaspora. 


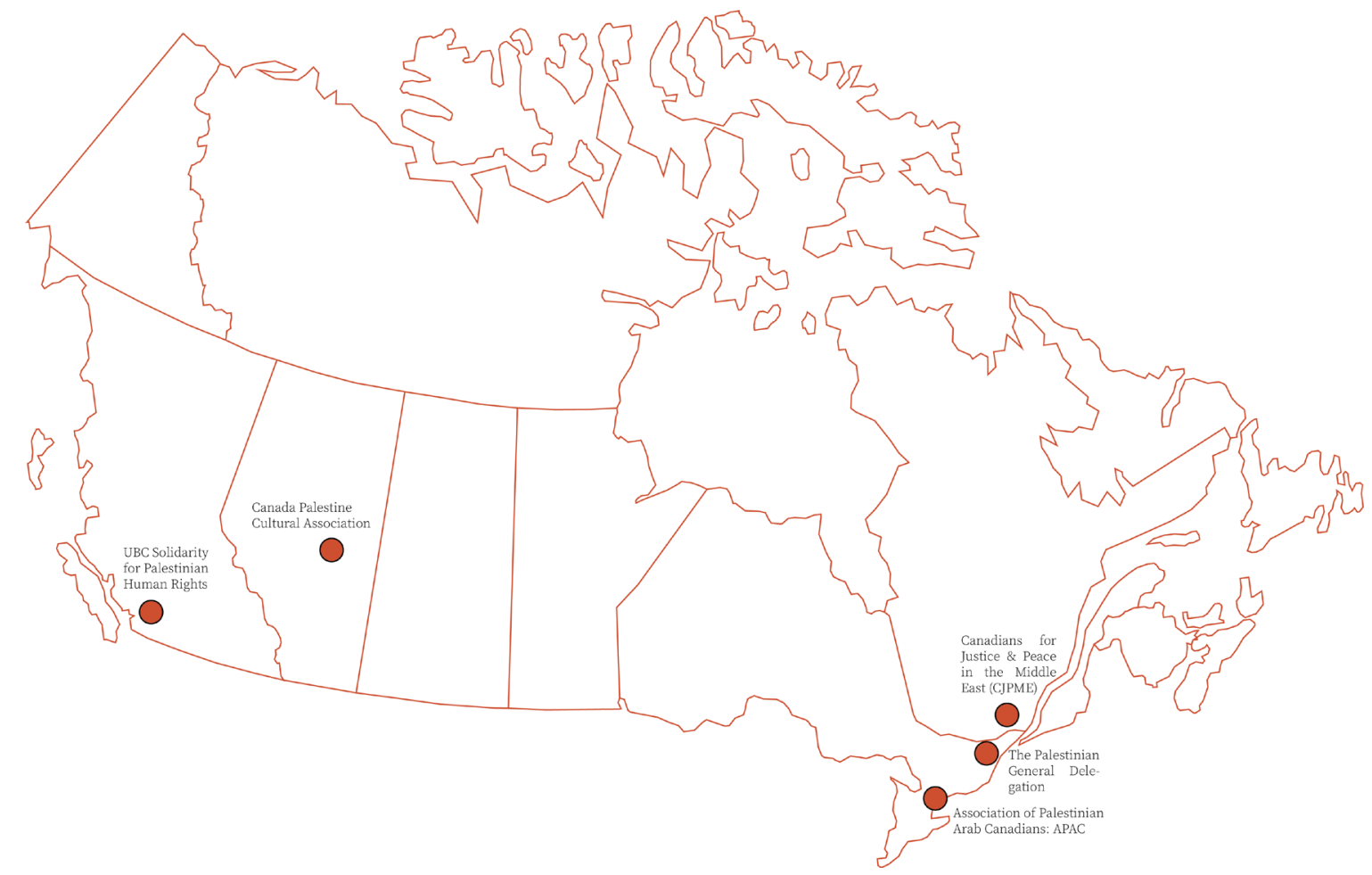

Figure 3.6 - Palestinian Organizations in Canada 


\subsection{Palestinian Diaspora in Canada}

This thesis is primarily concerned with Palestinians who reside in Canada. Canadian Palestinians are a diverse population whose point of connection to Palestine differs on a case-by-case basis. Despite the differences of generational gaps between various Palestinian-Canadians, Palestine conceived as a homeland, is a common factor amongst the majority of those who identify themselves as Palestinian. Whether born or raised, or not having set foot in Palestine, the diasporic community shares a strong bond to this national homeland. Their collective connection to this place is not only defined in physical terms, but also in everyday practices, given that due to permit restrictions the ability to visit their ancestral homeland may be an impossible mission for generations of Palestinians. Hence, the concept of return gains a new meaning within the socio-cultural boundaries of diaspora. It is not solely a physical process; It is operative and is activated with the passage of voice via oral storytelling. A tremendous number of records and evidence concerning Palestinian lives owe their survival to the oral history of generations of villagers and former inhabitants of places which no longer have the same physical presence. Their existence exceeds the restricted reality of the present. Such oral knowledge is, rather, transferred through the hearts and minds of those who witnessed and lived it to inform those who were not exposed to the stories kept hidden from them. This is a strong chain of knowledge production that is highly effective in a diasporic community where the younger generation lacks the first-hand experience and direct exposure to life in their original home. 
According to the 2016 census, 50,200 Canadians claim Palestinian ancestry, with a majority concentrated in Ontario and Quebec. ${ }^{1}$ This number, however, excludes permanent residents and refugees of Palestinian origin who have not yet obtained their Canadian citizenship. In major cities and localities with a considerable Palestinian population, there are several Palestinian-Canadian organizations that support the diasporic community. Although presenting the Palestinian cultural identity is central to the goals and premises of such organizations, each operates according to its own principles and objectives, including outreach through a variety of media.

Beit Zatoun, was one such organization, that operated from 2010-2016. It was a Toronto-based non-profit organization and community-funded cultural centre with a gallery, that explored issues of social justice and human rights through the interaction of art, culture, and politics. The name Beit Zatoun stands for "House of Olive" in Arabic, which represents the focus of the cultural house. The house seeked to utilize the community space and its resources to bring peace and justice to Palestine and Palestinians in the global context. Beit Zatoun successfully managed to engage its respective community in the notion of shared experience through the medium of culture and art. The house hosted numerous workshops and events, including those involving the practice of the traditional Palestinian dance 'Dabka,' as well as the sharing of Palestinian dishes and the curating of exhibitions displaying Palestinian artifacts and embroidery. The valuable accomplishment of Beit Zatoun could be summed up in its ability to foster solidarity among multiple socio-ethnic groups by sharing the stage with them. ${ }^{2}$

1 Government of Canada, Statistics Canada. "Census Profile, 2016 Census Canada [Country] and Canada [Country]." Census Profile, 2016 Census - Canada [Country] and Canada [Country]. August 09, 2019. Accessed February 19, 2021. https://www12. statcan.gc.ca/census-recensement/2016/dp-pd/prof/details/page.cfm?Lang=E\&Geo1=PR\&Code1=01\&Geo2=PR\&Code2=01\&SearchText $=\&$ SearchType $=$ Begins $\&$ SearchPR $=01 \& B 1=$ Ethnic origin \&TABID $=1 \&$ type $=0$.

2 "About Us." Beit Zatoun. January 21, 2014. Accessed February 27, 2021. http://beitzatoun.org/about/. 
The Toronto Palestinian Film Festival (TPFF) is another organization that operates as a volunteer-run NGO, focusing on introducing Palestinian cinema, music, cuisine and art to the residents of the Greater Toronto Area. The program was founded in 2008 to commemorate the 60th anniversary of the Nakba, and welcomes both Palestinian and non-Palestinian filmmakers. The use of film as a medium through which TPFF presents Palestine is successful at engaging those who may not necessarily be familiar with Palestine, but are keen to participate due to an interest in cinema. ${ }^{3}$

Further west, the University of British Columbia's Solidarity for Palestinian Human Rights (SPHR) is a non-profit student-run organization that serves as a social justice platform to uphold the rights of the Palestinian people, with regards to all forms of human rights violations, discrimination, and misrepresentation. The organization is dedicated to raising public awareness towards Palestine, not only as a political subject of interest, but also as a cultural identity. The group regularly hosts events filled with Palestinian music, food, and performances that bring together individuals across the student community in solidarity with Palestinians. In Vancouver, they host workshops as an educational resource for Canadians to learn more about Palestine. The organization also runs a series of workshops that serve to educate the public about Palestine, as well as discussion platforms that explore the opportunities and challenges posed by technology, geopolitics, and the reality as a diaspora.

The common ground for all these organizations cannot be simply defined in their effort to raise awareness about Palestine. There exists also a notion of return, not in a physical sense, but in terms of forging new and dynamic links to Palestine with respect to the hybridity of diasporic identity. With ongoing political struggles to raise active voices regarding Palestine in Canada, this thesis aims to frame the Palestinian question within a series of diasporic experiences that reflect the hybridized identity of 3 "ABOUT TPFF." Toronto Palestine Film Festival. Accessed February 27, 2021. https://www.tpff.ca/about-tpff. 
the diasporic community. Such pursuit helps to establish a socio-cultural platform for presenting Palestinian nationhood and setting up a framework for congregation and interaction within a multi-cultural context.

Architects and scholars have expanded on the nature of exile in the Palestinian case. Decolonizing Architecture Art Research (DAAR) discusses exile as a social condition that stems out of alienation and non-belonging which cannot be simply cured by return. ${ }^{4}$ It is important to note that expanding on diasporic life as a separate exercise is not an inadvertent means of merely accepting the loss of the right of return for Palestinians. Instead, the thesis attempts to unpack the complexities of generations born outside their ancestral homeland and their daily realities. The diasporic condition is indeed a critically important socio-political domain that illustrates the way the Israeli occupation and settler colonialism has shaped the future for generations of Palestinians. DAAR's notions of life lived in exile. The emphasis of the socio-cultural dimension of life in diaspora reflects on the fatigue of this generation that does not only wish to be seen solely as political activists, but also desires to deeply connect with their ancestral heritage.

4 "Present State of Conservation." E. Accessed March 24, 2021. https://www.e-flux.com/architecture/refugee-heritage/100716/ present-state-of-conservation/. 
PART I

ATLAS 


\section{Diasporic Experiences}

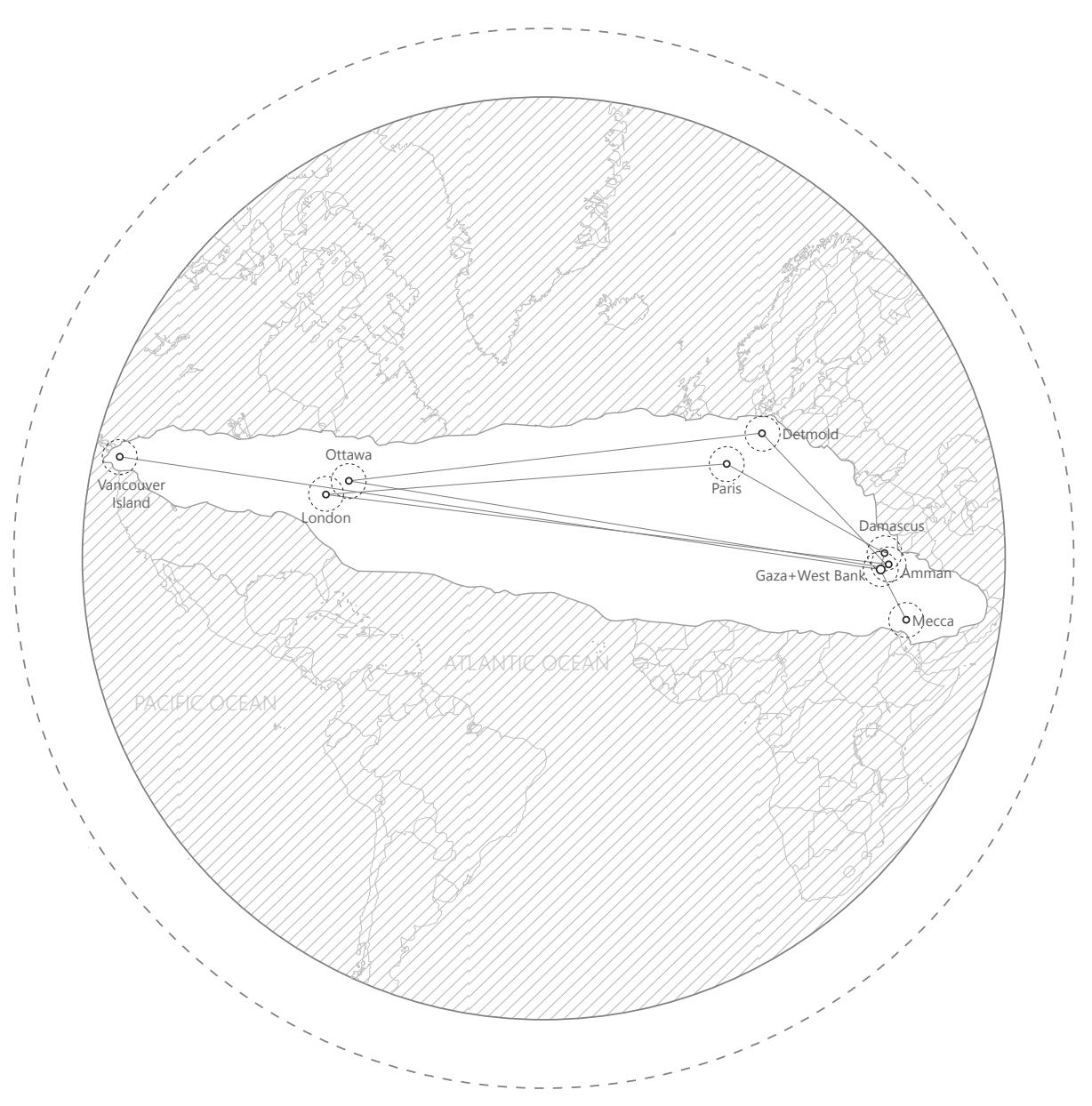

Figure 4.0 - Geo-located Map of Interviewees 


\subsection{Narratives}

Given the contentious history of cartography and atlases in determining the fate of Palestine, this atlas is intended as a subversion to those earlier forms. It is rooted in personal narratives, experiential visualizations of deep emotions and therefore not similar to colonial and military atlases. The atlas seeks to act against the colonial agendas and demarcations implemented in traditional atlases. Unlike other fieldworks that have been executed on-site and particular to the geographic boundaries of the investigation, this atlas is created through collecting experiences from those who have resettled or been deprived of visiting their ancestral home. Hence, the work puts human condition above geographic boundaries. The documentation further explains the ongoing nature of occupation and the passage of knowledge through generations of Palestinians. The aim with a counter-atlas is to re-stitch unrecorded histories and to ensure that they can reach the second and third exilic generations effectively. The term 'Atlas' as a mode of subversion aids in showing how it can act as an instrument to reconcile some of the earlier top-down, colonial documentative violence.

For all narrators who took part in the Atlas, Palestine remains central in their multi-layered conception of home. This is valid for a diverse group of individuals whose lived experiences have been spent in Palestine or outside their ancestral home. For the majority, most of their lived experience has been in the diaspora. It is in Canada, and places where they used to live prior to moving to Canada (Syria, Jordan, etc.) that they have established family, social connections, and jobs. However, the majority of individuals interviewed see Palestine as the primary part of their self-identification. The process of recreation of the homeland in diaspora is rather accomplished through transferring knowledge and memories down to younger generations, as well as re- 
taining cultural and social practices that reiterate the experience of Palestine in the absence of a lived experience of the place. The testimonies and the visual documents assembled from the interviews clearly show how Palestine has been made tangible and real to a sensory level to individuals who have not even set foot in Palestine but are able to offer the most detailed description of their ancestral home and the everyday occurrences of their grandparents before the mass displacement in 1948. 


\section{Interviewee 1: Anonymous}

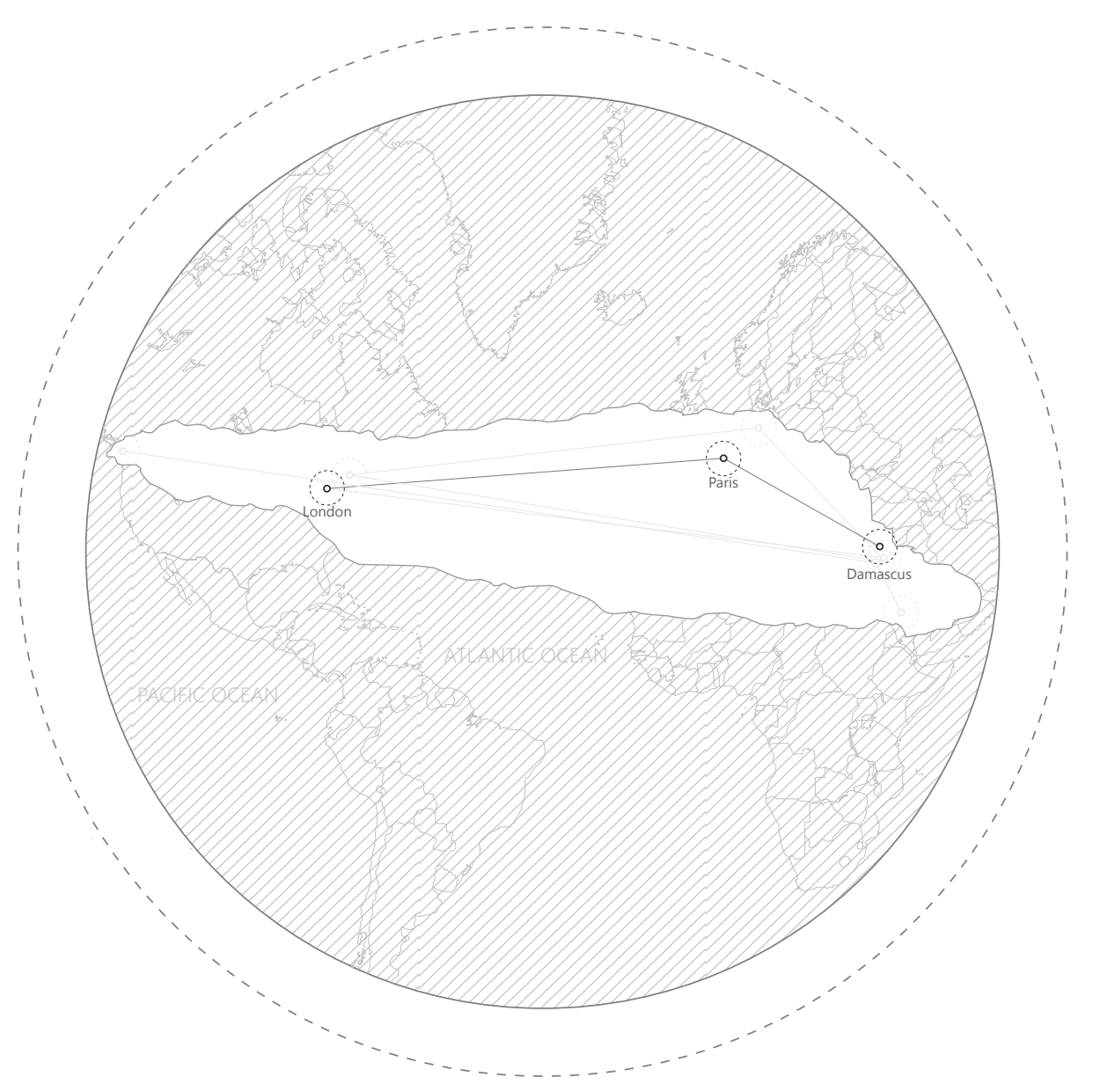

Figure 4.1 - Geo-located Map of Interviewee 1 


\subsection{Recalling the Unvisited}

As a 44-year-old musician born in Damascus, Syria, this interviewee has retained a strong bond with Palestine since she was a child. Her parents were born in Haifa, Palestine, which they were forced out of in 1948 during the Nakba. Her maternal grandparents moved to Lebanon for six months and then moved to Damascus. Her grandparents on her father's side went to Baghdad, Iraq. However, since they were from the same family, her father came to Syria after finishing his education in Iraq, where he would get married and stay for the rest of his life. Despite never having visited Palestine in person, the interviewee has gained an expanded knowledge of her ancestral place of origin, Haifa. From hearing about her ancestral place of residence to familiarizing herself with the daily routines of her family members, she has been able to retain a diverse set of memories that function as historical accounts of a place from which generations have been separated. Such experiences are described in the following quote:

"My grandparents' apartment used to be a block away from the water, not far from the Haifa oil refinery. In 1944-45 when the war was about to end, they moved to the suburbs in the fear of bombings. They moved to a small village called Balad al-Shaykh (بلد الثيخ). Their house there was later turned into an Israeli civil association. My grandfather left me a manuscript, which is essentially a long list of the contents of his apartment in Haifa. The manuscript lists every item in the apartment, including the furniture and French beach chairs which used to be in the salon, as well as chandeliers. Also, he had written down the name of every single book in the house library. I remember Ikhwan Al-Safa (إخوان الصفا), among a series of study books and dictionaries."1

1 Interviewee 1. (2021, January 17). Personal Interview. 
For the interviewee, Haifa is not only perceived in terms of factual information, but also through the sensory perception of the place with respect to the physical and atmospheric elements that construct it. She states the significance of the sea in her vision of places she visits, alluding to her ancestral connection to water in Haifa. When she returned to Syria from Paris, she moved to the city of Latakia to work on a project. Situated by the Mediterranean, Latakia became a point of comparison and a superimposition for her. For the interviewee, the sea and its surrounding atmosphere resembled Haifa, a city which she had only heard about and seen through images. Here, the way Latakia is conceived in relation to Haifa represents the sensory effect of memories, even in those who have been simply recipients of such narratives and not necessarily experienced them firsthand.

In one of our interviews, she described a work of art she wanted to share:

"I have a painting to show you. [Holds a painting depicting boats in the sea]. This is a painting I bought at a garage sale for $\$ 4$. This is not Haifa, but only a beach. I know that my grandparents used to live by the sea and my grandfather was from a family of merchants who worked in commerce. He has many memories from the port and used to have his uniform with metal badges. We had them when I was young. So, I have a special love and nostalgia for the beach and the sea as a result. When I returned to Syria from France, I began working on a project in Latakia, a city by the water. I found the streets resemble Haifa to me. Some refugees and elderly people who had moved there from Palestine also told me that it looked like Haifa, as well."11

$1 \mathrm{lbid}$ 


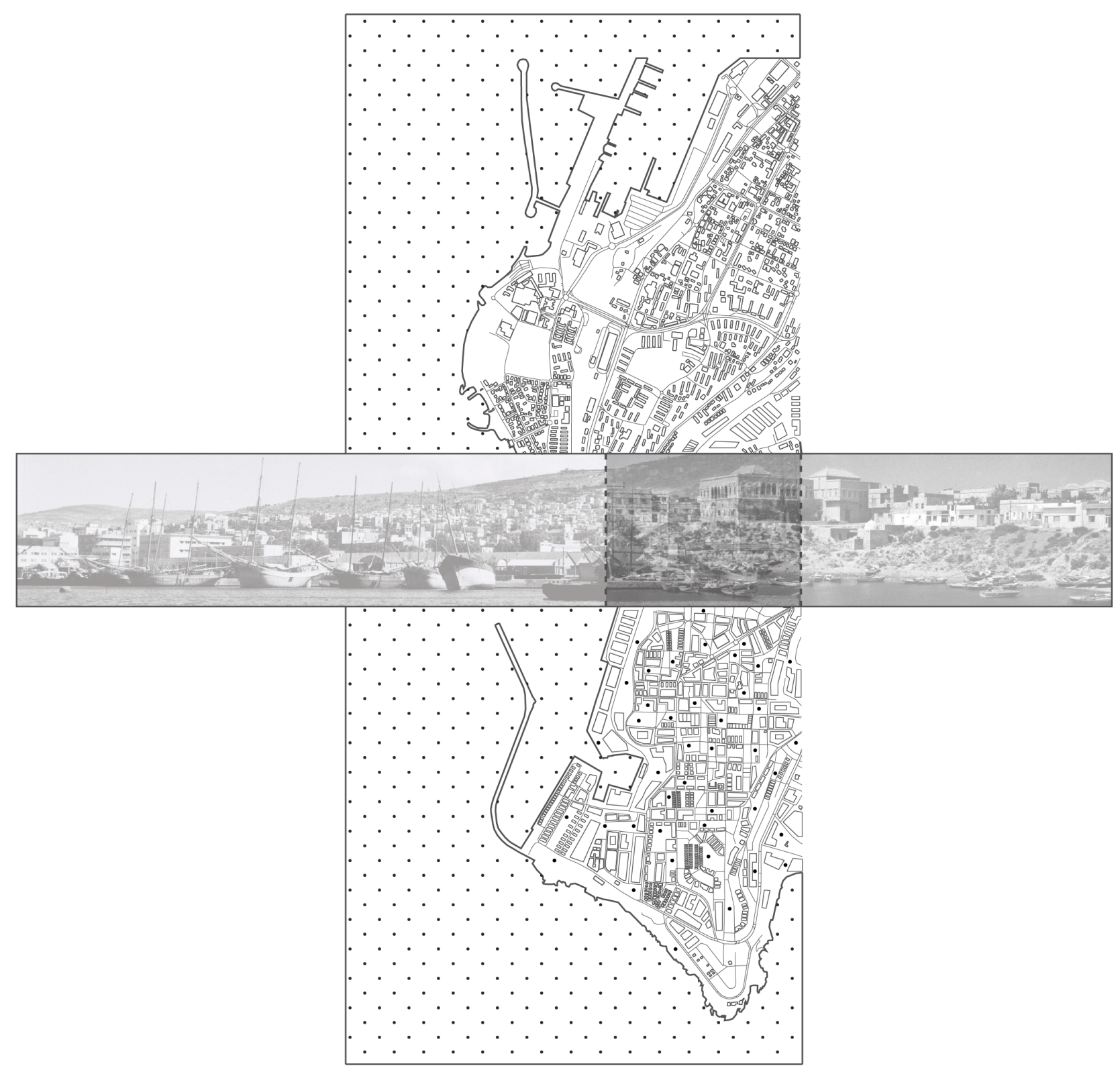

Figure 4.2 - An Imaginary Dichotomy of Haifa (above) and Latakia (below) 


\section{Interviewee 2: Maya Jarrah}

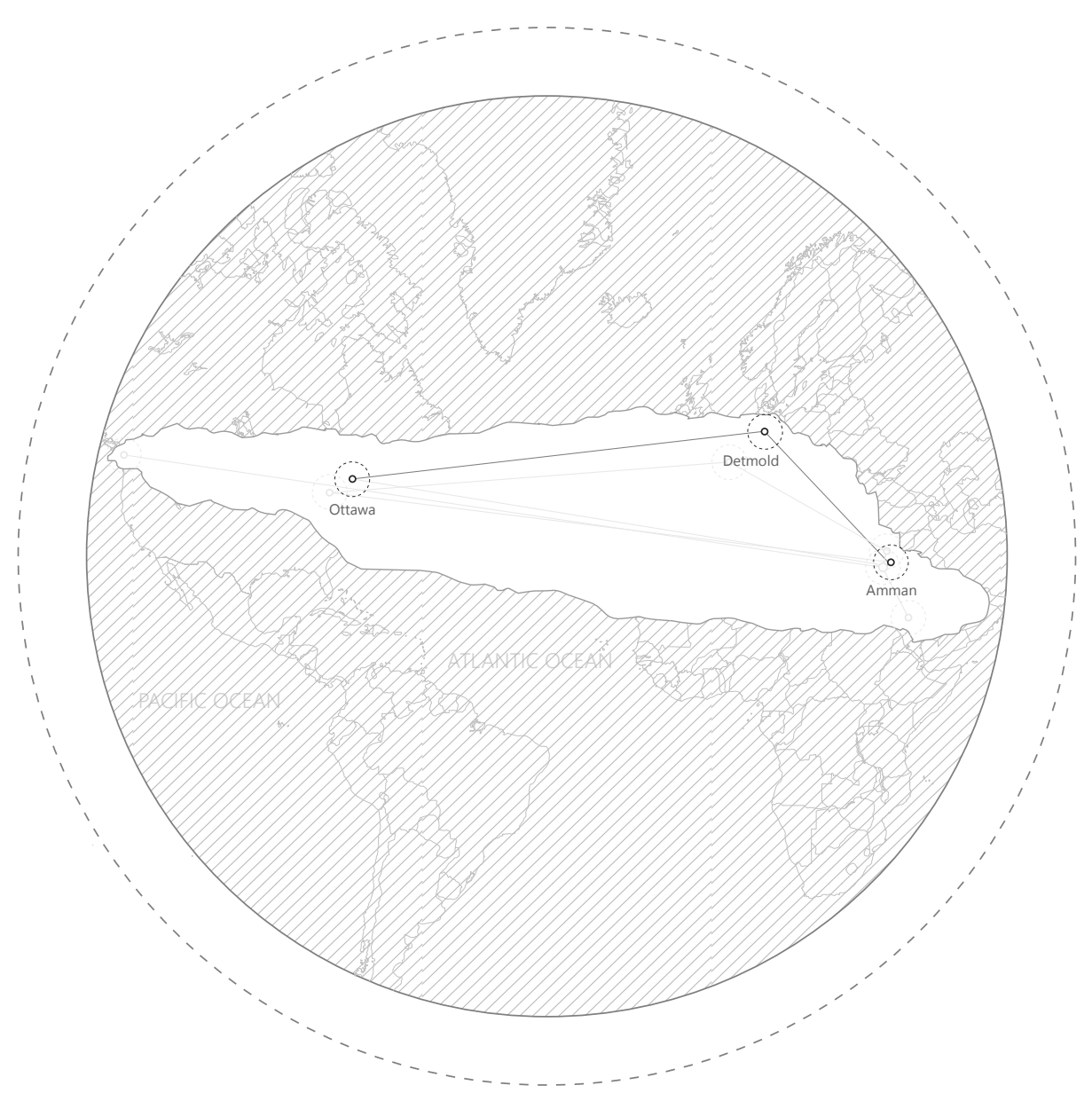

Figure 4.3 - Geo-located Map of Interviewee 2 


\subsection{Family Home In Akka (عَّ)}

The story of the Jarrah family is narrated through the words of Maya Jarrah, the granddaughter of Issam Jarrah, the latter only a 16-year-old boy when he was forced to leave his home like thousands of other Palestinians in 1948. Maya belongs to the second exilic generation of Palestinians in diaspora, whose point of connection to her ancestral home is maintained through memories and lived experiences of older family members, which were eventually passed down. Born and raised in Amman, Jordan, Maya identifies herself as a Jordanian of Palestinian origin. She moved to Canada in 2017, just after finishing her undergraduate degree in Germany, arriving to begin her graduate studies in architecture in Ottawa. Maya's parents were both children of Palestinian refugees in Syria and Jordan. Maya's grandparents were from the city of Akka, also known as Acre, a place that is greatly emphasized in her words. The city and the belongings left behind by former residents during the 1948 expulsion remain standing to this day, including houses and shops owned by the Jarrah family. These places owe their survival to the passage of memory among the Jarrah family, without which it would have sufficed to allow time to obliterate their existence. The following narratives are not simply random memories recalled from the past, but essential components of a family's history and identity that lost their physical connection to their place of origin once the great exile took place in 1948. The integrity and the intact quality of these narratives are the focal point of this section. 
Issam Jarrah was still a high school student when he had to leave his country, along with his mother and three sisters. Due to the absence of their father, Issam was in charge of their journey as refugees to Lebanon and later to Jordan, where they were able to settle with the help of a man named Khairullah Jarrah, who worked as an escort for King Abdullah I of Jordan at the time. Khairullah was the one who ensured that Issam and his family would be granted Jordanian citizenship, something that would have never happened if they had stayed in Lebanon (Palestinian refugees are not considered Lebanese citizens to this day). Due to his young age and the difficulty in finding a proper job in Jordan, Issam joined the Jordanian army - a personal top choice back then. He did so along again with the help of Khairullah Jarrah. He had to falsify his age, as he was 16 and the minimum age for joining the army was 18 . So, the young Palestinian refugee became a Jordanian citizen and joined the army at 16 . He later married Khairullah's daughter, Ra'efa Jarrah, Maya's grandmother, who passed away when Maya was only 4.

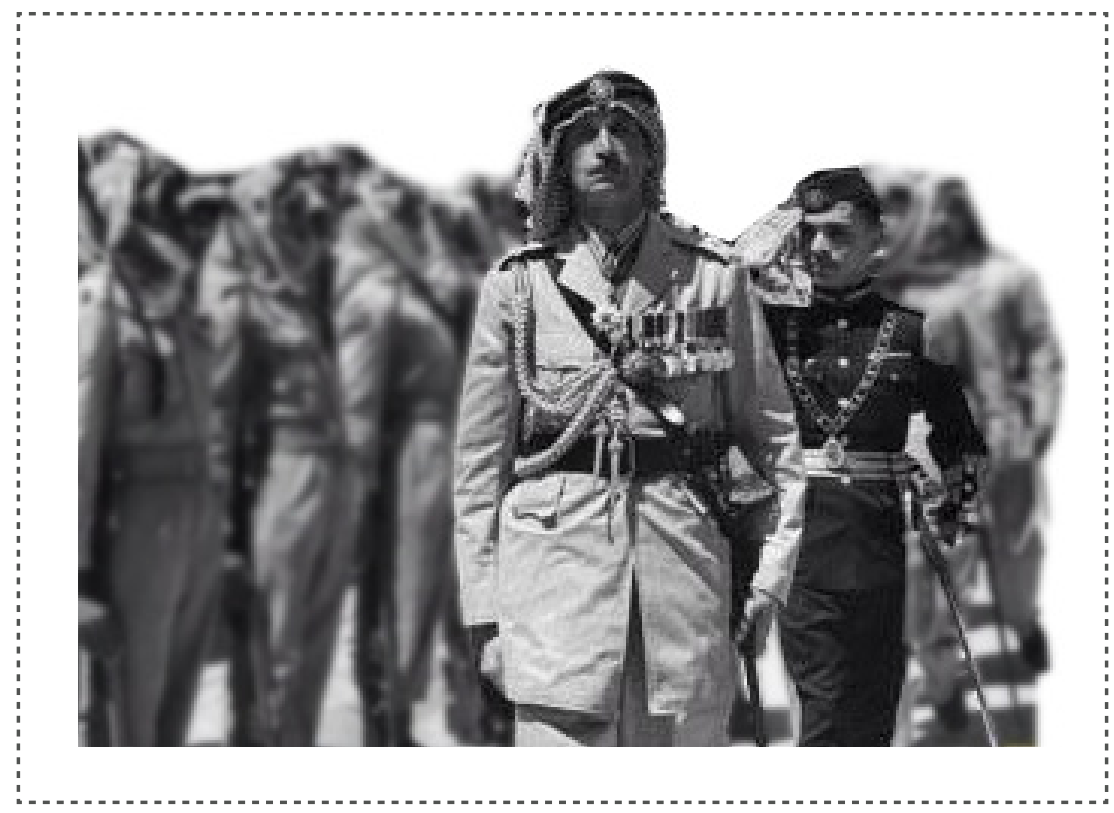

Figure 4.4 - Kheirullah Jarrah (front) with King Hussein (back) 


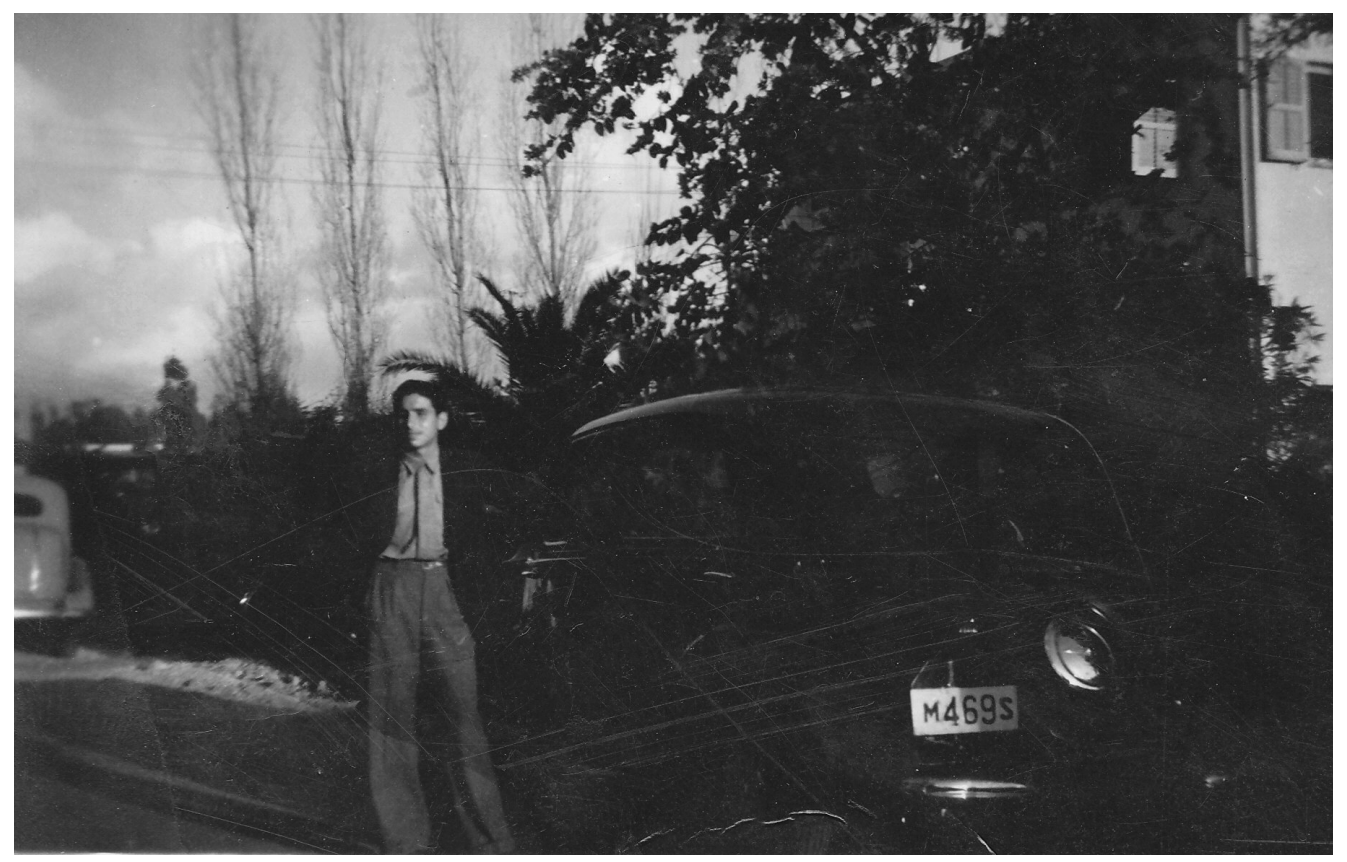

Figure 4.5 - Issam Jarrah in Akka (Acre) 
Following a failed attempt to obtain a visa to visit her ancestral homeland, Maya has never been able to visit Palestine. Yet, accounts of her family's past and images acquired by her father and relatives have managed to partially fill the gap for her. Maya owns an extraordinary collection of images taken by her father in 1996 which depict the houses and businesses owned by the Jarrah family prior to the 1948 mass exodus. Although these places are reinhabited by Israeli residents, they invoke the strong sense of belonging in their previous owners. Most importantly, such tactile encounters with space account for the irreducible durability of memory, something that seems to erode over time and turn into dust but yet sits in place, on the same ground.

Maya described to me this area:

"Most of the Jarrah family members lived on a street called (Matla' Al Hursh Street), which is difficult to find on the map today due to the change in street names. That section of the neighborhood inhabited by the family used to be called Hay Al Jarrah - The Jarrah Quarter, as most houses were owned by the Jarrah family. Quite close to that quarter, stood Samiha Jarrah School for Girls, which was named after Samiha Jarrah, my mother's aunt, who was a well-respected educator and the principal of that school. The school still stands till this day but has a different name. The older generation of the family lived in Al Mjadleh neighborhood."1

Reflecting on the details of her memories, Maya added:

"I always imagine how my grandparents' house would look like, thinking of the stone cladding on the outside and similar features. I think about how my life would look like if they had stayed in Palestine, which would mean we would live by the Mediterranean which is something nice."2

1 Jarrah, Maya. (2021, January 18). Personal Interview.

$2 \mathrm{lbid}$ 


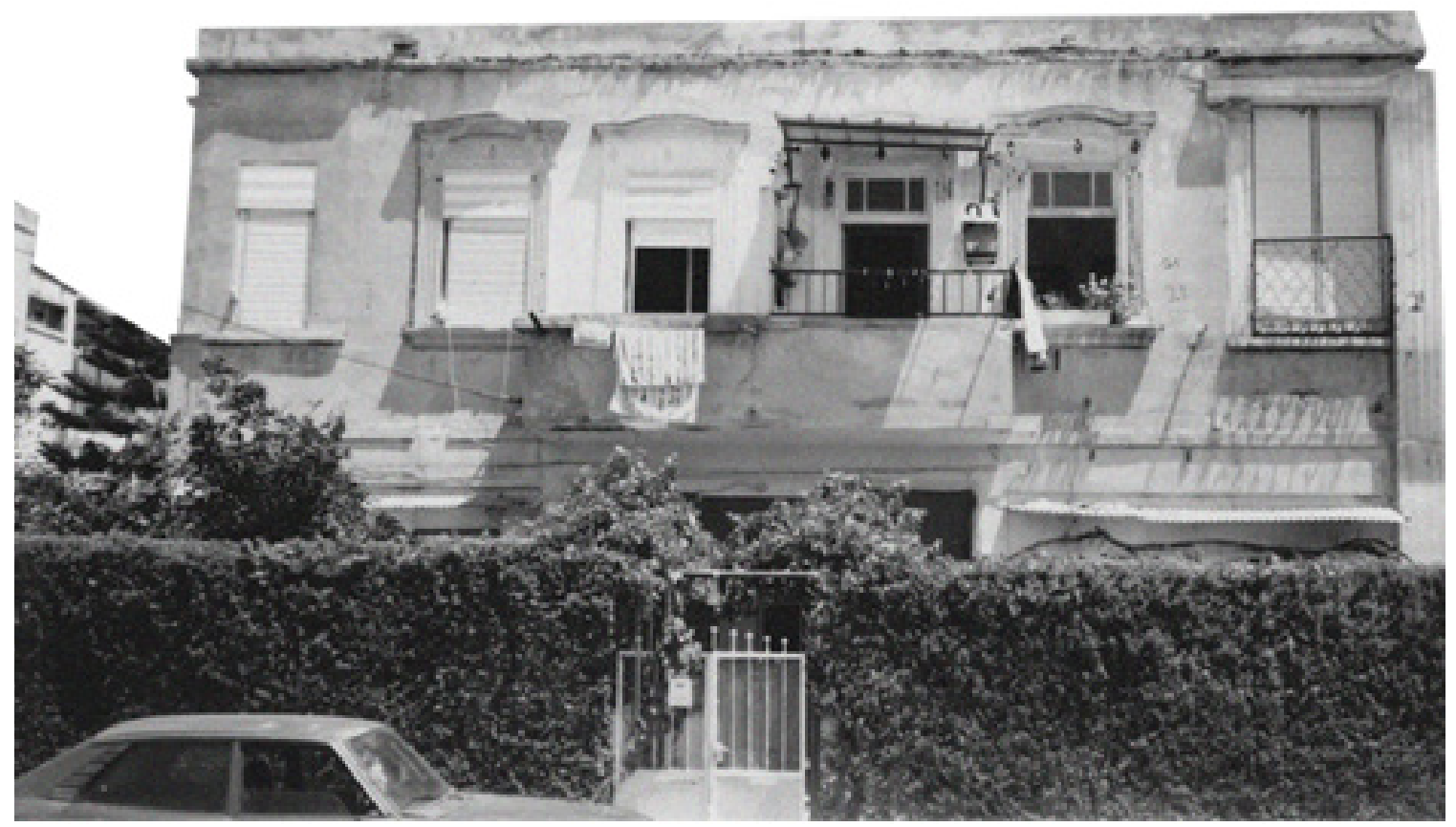

Figure 4.6 - Husni Jarrah's House in Akka, 1996.

This house used to belong to Husni Jarrah 


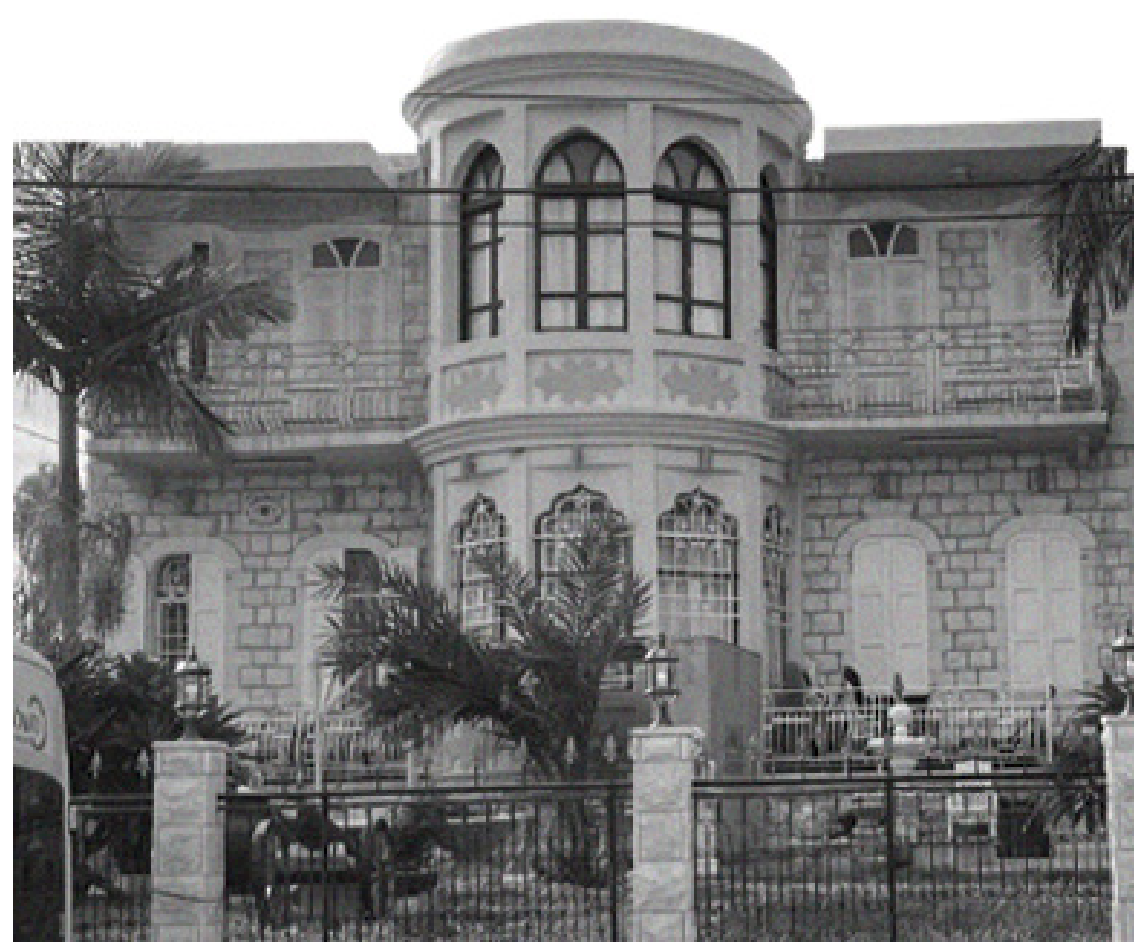

Figure 4.7 - Moied Jarrah's House in Akka

This house used to belong to Moied Jarrah 


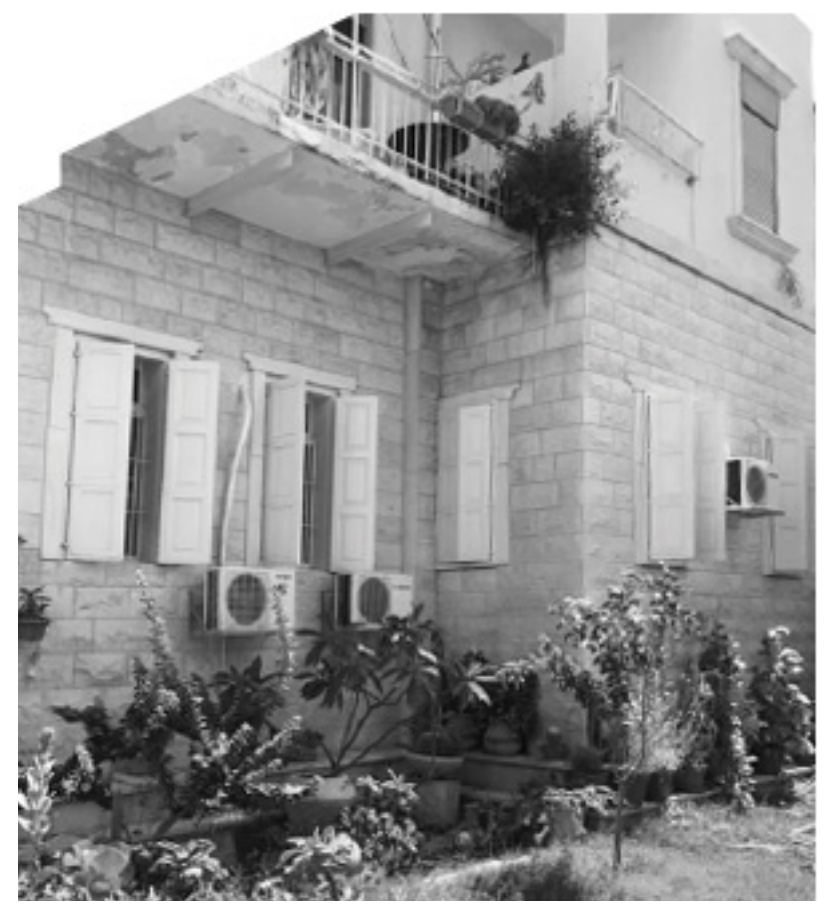

Figure 4.8 - Fawzi Jarrah's House in Akka

This house used to belong to Fawzi Jarrah 


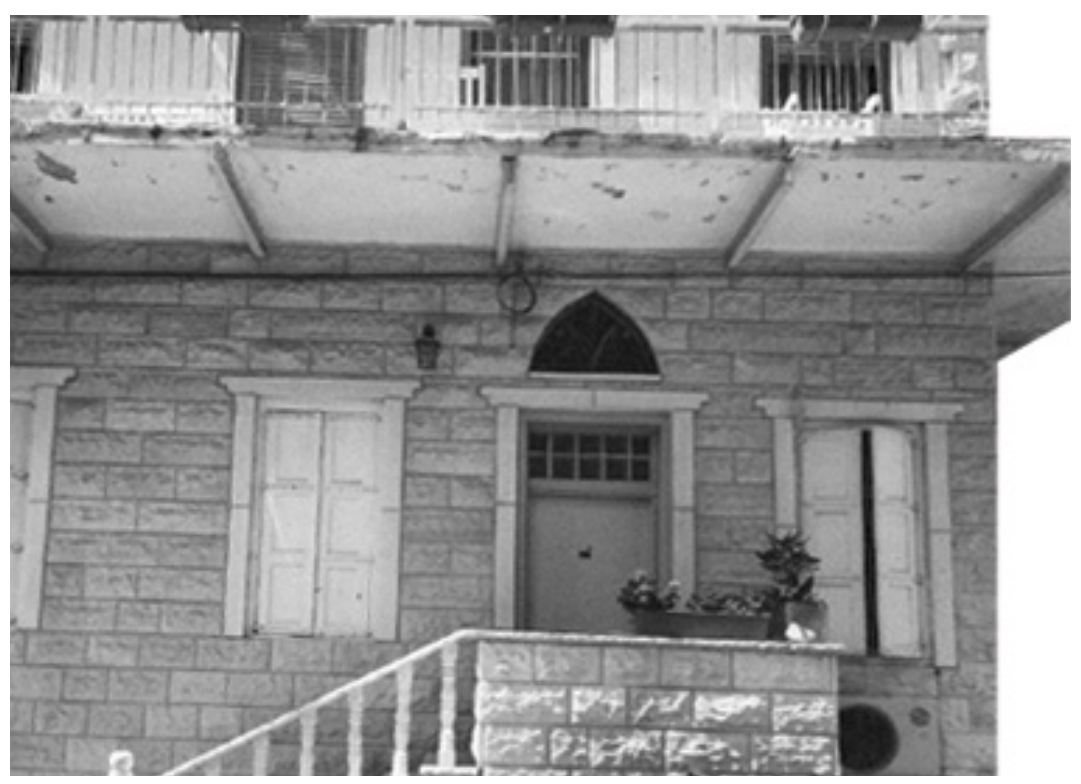

Figure 4.9 - Anis Jarrah's House in Akka, 1996.

This house used to belong to Anis Jarrah 


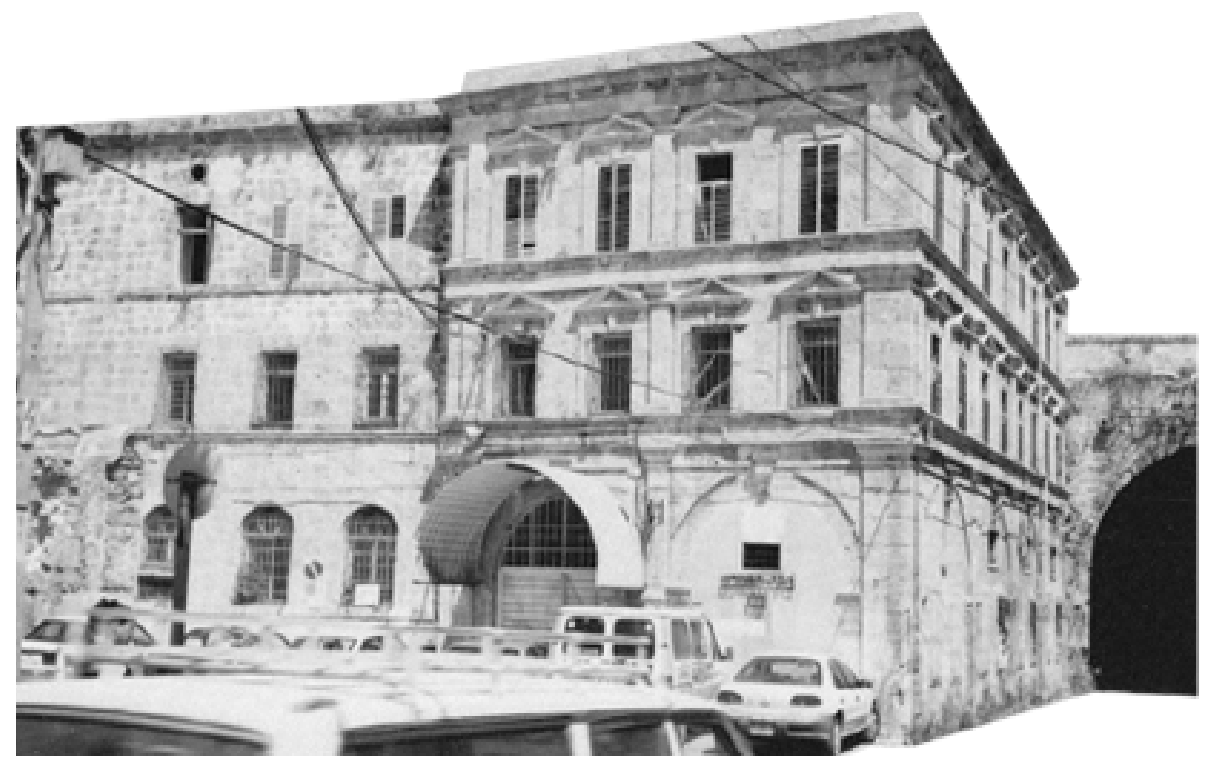

Figure 4.10 - Issam Jarrah's high school in Akka, 1996. 


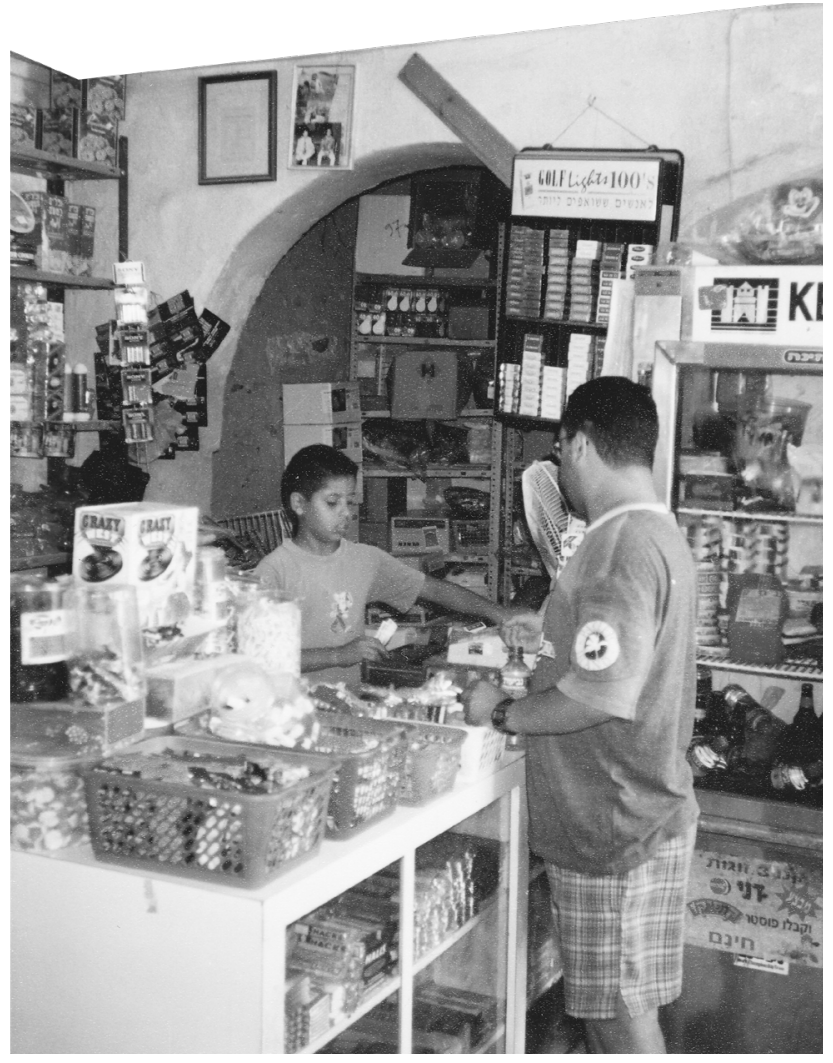

Figure 4.11 - The Jarrah Shop, 1996. (Interior) 


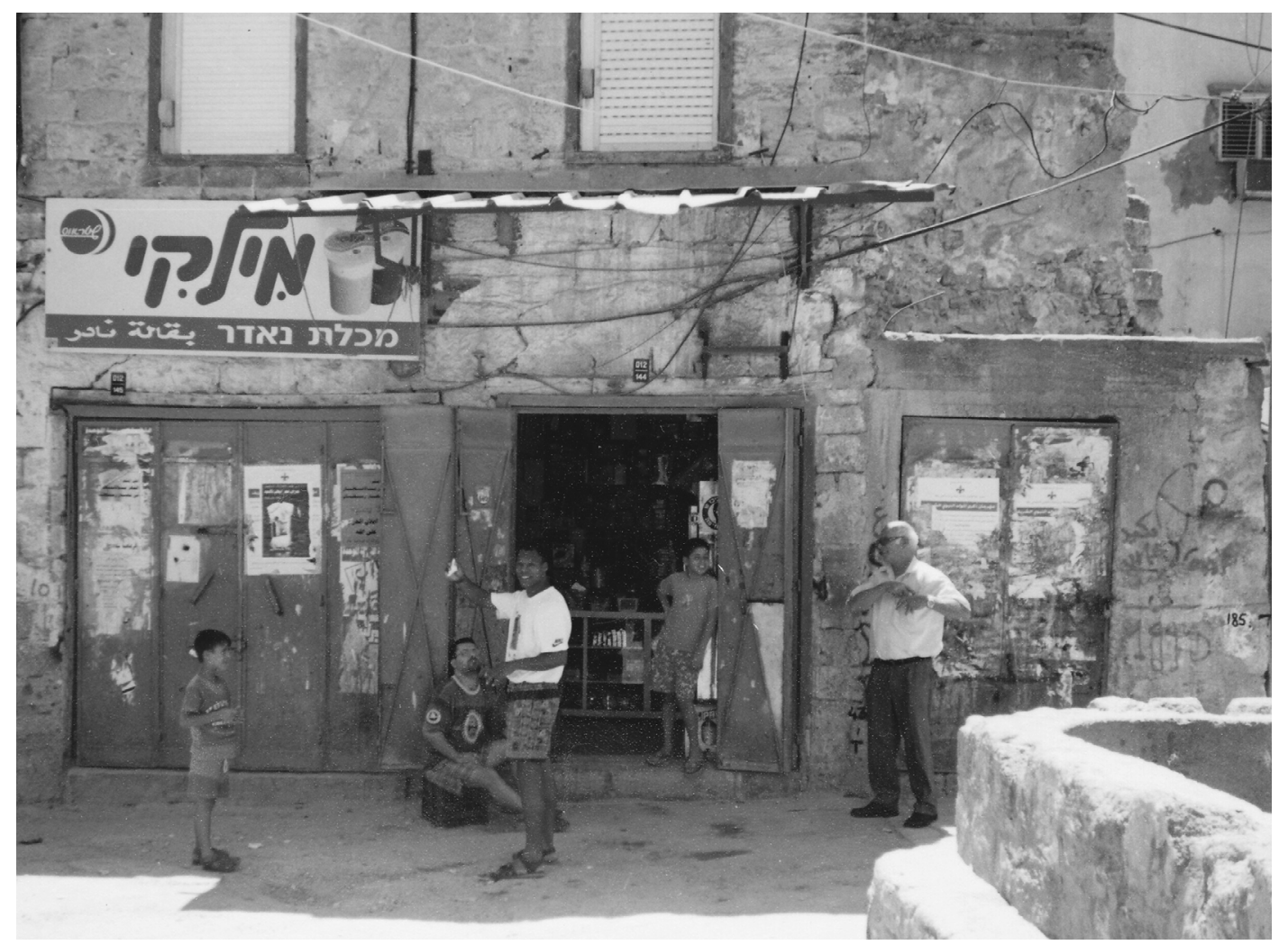

Figure 4.12 - The Jarrah Shop, 1996. (Exterior) 


\subsection{Al-Jazzar Masjid (Mosque)}

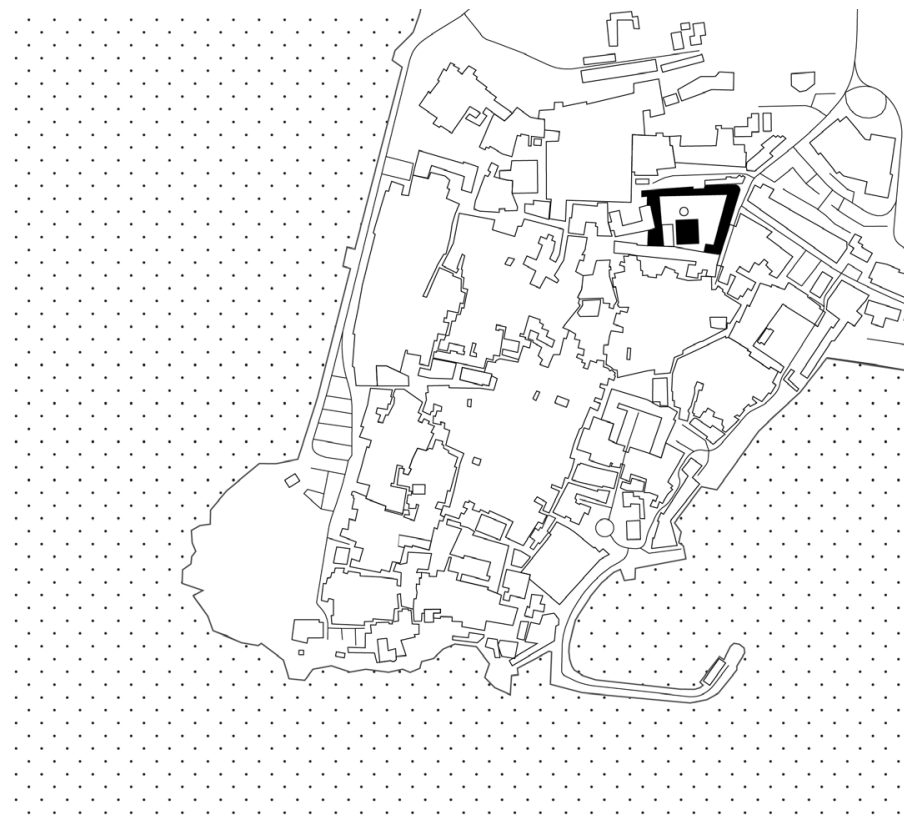

Figure 4.13 - Masjid Al-Jazzar, Akka (Acre)

While domestic residences can be taken over and lose their ownership, public spaces largely remain intact over time. This is evident in the case of Al-Jazzar mosque in Akka (Acre), where the Jarrah family used to attend prayer prior to 1948 . However, to the Jarrah family the mosque's significance does not solely lie in its public use as a religious point of reference, but also as a critical public sphere. As mentioned, Maya's grandfather, Issam Jarrah, was born in Akka (Acre) in 1932, and left when he was only 16, in 1948. His father, Kamal Jarrah, used to work as an employee for the Waqf or Awqaf sector in the government (Arabic for endowments). He was also in charge of the preservation of historic and non-historic Islamic buildings, sites, or attractions. His office was located at Al Jazzar Mosque, which is located on Al Jazzar street, in the old city of Acre. During a visit to Acre in 1996, Maya's father was able to visit the office, which still stands to this day. Kamal Jarrah died in 1939, when Issam was only seven. 


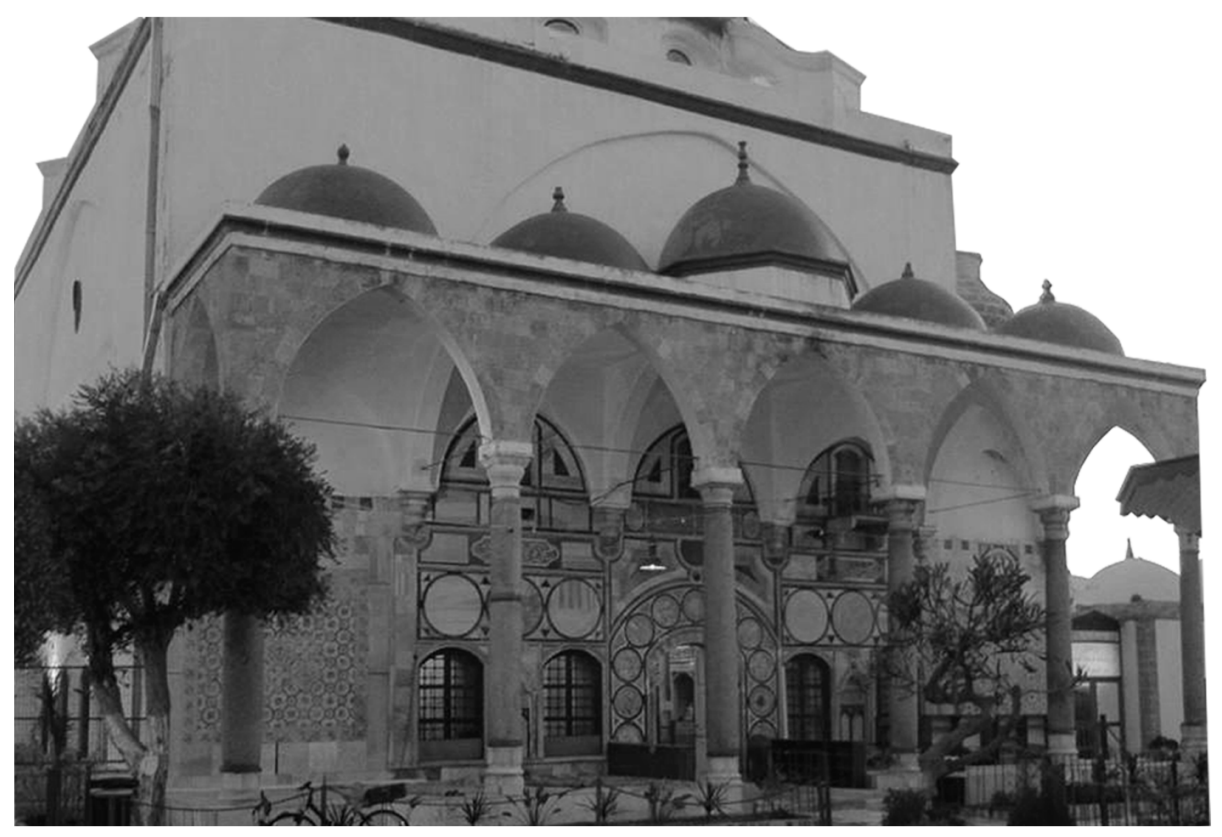

Figure 4.14 - Masjid Al-Jazzar (Exterior)

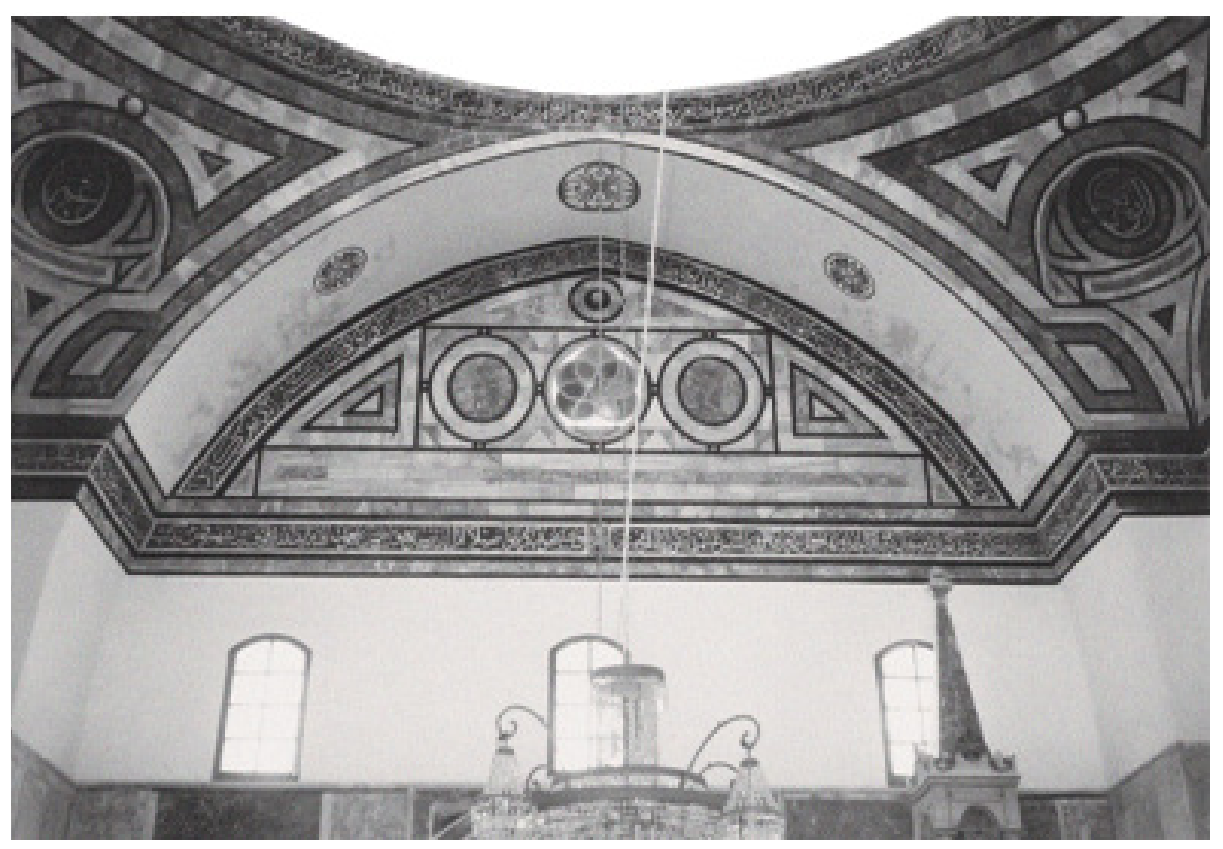

Figure 4.15 - Masjid Al-Jazzar, 1996. (Interior) 


\subsection{The Seawall Jump}

The persistence of performing an act is the key component of continuity for human interaction across time. In relation to nature and place, certain traditions or behaviors are essentially defined through such encounters. Due to its adjacency to the Mediterranean, Akka has hosted sea wall jumps for centuries, which has become a recurring memory of the Jarrah Family. In this case, the importance of reciting such activity is not simply limited to the survival of memory, but also pertains to the fact that it is narrated by the youngest generation of the family who has never even had the chance to visit the place itself in its current state, yet they are capable of providing detailed descriptions of the place the way that it was many decades ago. As Maya describes:

"Since Akka is by the Mediterranean Sea, I remember stories related to the water and the sea. One of the stories that I remember is about guys in Akka who would impress girls by jumping off the cliff into the sea, and this would be a measure of how strong they were. I still see videos of people in Akka jumping into the water. I used to hear that people would also race each other at the beach. I was often told about fishing and cooking seafood in Akka by my grandfather. And my grandparents also retained their dialect from their homeplace, even though they moved to Jordan."1

1 Jarrah, Maya. (2021, January 18). Personal Interview. 


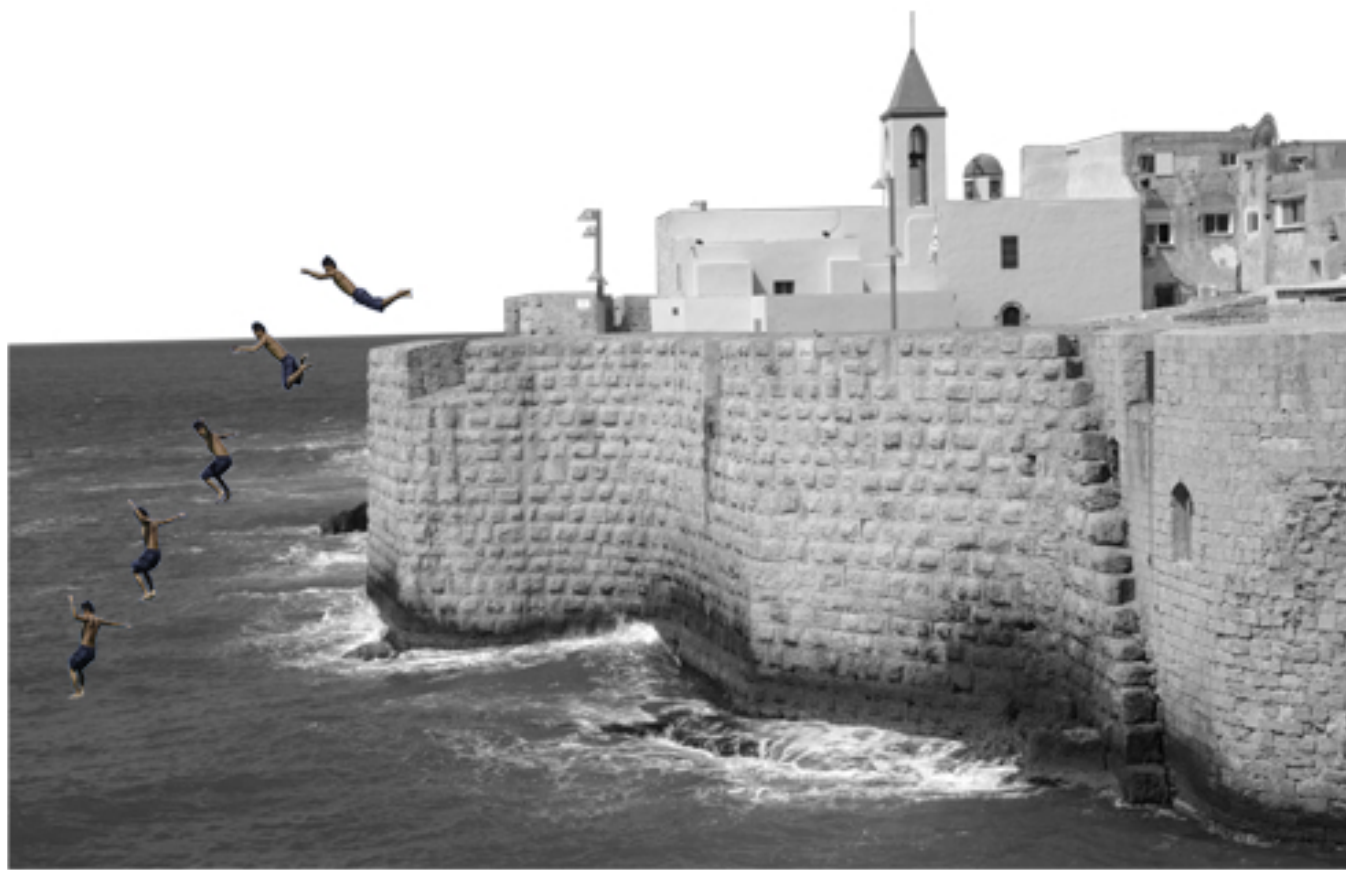

Figure 4.16 - The sea wall jump 


\section{Interviewee 3: Rifat Audeh}

\subsection{The Guest House}

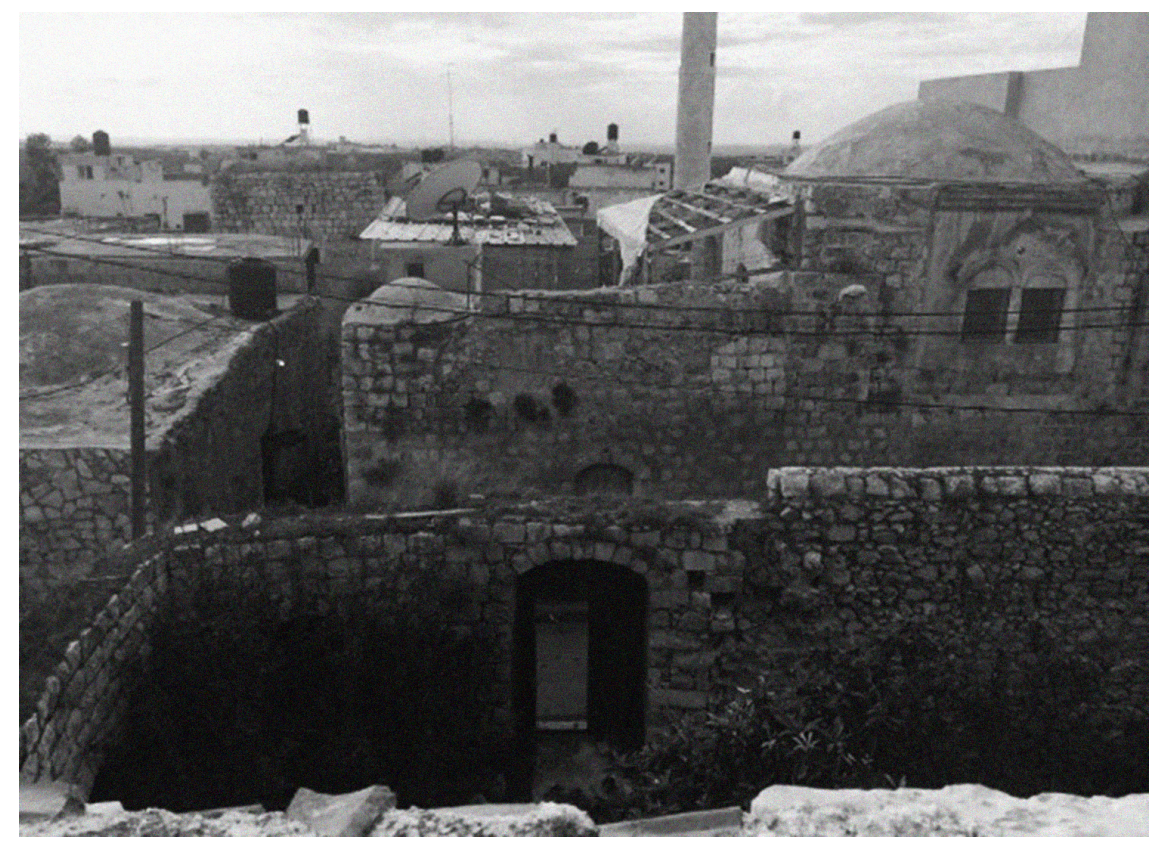

Figure 4.17 - The village of Biddya viewed from a family house

Born and raised in Canada, Rifat Audeh, is an engineer and an award-winning filmmaker, and one of the few of my interviewees who has been able to enter Palestine. Rifat's father visited Canada in the 1960s on vacation as a graduate from the United States and decided to stay as soon as he found a job. Both of Rifat's parents were born in Palestine, as well as his grandparents. They all come from a village called Biddya (بديا) not far from the city of Nablus. The ability to visit the village in person has offered Rifat a much easier connection with family members. Over the course of the interview, Rifat described certain features of Palestinian identity in terms of hospitality and the notion of kinship. These were elements explained through his description of the madafah, the Arabic term for guest house, that still stands to this day. 


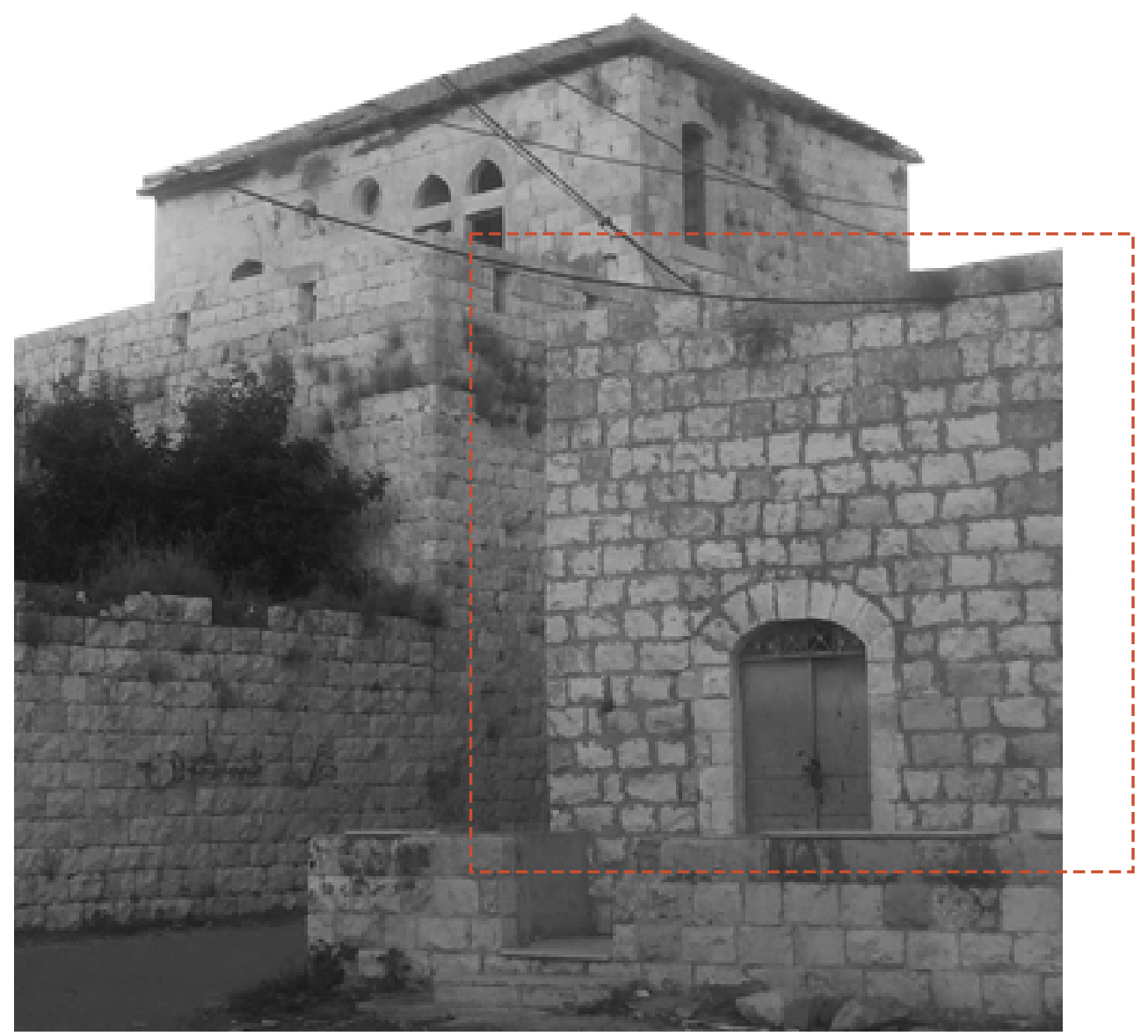

Figure 4.18 - The Audeh Family Madafah, Biddya 
Rifat mentions that the guest house used to be a place for travelers to stay in the absence of hotels, where the host would provide accommodation and food to the best of their ability. According to his father, people would come and stay at the madafah at the host's expense, where they would be served with food and allowed a place to sleep. The photos Rifat has provided portray the family madafah owned by the Audeh family in Biddya, which is located in proximity to the family house. The madafah is represented in a cubic form and cladded with stone, a common and symbolic material used in traditional Palestinian buildings. The front side includes a raised platform serving as a patio with less than a meter tall stone divider that defines the rhythm for approaching the place. The simplicity and the purity of the form accounts for the flexibility of the space in terms of accommodating a wide range of activities through which the house gets its meaning. 


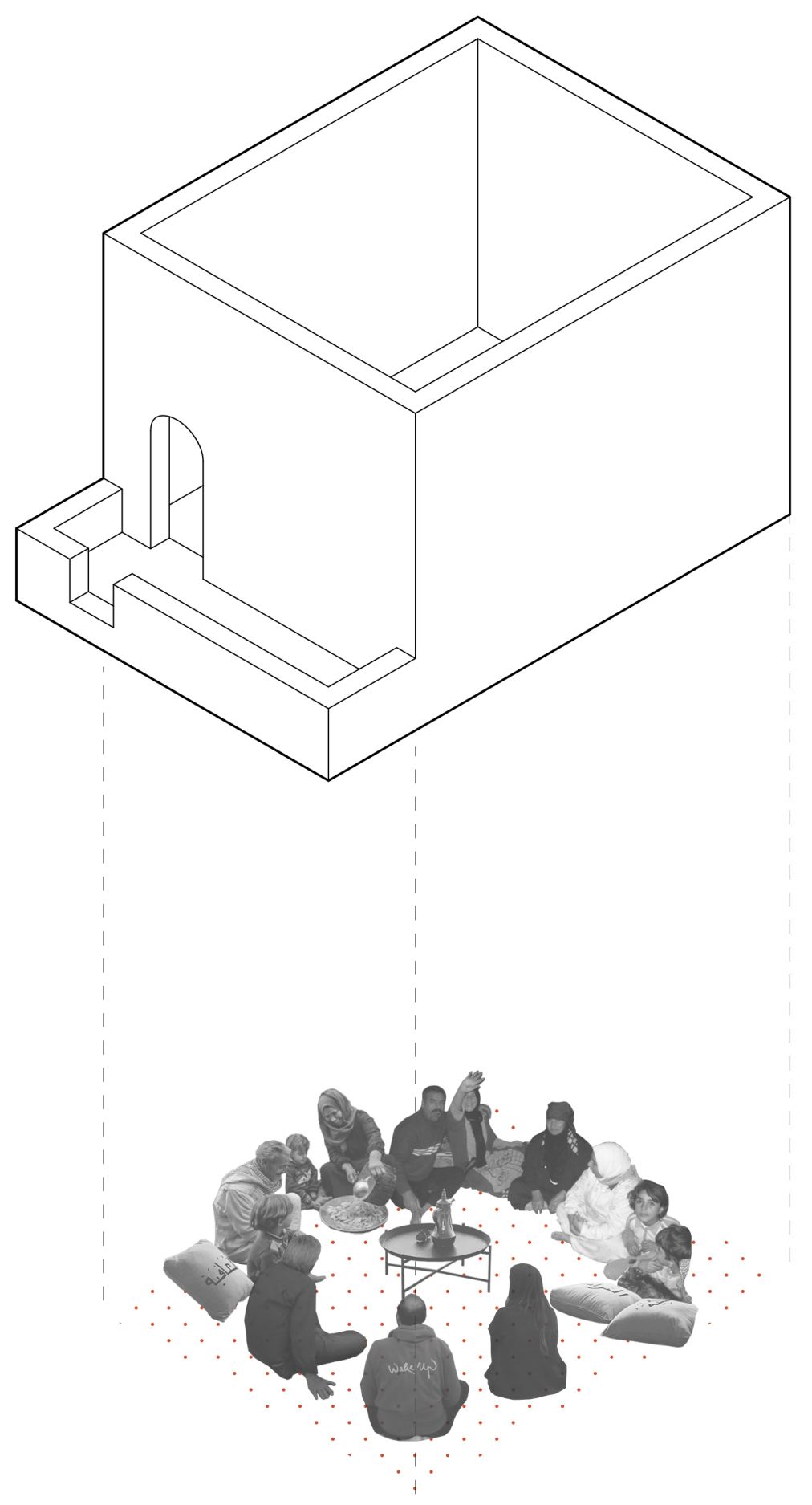

Figure 4.19 - Madafah (Axonometric) 


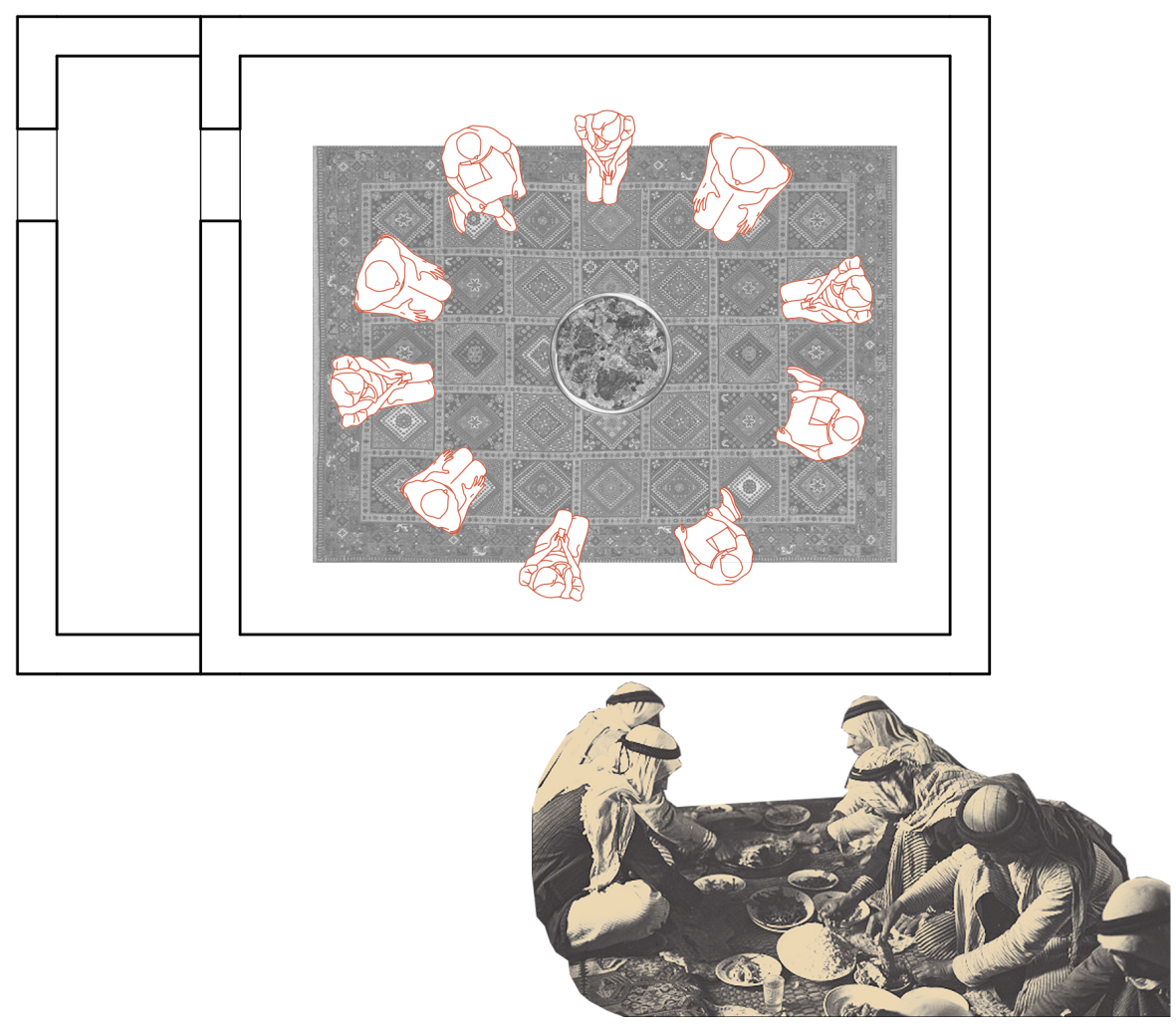

Figure 4.20 - Madafah, a place to eat 


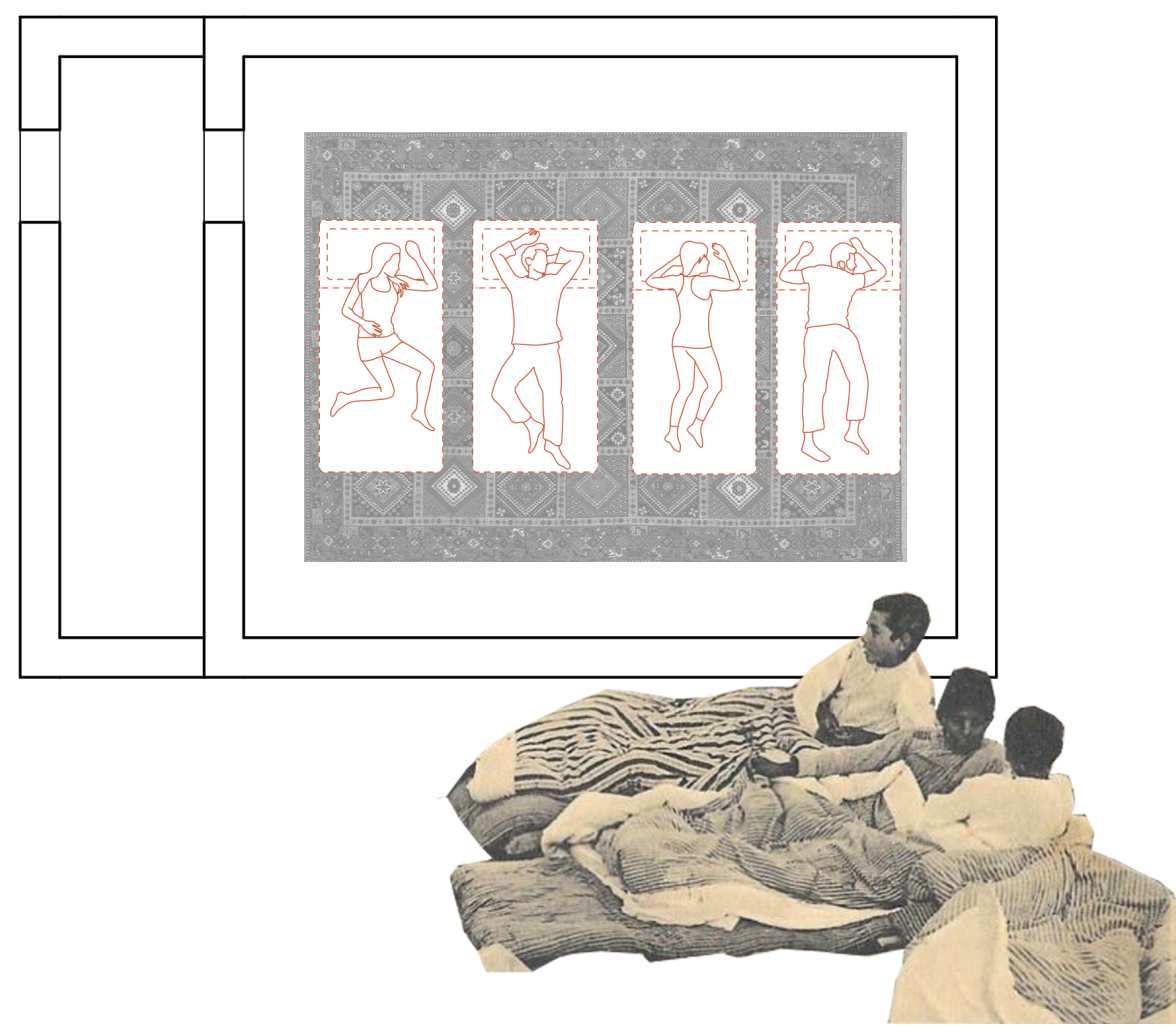

Figure 4.21 - Madafah, a place to sleep 


\section{Interviewee 4}

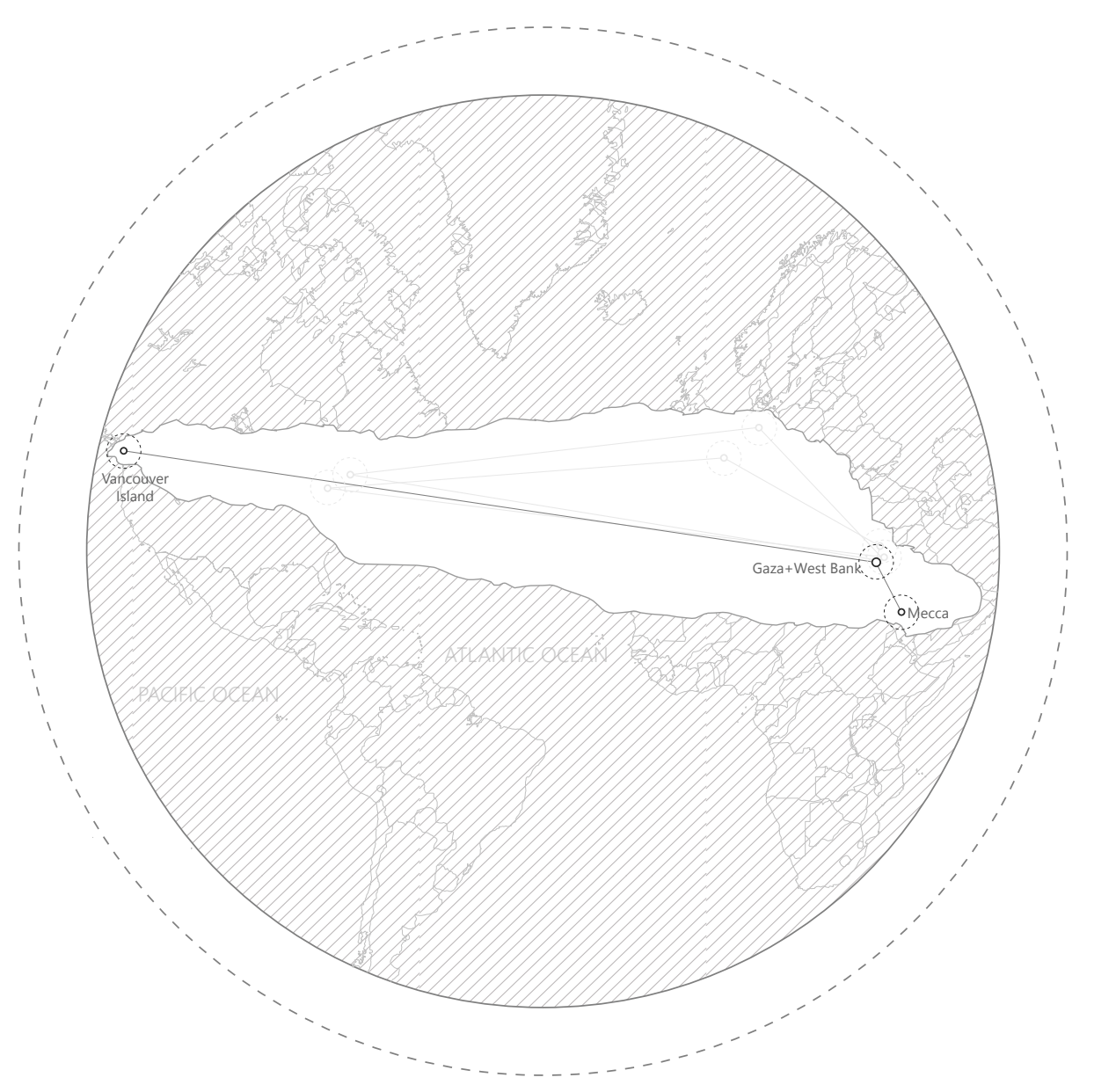

Figure 4.22 - Geo-located Map of Interviewee 4 


\subsection{Gaza, an Internal Separation}

Before moving to Canada in 2014, the interviewee spent the majority of his life in Gaza, a city cut off from the rest of the Occupied West Bank and the pre-1948 Palestinian territories. His family have been residents of Gaza for hundreds of years. Like many others, his perception of the territories beyond Gaza's imposed borders was left in ambiguity as a result of the Israeli occupation. While the interviewee could enjoy the freedom to wander through Gaza as a Palestinian, his essential right to visit the West Bank was deprived, a critical feature of his imaginary space making. Given the constraints on his physical experience of the place, he relied mostly on images and stories shared by family members and friends to construct an image of areas he was not permitted to visit. Although diasporas are often conceived outside borders of an original center, the case of this interviewee from Gaza reflects on an internal diasporic community that is shaped through physical separation and discontinuity. A distinct aspect of such condition is the ways spaces are perceived through one's imagination against how they would be experienced in person. In contrast to his clear vision of Gaza, the way in which the interviewee perceives places in the West Bank is particularly selective. Throughout the interview, he recites his desire for certain places that would appear much bolder in his mind due to their historical and cultural significance:

\footnotetext{
"My dream, however, is to visit the market in Bethlehem. The city has the mixture of Christianity and Islam, and you can feel the diversity in that market. For instance, you would speak to a shop owner who is a Christian whose family been there for thousands of years, telling you stories about the place. Bethlehem market is known for its souvenirs that represent different religions that I do not even know much about. I just want to have the dream of walking peacefully in Bethlehem with a piece of chocolate or ice cream, since Bethlehem is famous for its ice cream. I never had that chance."1
}

1 Interviewee 4. (2021, January 19). Personal Interview. 


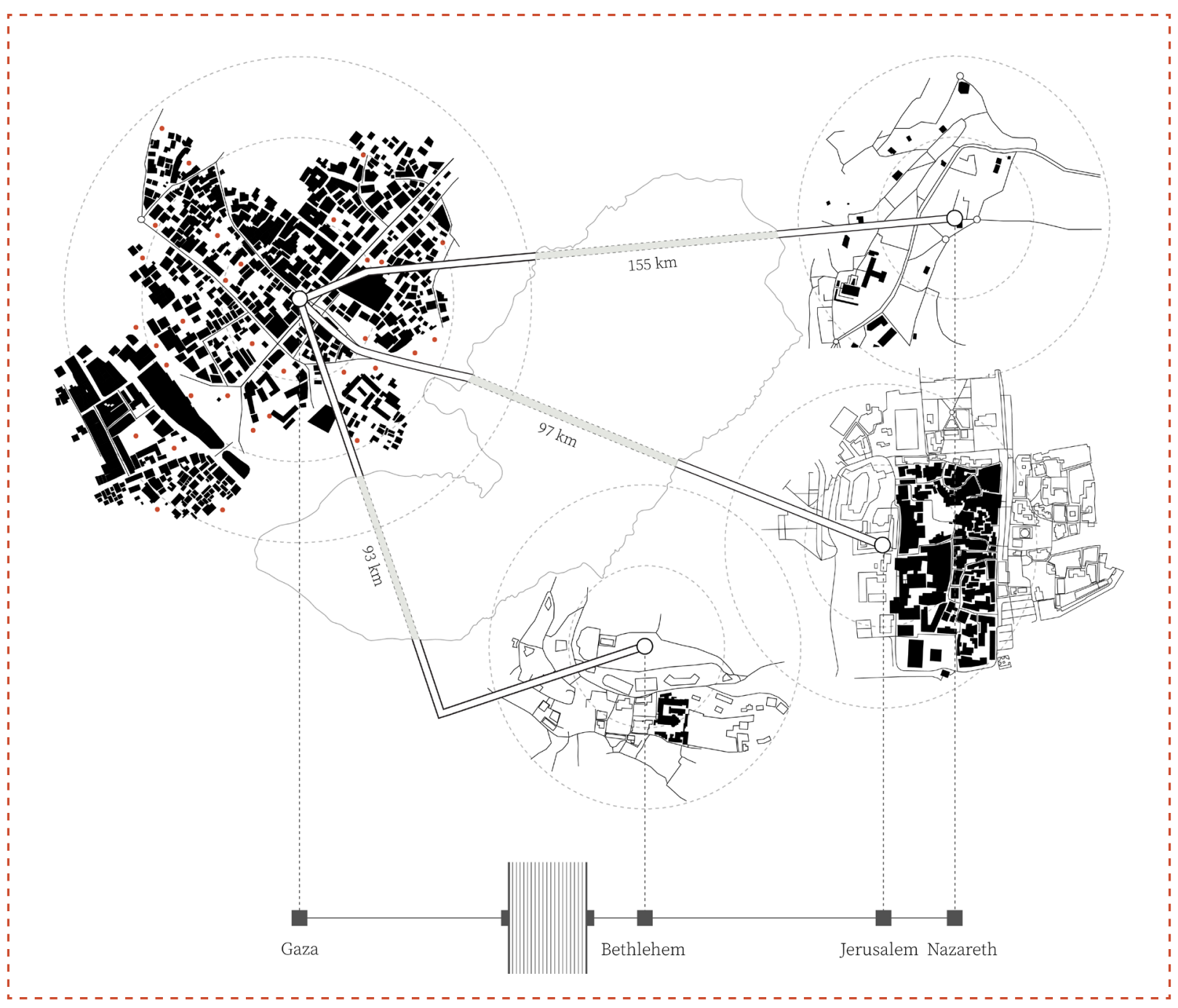

Figure 4.23 - Selective Domains

Gaza is depicted as a space that is entirely experienced in person by the interviewee. In contrast, the cities of Bethlehem, Jerusalem, and Nazareth are conceived for the selected areas based on a limited set of information gained through hearings from friends and family members. 
The selective domain which constructs the interviewee's perception of cities like Bethlehem, Jerusalem, and Nazareth comes from public spaces of great reputation. For example, when speaking of Bethlehem, he provides an astounding description of the market and its surrounding atmosphere-describing a market he has not visited, local delicacies he has not tasted, and vendors he has not met. In the case of Jerusalem, the city for him is summed up in the old market and the historic quarters, as if a lens has narrowed its focus into only a portion of a much greater domain, where the entirety of the place is represented to a much lesser extent though a singular destination.

Such scope of memory owes its existence to the frequent trips the interviewee's grandparents used to make to Jerusalem for shopping before the occupation. The same logic applies to spaces which he renders in his perception of the city of Nazareth. Due to the city's religious significance, he has acquired a limited knowledge of places like Mary's Well, the Old City square, and the basilica. His remarks strongly emphasize how freedom of movement restricts the notion of place in its entirety and disallows a full-fledged experience. Later in his life, the interviewee was able to visit the West Bank with a short-term permit, where he found places to be much bolder and significantly greater compared to the way he had imagined them. He recalls how dazzled he was by the greatness of the rocks from the mountains while he took his time to observe them for the first time. 


\subsection{Spatial Signals}

It could be presumed that disconnection from a familiar place would naturally distort one's vision and perhaps cause absolute longing and affection for it, but it would be much more challenging, or rather shocking, to unveil the existence of places which one would have been separated from. During his early youth, our interviewee experienced a distinct separation from the occupied territories in terms of absence of information. As a teenager, he would help his father on a farm in the north of the Gaza Strip which was the closest point to pre-1948 Palestinian territories (now part

of Israel). Despite the physical separation, he relied on the radio, and specifically the 'Voice of Israel' channel, as a spatial signal which would help him construct an imaginary inventory of places he would hear about. For him, daily information, such as road conditions and traffic jams, were much more significant than mere ordinary announcements. It was through exposure to such information that he would identify where the roads and highways would be connected to each other, utilizing the signals as a tool to map out Israel and the West Bank. 


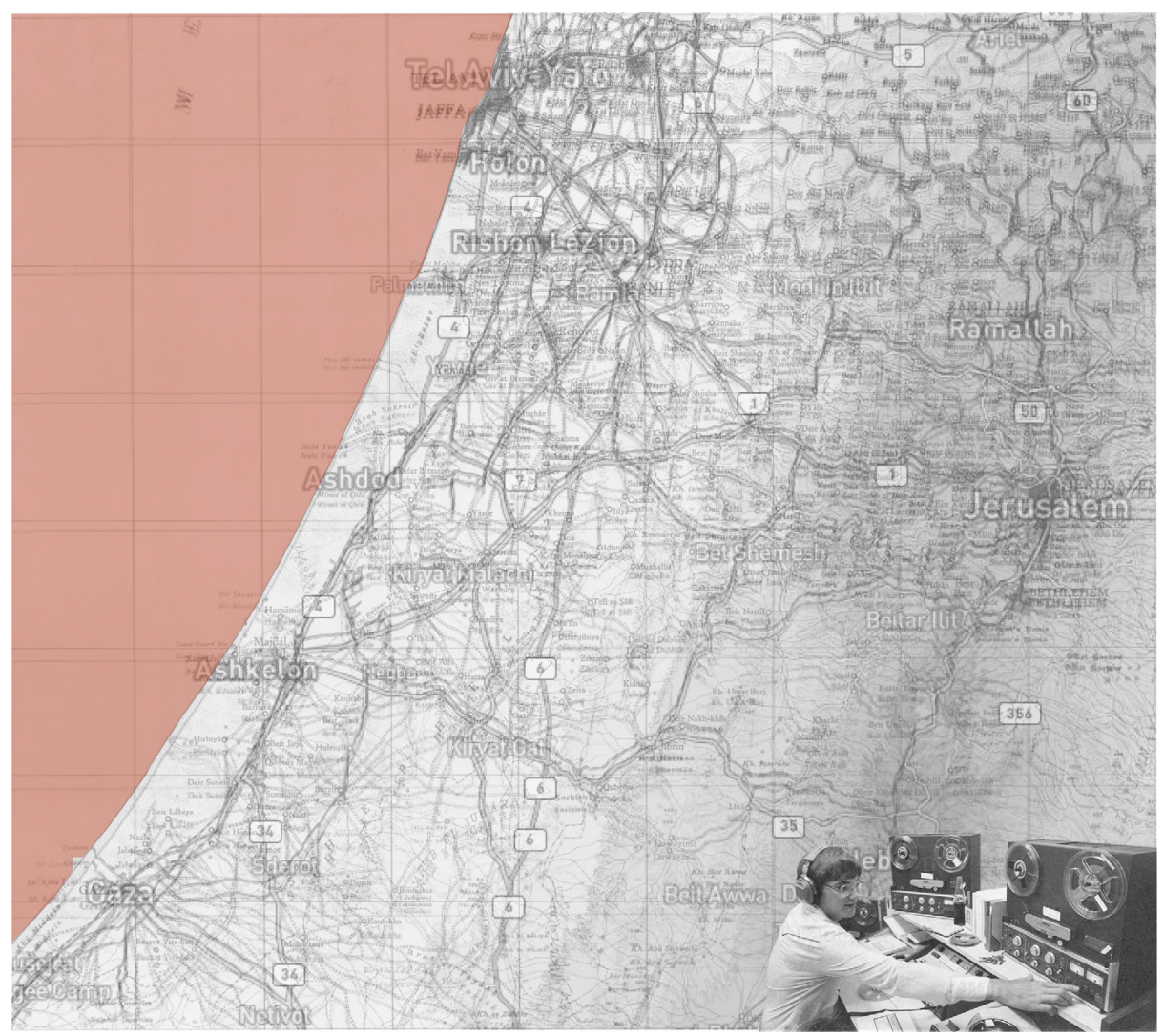

Figure 4.24 - Pre-Radio Perception

An obscured image was in essence how the interviewee perceived the territories which he was not permitted to visit. 
Describing how he gained this knowledge, he said:

"The 'Voice of Israel' would announce the traffic situation, road conditions, and where traffic jams would happen. I got to know about Highway 6, the north-south bound highway, which I would have never known as a Gazan, if I had not listened to the radio. When I managed to travel to the West Bank, I found it easy to navigate by myself and to figure out which road connects to another. This was basically built off more than seven years of listening to the Israeli radio. They would mention road situations and even mention the family names, since in Palestine people recognize each other by their family name. So, I would have known about the families and tribes that lived in every single village by following up daily on the news. This built up a huge knowledge for me, that even my friends from Israel would be shocked when I would tell them they are from which town. They would say how the heck I would know, and I would say that I had been listening to the specified radio channel since I was seven years old."1

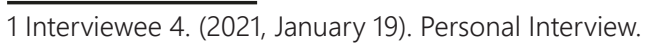




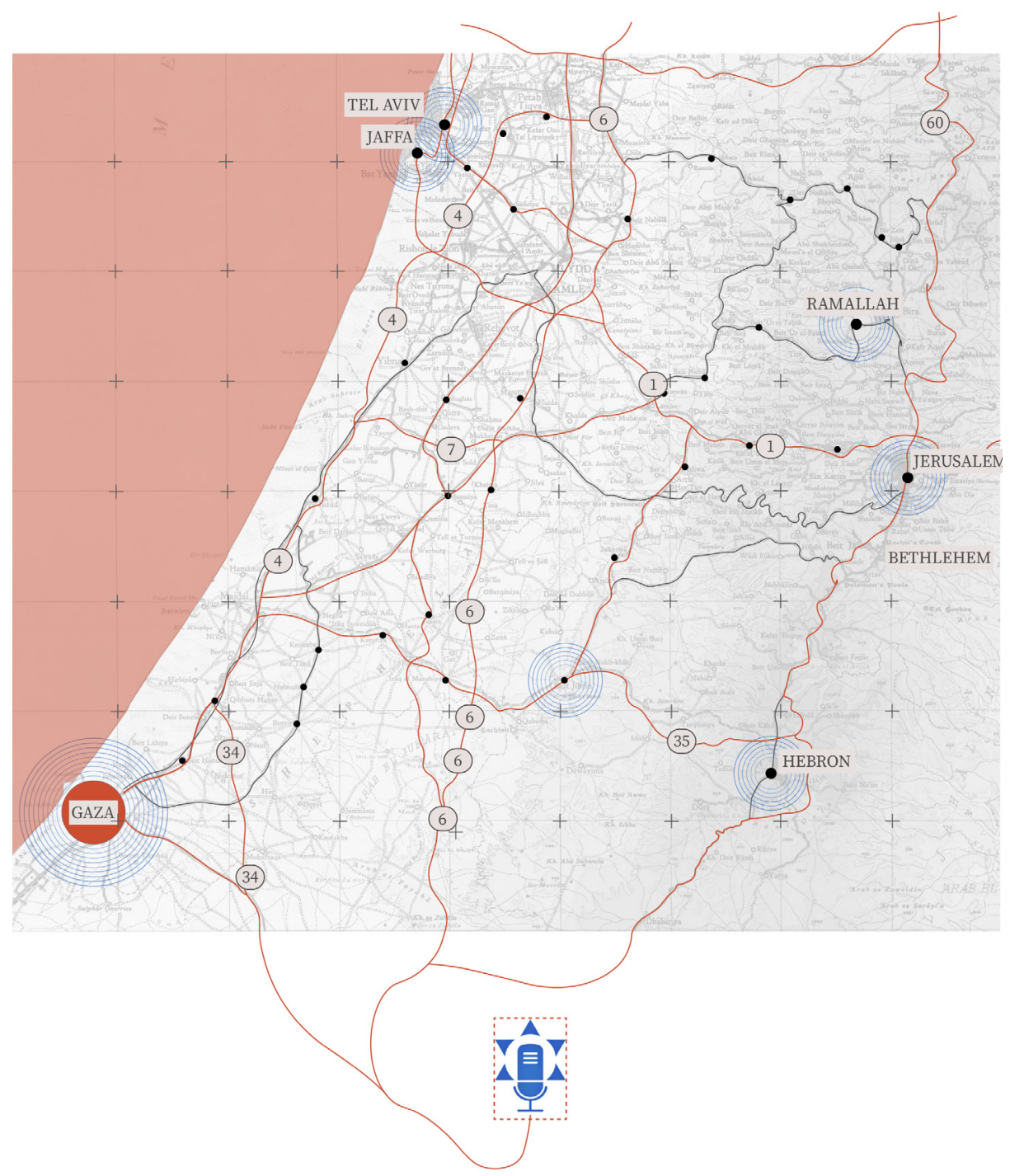

Figure 4.25 - Post-Radio Perception

By listening to the 'Voice of Israel,' the interviewee was able to construct a network in his mind, mapping out road junctions and the location of towns and villages. 


\section{Interviewee 5: Anonymous}

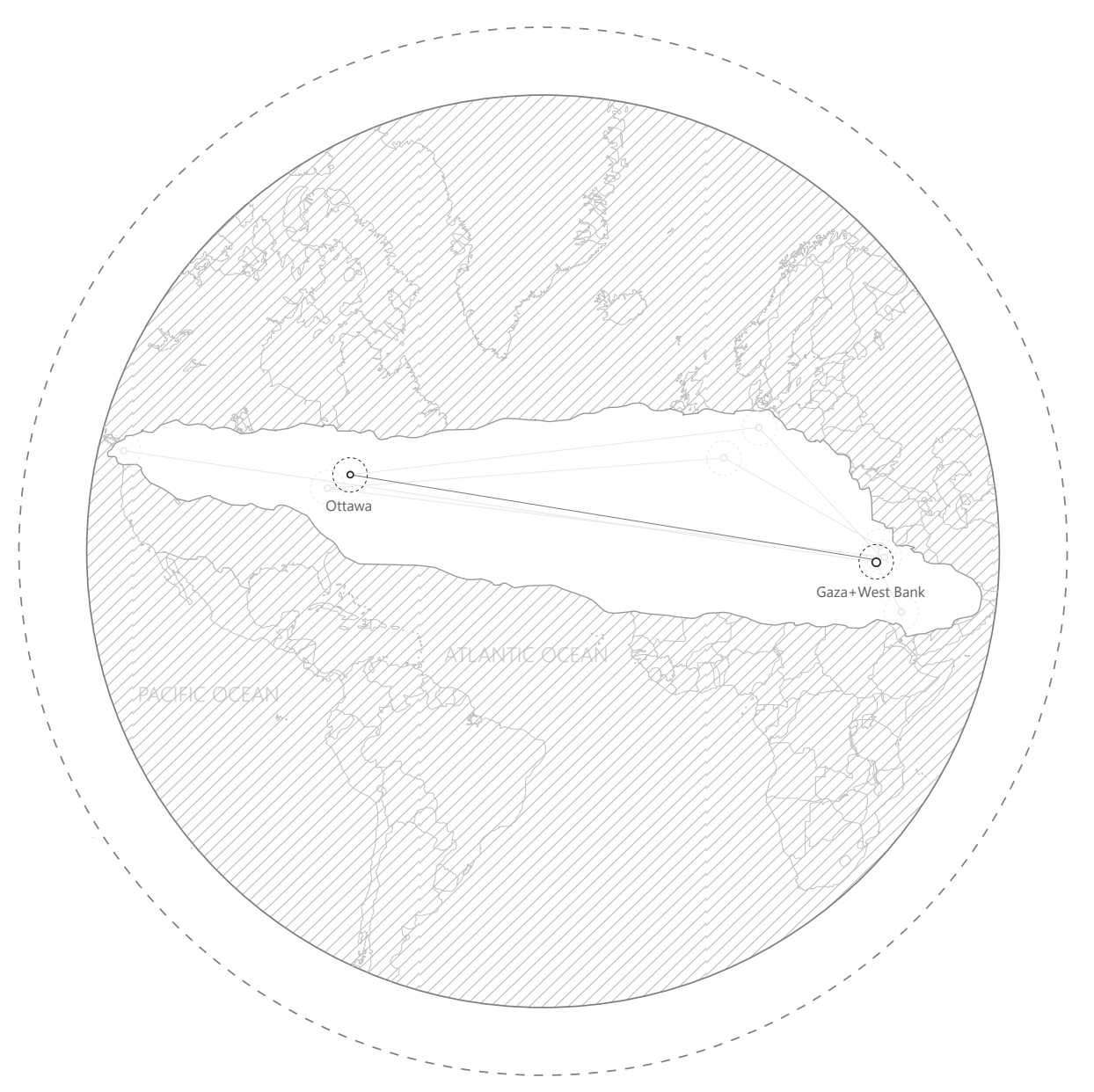

Figure 4.26 - Geo-Located Map of Interviewee 5 


\subsection{Permitted Views}

Originally from Ramallah, the interviewee was born and raised in Canada. Their parents come from Beit Ummar, a Palestinian town situated between Bethlehem and Hebron. Having spent a number of years in Ramallah as a Palestinian-Canadian, the interviewee has experienced the two layers of diaspora, both the internal separation from the Gaza Strip and the pre-1949 Palestinian territories, and being distant from their ancestral homeland while living in Canada. The focus of this section is on the interviewee's experiences in diaspora inside the occupied West Bank. The interviewee recalls the challenges from crossing the border into Palestine as a child, and most importantly the imposed restrictions by Israel over people's movement within the Occupied Territories. Like many West Bank residents whose access to the Mediterranean Sea has been cut off by the occupation, the interviewee's only point of connection to the coast is rather a visual one. Just a few kilometers outside of the city of Ramallah, there is a spot where one can see the coast on a clear day. The interviewee often goes to the point as a retreat, with a highly distant view of the sea. The complexities of internal separation have created such alternatives for coming up with links to places that one is not permitted to visit in person, a feature that is exclusive to the West Bank residents.

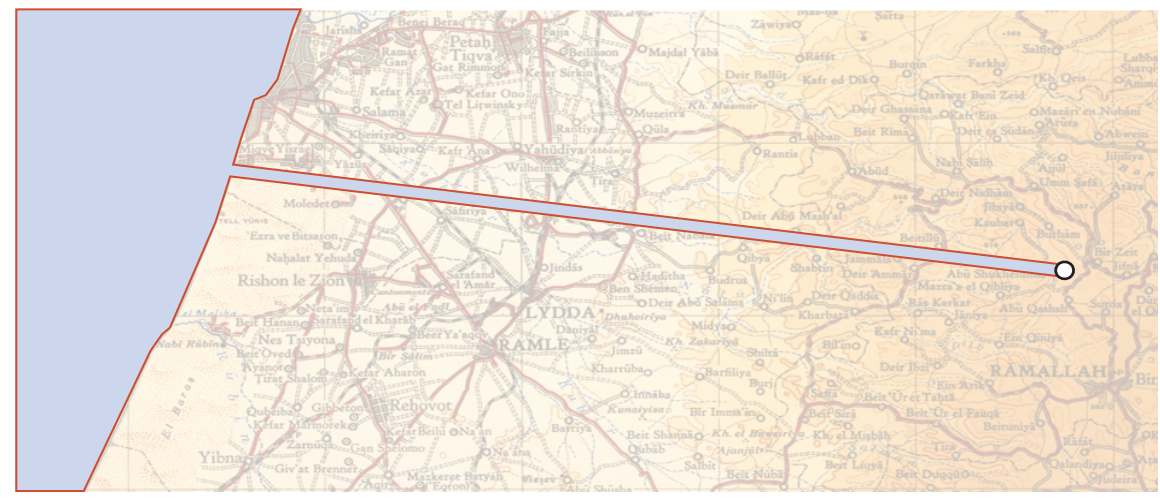

Figure 4.27 - Visual Route to the Mediterranean 

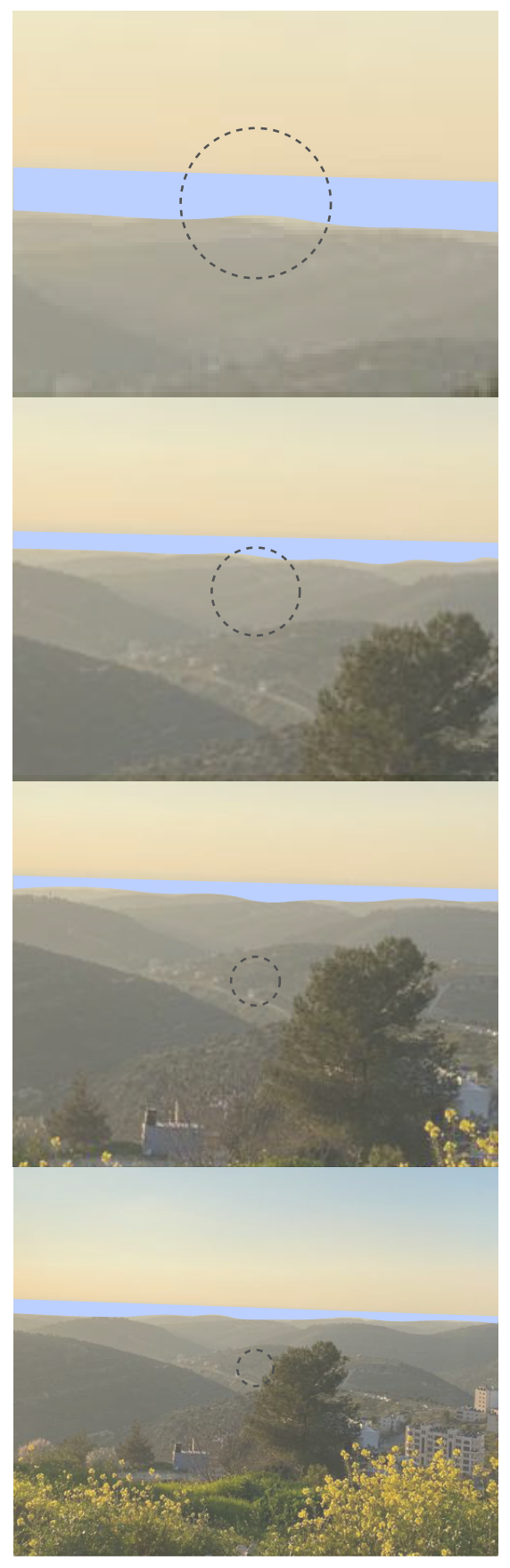

Figure 4.28 - View of the Mediterranean from Ramallah, 2020 
During the countless trips to their parents' home in Beit Ummar while studying and working in Nablus and Ramallah (2007-2017), the interviewee was able to identify a viewpoint where one would be able to see the Dome of the Rock in Jerusalem, one of the most significant places in the Islamic world. The spot is located in Ubeidiya, a Palestinian town six kilometers east of Bethlehem. The divisive logic of the occupying regime has meant that in order to observe the dome from distance-not even in person-an individual from Ramallah needs to drive to the south, all the way past Jerusalem to a place much farther away from Ramallah.

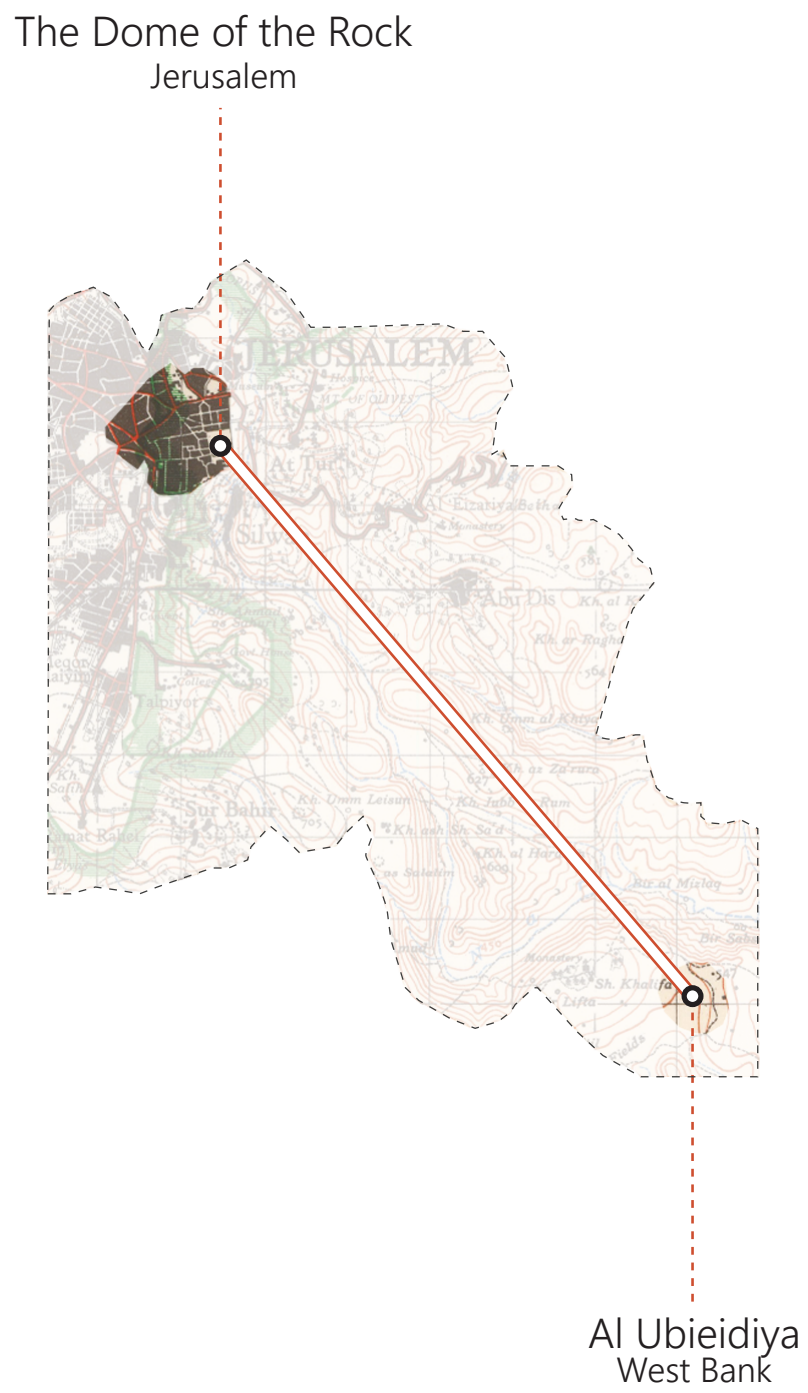

Figure 4.29 - Visual Route to Jerusalem 


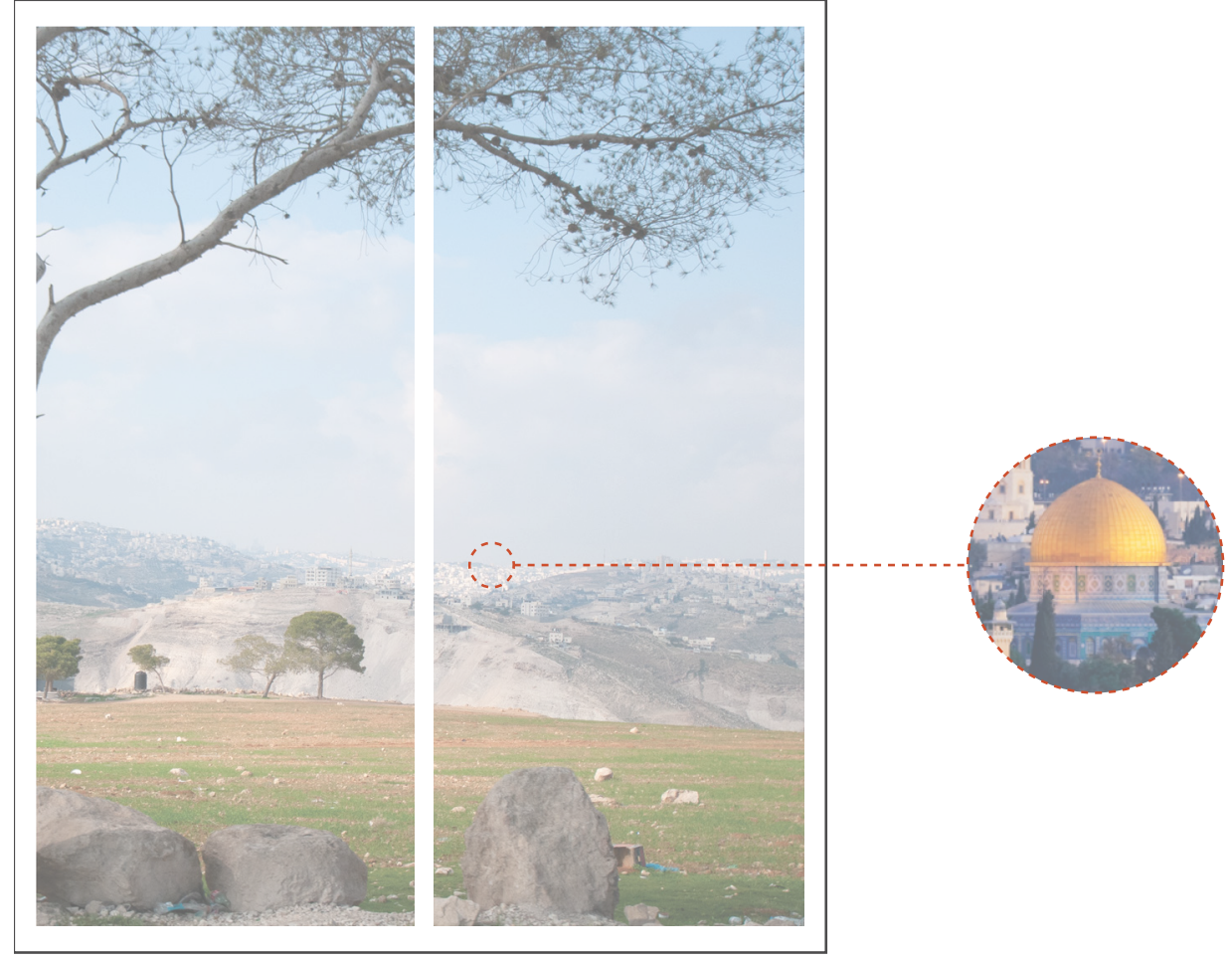

Figure 4.30 - The Dome of the Rock, 2018 


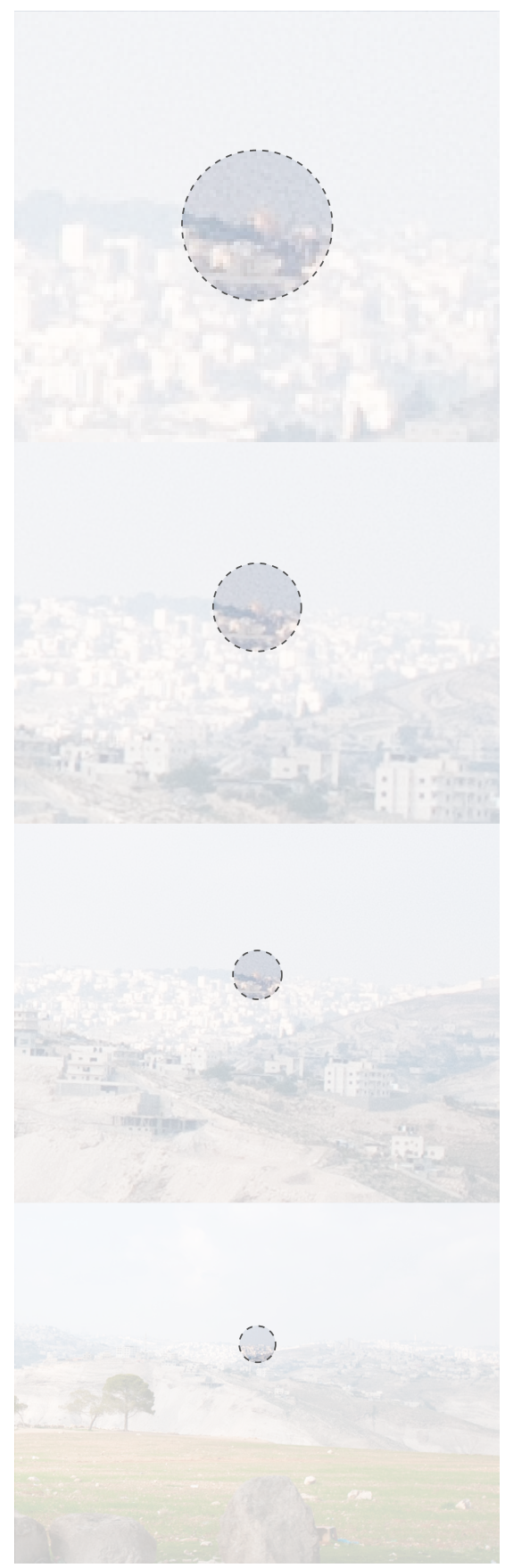

Figure 4.31 - View of the Dome of the Rock from Ubeidiya, 2018 


\section{PART ॥}

\section{INTERVENTION}




\section{Conceptual Framework}

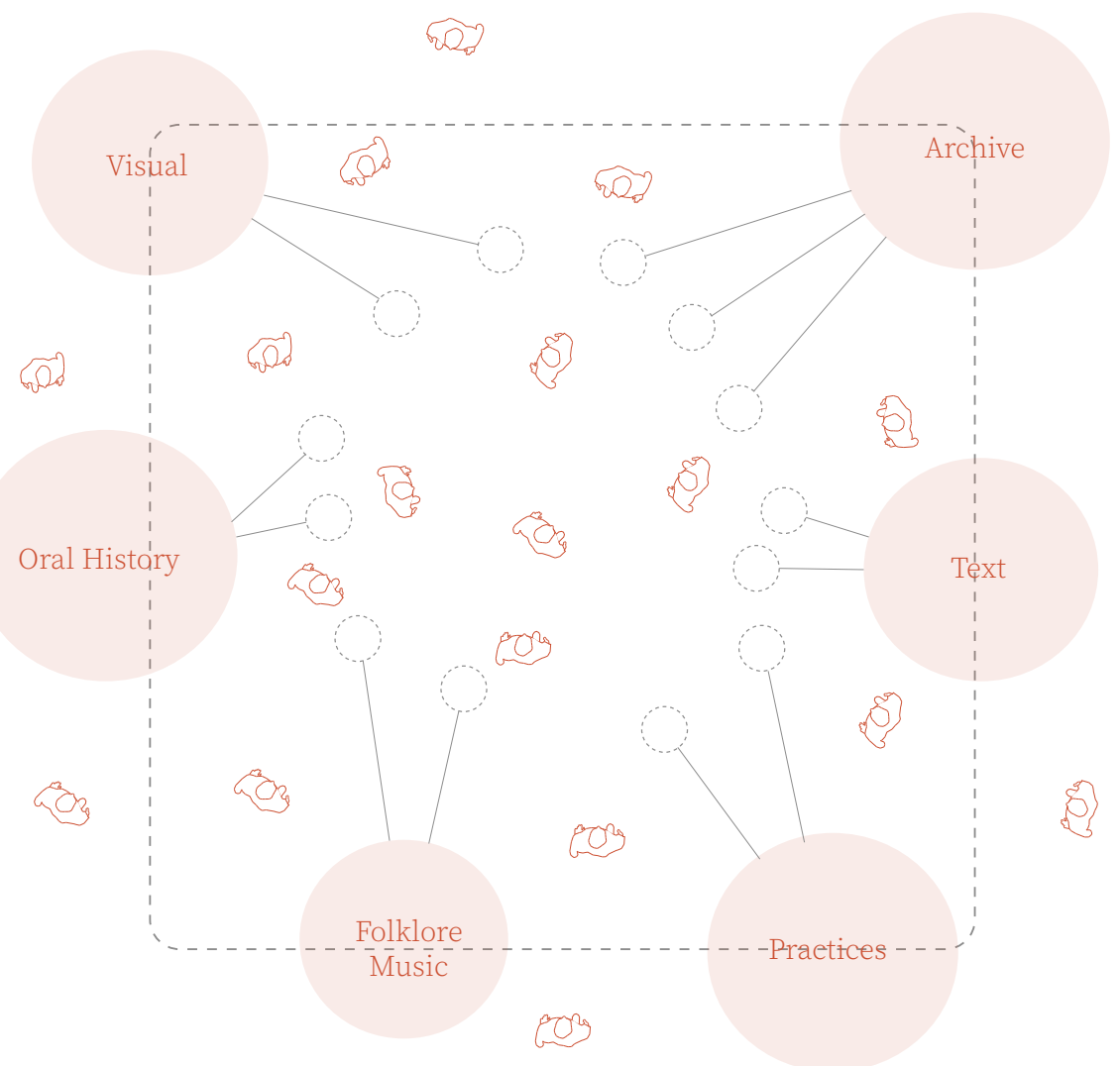

Figure 5.0 - Conceptual Framework 


\subsection{Spatial Agency}

Spatial agency serves as the conceptual foundation for the design phase of the project. It aims to describe space beyond what is imagined to be a void between physical objects. The critical vision here recognizes social space as a social product, placing an emphasis on the contribution of the public besides professionals in the field of architecture. Processes of creating social space as a form of dynamic space are acknowledged as key factors in the transition from an architectural production of static objects to a spatial production, where actors and processes are all considered key players. This acknowledges such production as a continuous and evolving process, rather than a linear sequence with fixed termination points. ${ }^{1}$ The intent is to surpass the self-defined constraints of the design professions, thus not limiting the creation of space to the realm of three-dimensional space, but allowing individuals to act independently and to step over the boundaries of social structures.

The replacement of individual agency with a spatial one affirms that the architect's role is not solely reduced to a technical facilitator and ultimate decision maker. The self-dependent autonomous production of buildings is tightly linked with the assumption that such act is undisturbed by external factors. The collective aspect of spatial agency addresses a notion of shared responsibility, by allowing others to engage in their spatial environments. The focus is shifted from objects of architecture to the consequences of architecture. The attention is not entirely dedicated to the world of form-making and creating three dimensional objects, but also concerns the social aspects of spatial production, and the ways these are affected by the formal. ${ }^{2}$

1 Awan, Nishat, Tatjana Schneider, and Jeremy Till. Spatial Agency: Other Ways of Doing Architecture. London: Routledge, 2011: 29 2 Ibid: 33 
Mutual knowledge in the field also places the same value for the amateur's power of contribution to spatial production as the expert's. Thus, shared experiences and interdisciplinary skills are transformed into opportunities in the process. Different ways of thinking and behaving are considered applicable to different settings, despite contextual differences. This implies a new way to perform architecture in a different way and to recognize and engage the public as agents in the process of production. Such concepts are of value in this thesis because they open up ways for the public to become spatial agents in the process of space production. The nature of the space and the way it operates is rather highly influenced and manipulated by those who contribute to the function that it serves. This is highly related to the planning procedure for hosting events and activities that take place through the proposed spatial intervention.

"Because of its dynamic context, the expression of spatial agency may lie in something that is either physical - a building, an installation, an exhibition - or in something that is less tangible - or both at the same time. To shift attention away from the building ... is to focus on the processes that connect the different parts of the production of the built environment. We don't claim these processes and sites of spatial agency to be new "inventions": they are part of any spatial production. What spatial agency does is to acknowledge their importance, so that they assume a new significance."

The shifting boundaries of spatial agency are defined, shaped, and reshaped by an intricate web of social interactions. This implies the possibility of spatial agency beginning with one site, and then evolved into other expressions and actions over time. ${ }^{4}$ Taking into consideration all these factors, the process by which a spatial intervention is to be imagined requires the freedom to accept contribution from a diverse range of actors as a key attribute to its formation and function. In relation to this thesis, it means that the expression of agency can be presented in various forms and shift 
something as small as a gathering into a formal or rather political congregation. This is not only narrowed to individuals, but also includes thought processes and social practices that each person would introduce to the production of space.

In order to establish people of diaspora's right to the society, an organization make take shape with people of shared interest, and in my case, not necessarily limited to the Palestinians in diaspora. They would then work collectively towards setting up events and manage activities in the space that they claim. The engagement in the process of spatial production would subsequently form a complex web of social relations where design knowledge blooms out of such interaction. When the architect is no longer the sole author of the design process, there is an opportunity for the participation of others in the processes of design and production. Such conceptual framework seeks to acknowledge the contribution of non-experts besides professionals during the process of creation. The premise of the thesis in terms of agency is that each interviewee who contributes to the process of production of the atlas has a share in this process and an equal right to its conceptual and intellectual ownership. Interviewees and future contributors to the space of solidarity can exercise their right of authorship as spatial agents. 


\subsection{The Guest House}

The guest house, known as the 'Madafah' in Arabic, serves as a meeting place for Palestinians, with a significant presence in the Arab world, and specifically in pre-1948 Palestinian villages. With regard to the social and architectural dimensions of the space, the Madafah has been described as "a private house that has been built by the members of an extended kinship group as a place for carrying out the activities which concern the kinship groups or one of the members." As a social institution, the madafah would traditionally be administered by clans or subclans, with a great emphasis on Arab hospitality and kinship. ${ }^{1}$ The internal components of the madafah would include designated benches for guests to sit and engage in conversation with one another, whether discussing business or dailiness, blessed with a retreat from the scorching sun, under the cool shade, served by coffee. These were simply the central elements of the madafah culture.

"The word 'Madafah' derives from a root meaning "to serve a guest" or "to be hospitable." It was considered a matter of honor that a family Madafah would be open at any time for any visitor, whether friend or stranger. Family ceremonies also took place here, including the gathering of the men for important meals and the famous Damascene sweets and Arab coffee that followed them. When it was originally built, the women of the household did not use the Madafah, but today men and women alike use these rooms."2

In pre-1948 Palestine, at least one madafah would be designated for every village, with respect to the village size and population. The place would serve a diverse set of functions, from a being a free lodge for visitors to a public meeting point, a coffee house, a reading room, and a small village court. ${ }^{3}$

1 Slyomovics, Susan. The Object of Memory: Arab and Jew Narrate the Palestinian Village. Philadelphia: University of Pennsylvania Press, 1998: 137

2 Khouri, Rami G. "Saudi Aramco World : Room for Tradition." AramcoWorld. Accessed January 23, 2021. https://archive.aramcoworld.com/issue/199303/room.for.tradition.htm.

3 Slyomovics, Susan. The Object of Memory: Arab and Jew Narrate the Palestinian Village. Philadelphia: University of Pennsylvania Press, 1998: 140 
The adaptability of the space according to the social needs of the village can be regarded to be the most important feature of the madafah as an architectural typology. The feasibility of accommodating such a wide range of activities pertains to the use of the madafah as a point of reference for the community it served.

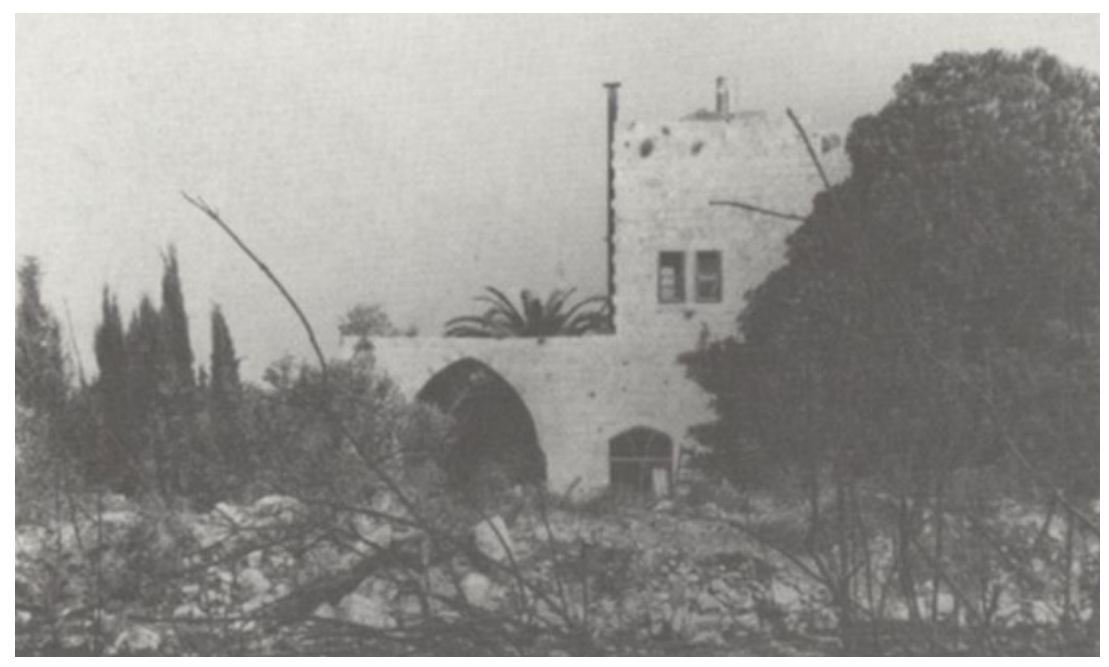

Figure 5.1 - The Madafah of Al-Madi family in ljzim, near Haifa. The village was depopulated in 1948 and the guest house was occupied and used as a villa.

In his ethnographically rich writing on the madafah, Omar Salih El-Barghuthi refers to the guest house as a somewhere more than only a place of gathering, but also as a place of resistance:

"The madafeh is used as a public meeting place for daily gatherings where people visit with each other in boasting of good deeds and in relating the history of their ancestors and their valiant deeds. In such a building there are small windows called tallaqat, which may be used for firing at an enemy. Sometimes there is sort of a bulwark wall on the flat roof, together with heaps of stones, to be used for defense, if necessary. In fact, the madafeh may be considered as a "castle," a meeting place, a coffee-house, a hotel and a marketplace for passing merchants .... The furniture is composed of a coffee set, the drinking vessels, a tin, a barrel, and a dipper, rush mats, made of barbir (papyrus), halfa or samar grass. In some villages also bedding is found there. Besides there is a lamp or lantern, and an earthenware sraj for light."

4 Omar Salih-El-Barghuthi, "Rules of Hospitality ( Qanun Yd-Diyafeh)," Journal of the Palestine Oriental Society 4, no. 4 (1924): 178-79 
The layout and the architectural articulation of the space that comprised the guesthouse (madafah) was not the only defining factor in terms of functionality and character. The daily activities and the occasional events that would take place in the space would be as significant in applying meaning to the place. ${ }^{5}$ The sum of such activities could be further synthesized into the modern concept of program, where performance is the key organizer of space. The fundamental aspect of the project rather emphasizes the multi-vocality of the spatial intervention in terms of accommodating various activities to be performed in the recreated guest house. The space offers a degree of flexibility in order to adapt itself to certain events and activities to be undertaken. The programmatic agenda would reexamine the traditional notions of kinship ties and Palestinian hospitality within the diasporic context to better translate such relationship model into modern life. The reinvented guesthouse is intended to serve as gathering and networking places for people, to become aware and active participants in the affairs of the Palestinian community.

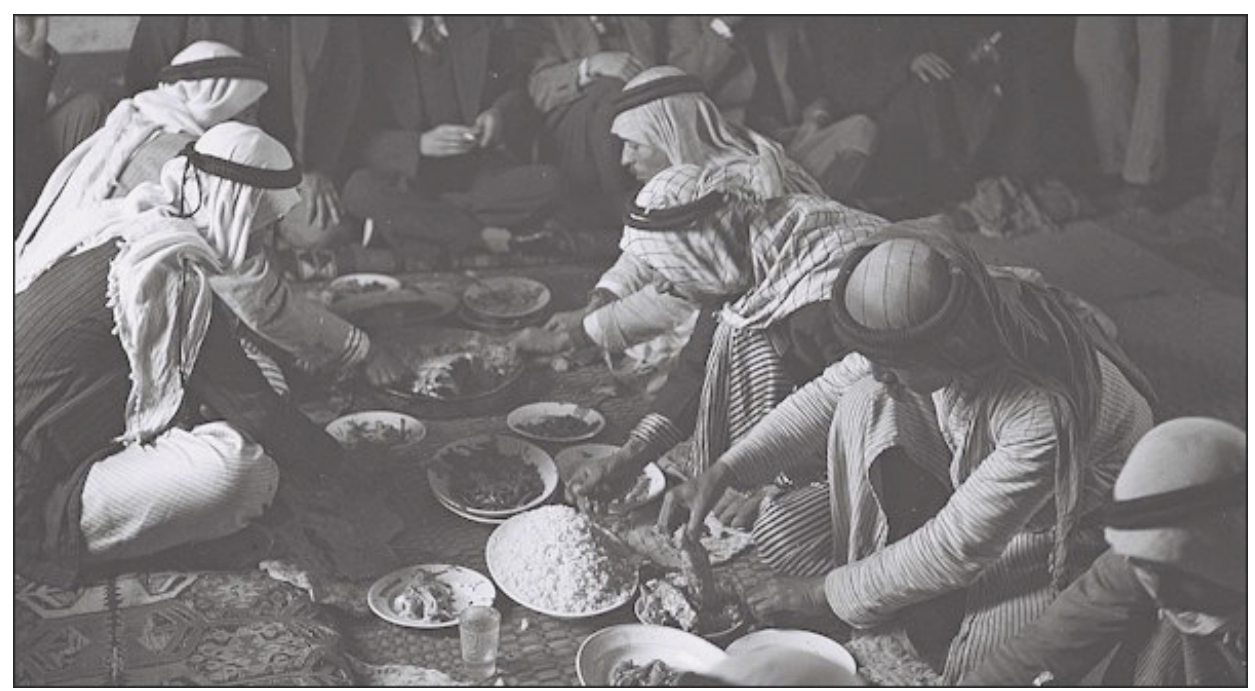

Figure 5.2 - An Arab Feast

5 Suad Amiry, "Space, Kinship and Gender: The Social Dimensions of Peasant Architecture in Palestine" (Ph.D. diss., University of Edinburgh, 1987), 3 
To date, some of the most extensive explorations of the potential of the madafah have been led by Palestinian architect Sandi Hilal. In 2016, Hilal established a contemporary iteration of the madafah in the form of a living room space which could be relocated across Europe. Hilal's work was heavily influenced by a Syrian couple in the city of Boden in Northern Sweden, who subverted their social role as guests to hosts by sharing their living room with community members. Two years after first opening, Hilal's project the 'Living Room' is now used every day. The couple further hosts a gathering every Saturday that begins at noon where people gather, cook, and eat together. Each week the group assigns a head chef who cooks for everyone and also teaches them how to cook the food they know how to cook. The living room has become a social hub and an important reference point for all new refugees arriving in Boden. The importance here lies in the fact that they are all aware that they are always welcome to the space. ${ }^{6}$ The emergence of such complimentary events reflects back on the shifting boundaries of spatial agency, where the spatial production takes up various forms of expression that are distinct from the original space.

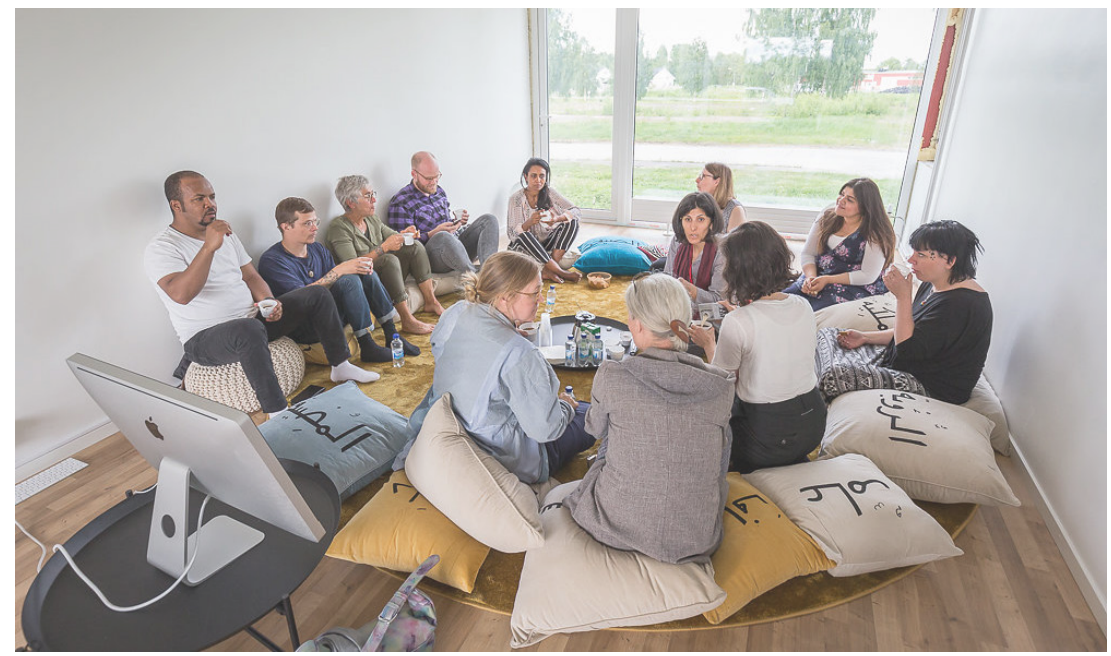

Figure 5.3 - Sandi Hilal's living room used as a community hub

6 "The Right to Host." E. Accessed November 26, 2020. https://www.e-flux.com/architecture/overgrowth/287384/the-right-tohost/. 
Hilal's stance on the host-guest relationship is rather central to the development of the madafah in this thesis. For Hilal, subversion of the notion of host and guest is a critical component of the guest house as a place where the diasporic community exercise their right to host, rather than to act as ultimate guests. ${ }^{7}$ This thesis adopts a similar approach towards providing the Palestinian community both with an intellectual and a spatial platform that frames hosting within everyday practices. For this reason, the types of activities hosted by the community enjoy multiple degrees of formality, based on the number of people hosted and the nature of the specified activity.

7 "Hosting Is Power and by Having Power You Become Visible" - ArkDes - Swedens National Centre for Architecture and Design." ArkDes. September 18, 2020. Accessed November 26, 2020. https://arkdes.se/en/hosting-is-power-and-by-havingpower-you-become-visible/. 
6 Revisiting the Madafah

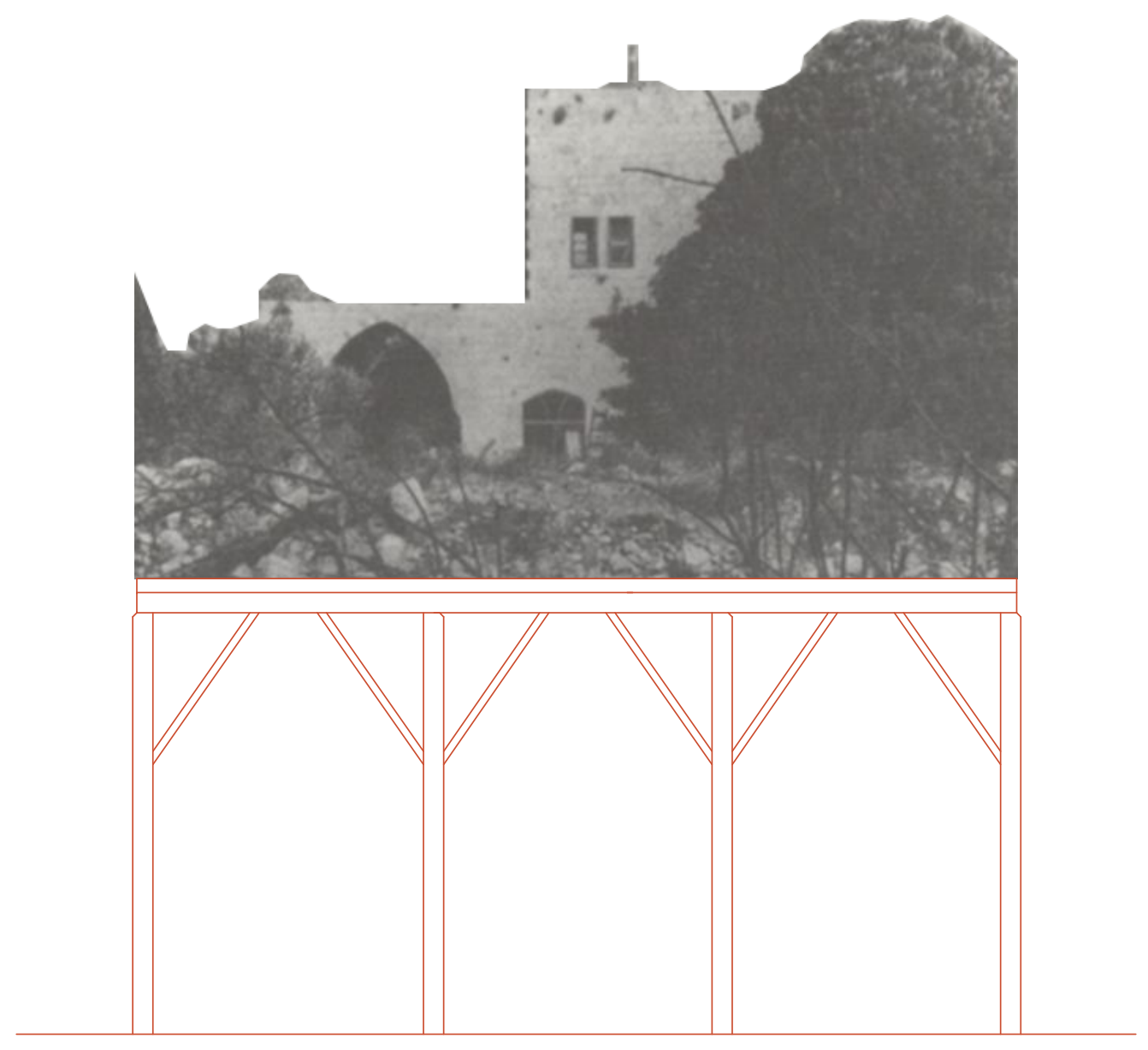

Figure 6.0 - A mobile madafah 


\subsection{An Interpretation}

Parallel to the creation of an atlas of diasporic experiences, this thesis seeks to introduce a design intervention that would support the Palestinian diasporic community in Canada. It serves to acknowledge the Palestinian presence not only as a political entity, but also as a cultural one. The construction of a diasporic space in the Canadian context serves as a place of solidarity and resistance to the hegemonizing impacts of the dominant culture.

The notion of 'home,' a contested subject in diasporic literature, can function as a counter-definition for what 'loss of home' is defined as within a new country of residence. One such condition would include a thorough search for the traditional meaning of home as a cultural identity rooted elsewhere. The diasporic space produced with the aid of the design intervention is essentially a vehicle for the re-translation of practices, customs, and traditions tied to the place of origin. Here, the term 're-translation' is used due to identify the impossibility of a pure replication of these actions. However, a domestic atmosphere can be generated to allow for the active production of space.

One such mode of production is intended to be implemented through hosting events and practices that require communal work and bring individuals together. For this reason, the project studies Al Madafah, or the Arab Guest House, an architectural feature dominantly present in the pre-1948 small towns and villages of Palestine, as well as in counties like Syria and Jordan, as a programmatic and spatial precedent for the accommodation of these practices. The engagement of the public and their familiarity with unique Palestinian experiences opens up an opportunity to create solidarity among multiple ethno-cultural groups in the Canadian context. Most people who will 
form the space may not even be aware of the exact history of Palestine; they would only know it as a place to come to for gathering.

The thesis inevitably bemoans the risk of fading firsthand memories with an aim to keep these memories and connections alive in the younger generation. The recollection and distribution of memories not just through engaging people with food and fashion but by learning about the homeland in the madafah. There is no doubt that such themes come up as notable remarks over during conversations. However, the overarching idea that ties them all together is the process of acquiring knowledge about Palestine and the experiences that are less often shared in a public setting. This is well expressed in the living room format of the madafah where the space serves as a place of discussion and allows for the exchange of thoughts. The madafah rather functions as an alternative archive for recording local narratives similar to the interviews.

The madafah was indeed a common ground for most interviewees, recited by many of them as a cultural symbol for Palestinian hospitality. The following quotes portray a diverse set of descriptions provided by several interviewees:

"I know that visitors who visited families or traders who travelled from town to town for business, would be hosted for up to three days, with the greatest accommodation, hospitality, and service, provided with the best food. The guest would not be asked for the reason they had come to the place only after the third day had passed. Every big tribe or family would have their own madafah or guest house, where you could show visitors from different towns and villages would be shown the generosity of your tribe. It is a very nice tradition which we have retained to this day. If you go to any Palestinian house, they will still host you with the same level of hospitality and generosity."11

1 Interviewee 4. (2021, January 19). Personal Interview. 
"My father used to say that in our village Beit Ummar there were three. One for each of the main families in Beit Ummar. For each family there was a Mukhtar, one of the elder men of the family who was more like the spokesman. In any occasion the Mukhtar is always present, and if there is a problem or a conflict between any member of that family or with another family in the village of another village the Mukhtars get together and solve the disagreement. My great grandfather, my father's grandfather was a Mukhtar and he had a madafah in his house for our family. Going back to the madafah, each of the three Mukhtars in Beit Ummar had part of their own house designated for the madafah. It was always open to any guests who come not only to visit the Mukhtar but any member of that family. And that is because people at that time did not have a place to host someone in their homes there were mostly a home of a room or two. So, the guests would stay in the madafah. The place was essentially not only for guests but also for the men of the family to gather on a daily basis. During holy month of Ramadan, most of the men did not break their fast with their families. Instead, they would bring a plate of food to the madafah and eat with the rest of the men. The last madafah to remain open in Beit Ummar operated until the early 1960s."2

2 Interviewee 5. (2021, February 12). Personal Interview. 


\subsection{Mobile Madafah}

The spatial intervention of this thesis is conceived of in the form of two mobile madafahs, or pavilions, which are expected to be utilized by Palestinian Organizations in Canada as essential components of conducting their public performances. The programmatic aspect of the pavilions, which take the shape of custom-designed, expandable trucks, is essentially founded upon differentiating between collecting and generating. In other words, the mobile madafah space is meant to engage the public not only as an ultimate guest but as an active user who contributes and gives back to the space in which they use. In this manner, the mobile madafahs function in four distinct ways, with serious consideration of activities that are not only important for their cultural significance, but also produce an ideal atmosphere for the exchange and formation of memories and community narratives. Hence, the space becomes a platform for the transfer of such knowledge that is often shared without intention and through engaging in social activities. The proposed programs include a living room-archive space (figures $6.3,6.4$ ), a space for the production and teaching of Tatreez (Palestinian embroidery) (figures 6.5-6.9), and a space for visual media (figures 6.10-6.15), all accommodated in the first mobile madafah pavilion. The second mobile madafah holds a space for recipe-sharing (figures 6.16-6.22), an activity that requires much more public participation compared to the other three. The architectural elements produced in the design process are chosen with a reasonable degree of care, ensuring that the architecture remains ordinary and simple, in order to allow for social activities to define the space. Each pavilion is depicted in both a casual setting (figures 6.4,6.6, 6.10,6.17) and during the course of an event (figures 6.7, 6.12, 6.20), emphasizing the possible change in the atmosphere. The casual scenario for all mobile madafahs is situated in a laneway, reflecting on their ability to adapt to the domestic realm, and parked at ease where the owner organization wishes to do so. 


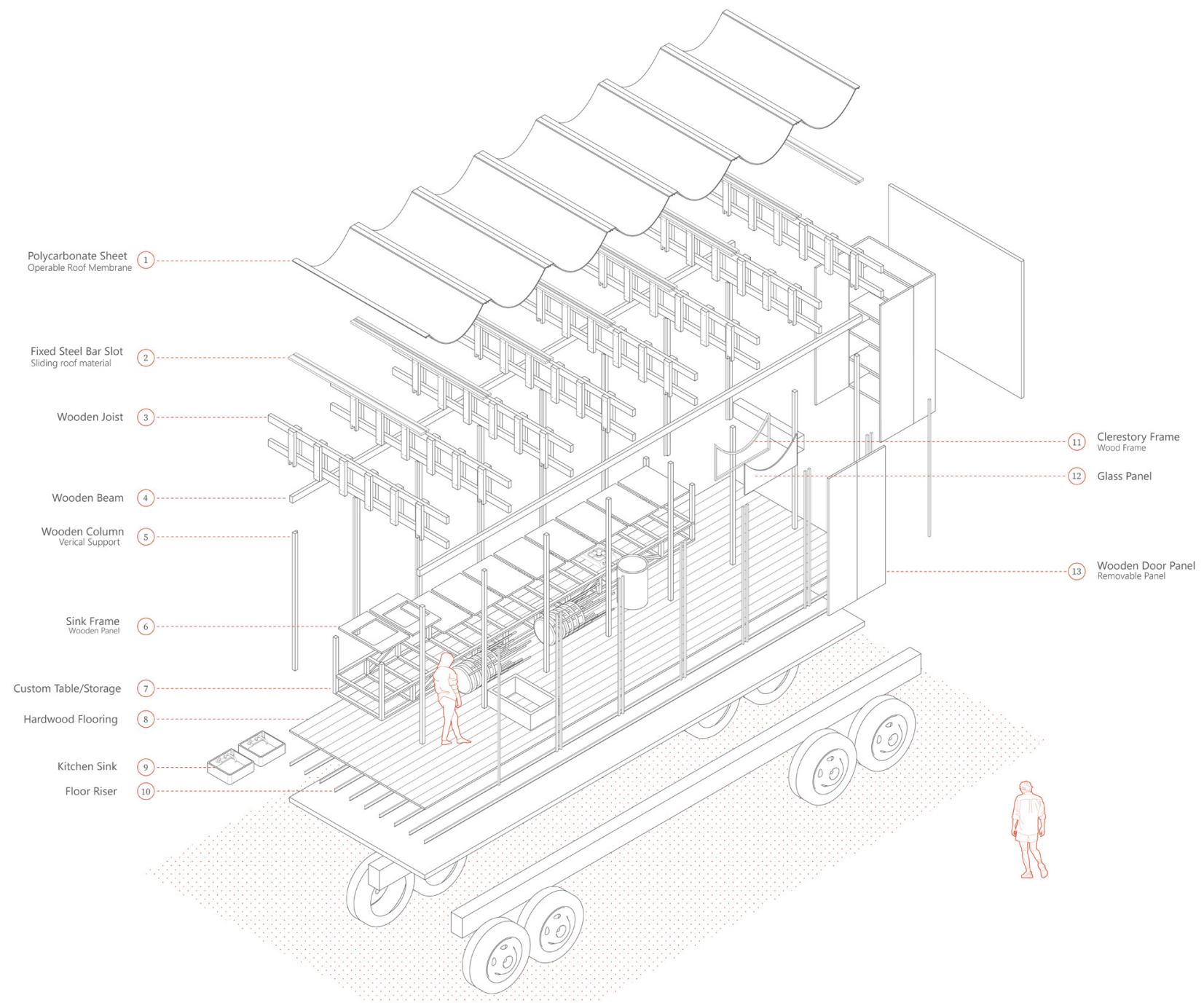

Figure 6.1 - Madafah no.1, Exploded Axonomet- 


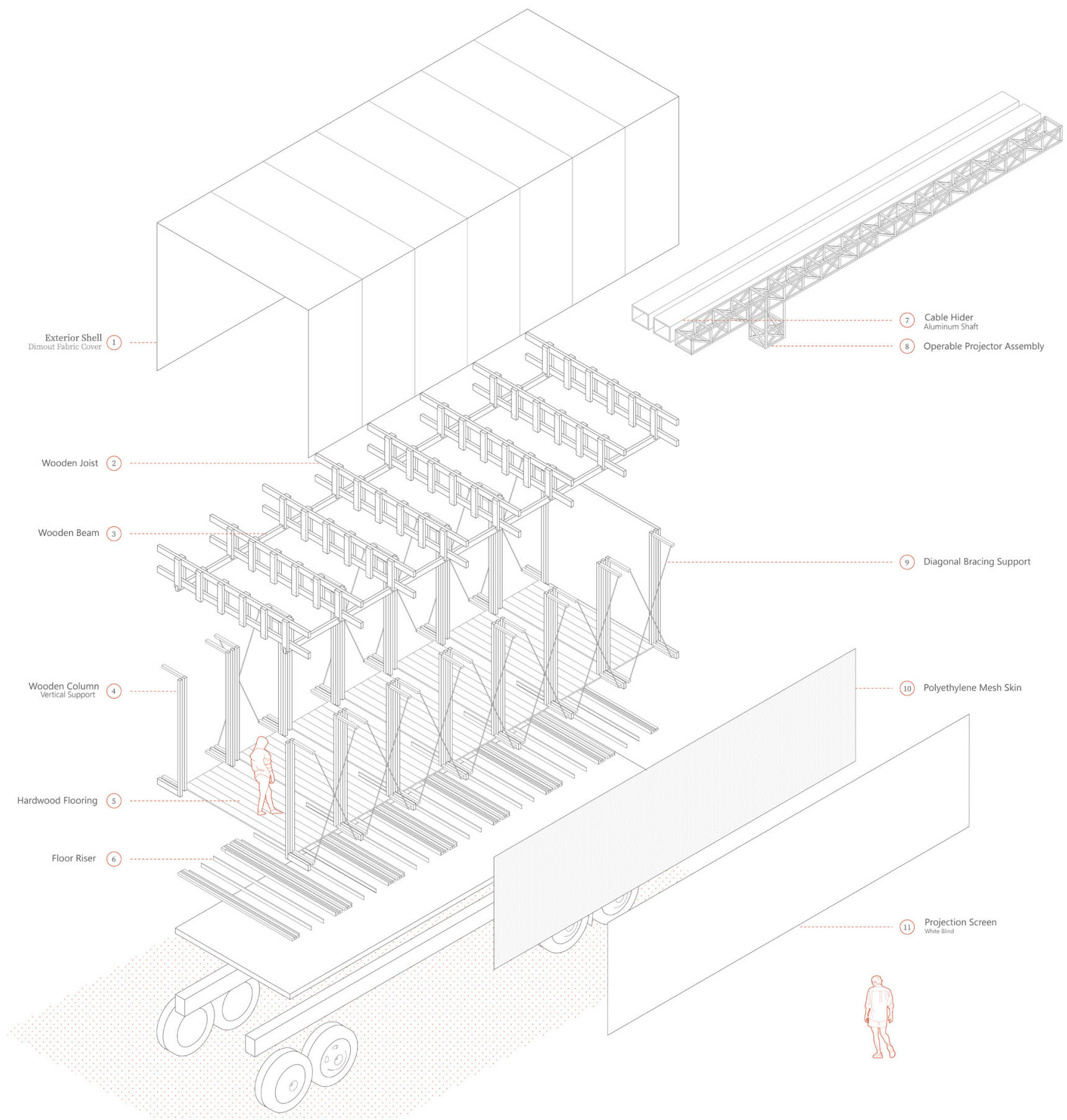

Figure 6.2 - Madafah no.2, Exploded Axono- 


\subsection{Living Room}

The living room is in essence the most generic form of the madafah. The space is the closest derivative from the traditional guesthouse, only furnished with a table and rug, as well as repository for archiving the items that each guest brings to the space. The living room serves as a space for discussion and exchange of knowledge through poetry, debates, and reading sessions. The distinct feature of the living room in comparison to the other programs is that it is not an event-based space. In other words, it does not rely on the performance of a certain activity in order to function. The space can be occupied by those who wish to stay for up to three nights, a historical timeframe driven from the traditional madafah. It can also serve a group of people who would only like to gather for a casual conversation or a cup of coffee, which the space is determined to always offer just like its original model.

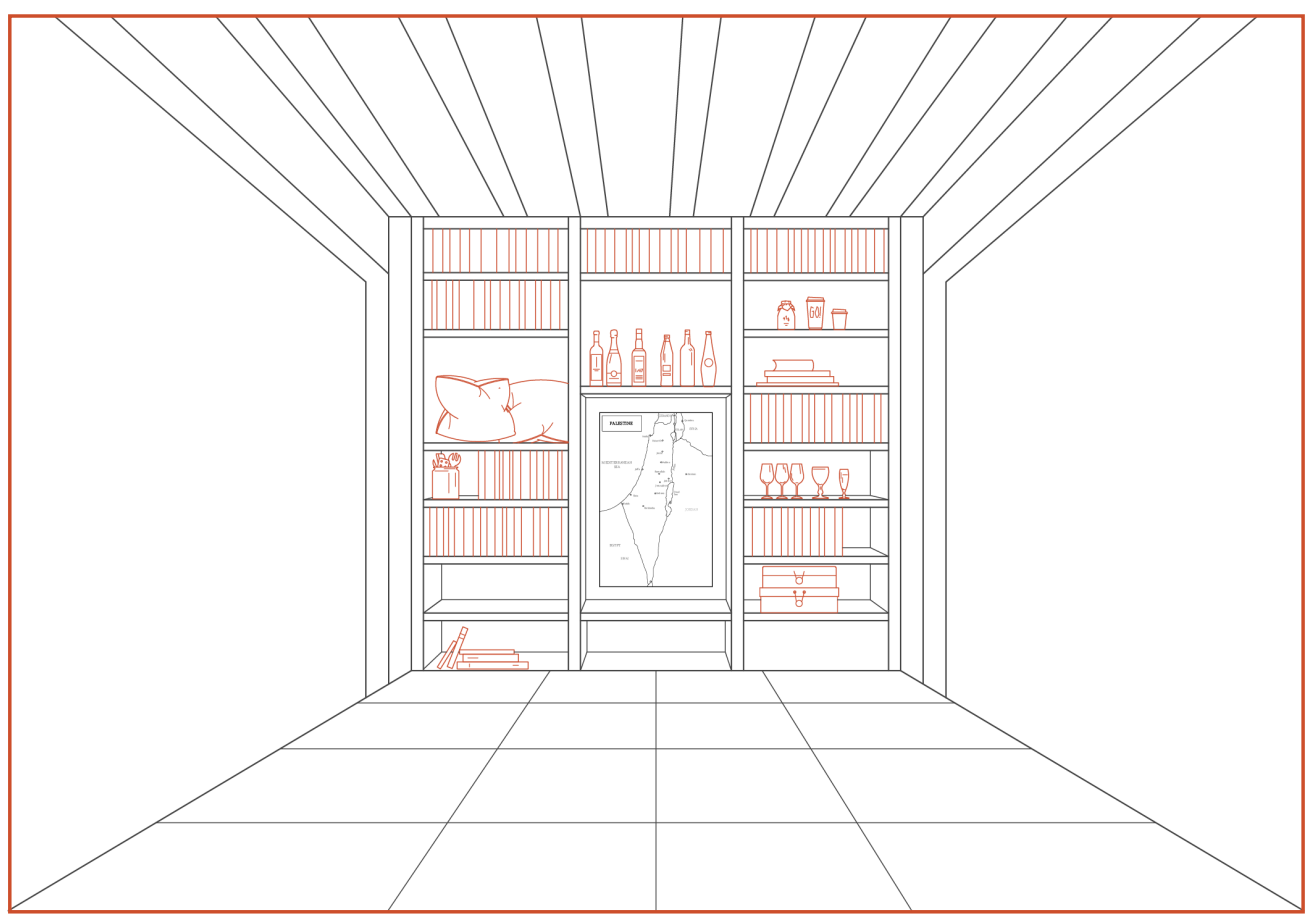

Figure 6.3 - Living Room, Interior 


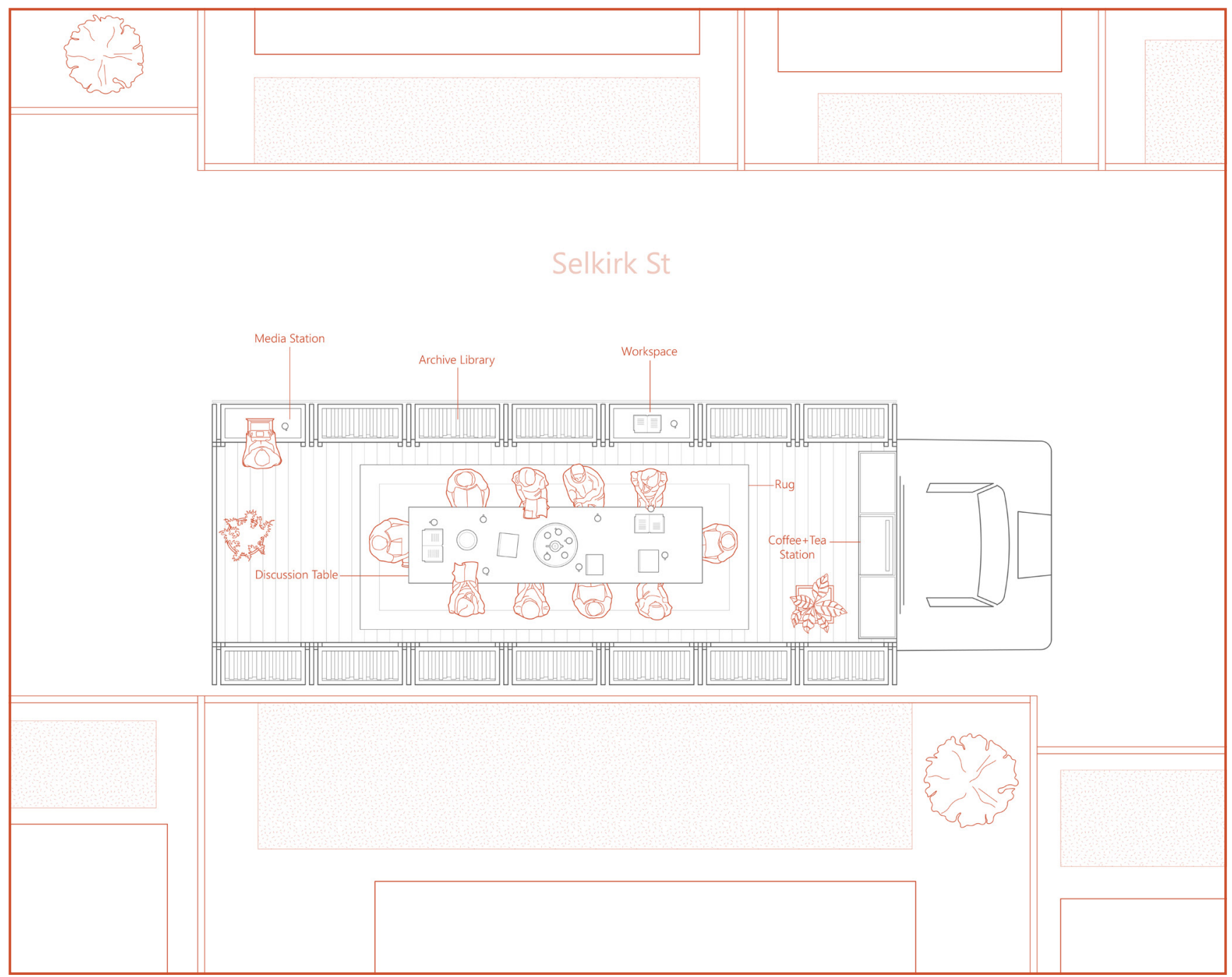

Figure 6.4 - Living Room Plan, Selkirk Street

The madafah is shown in its possible configuration on Selkirk Street in Vancouver, Canada. The truck is parked adjacent to a nearby lot, allowing the person in charge to host their community. The living room primarily serves as a place of gathering for the neighborhood in which the madafah is usually parked. The madafah rather becomes a fixed addition to the lot next to which it is located. 


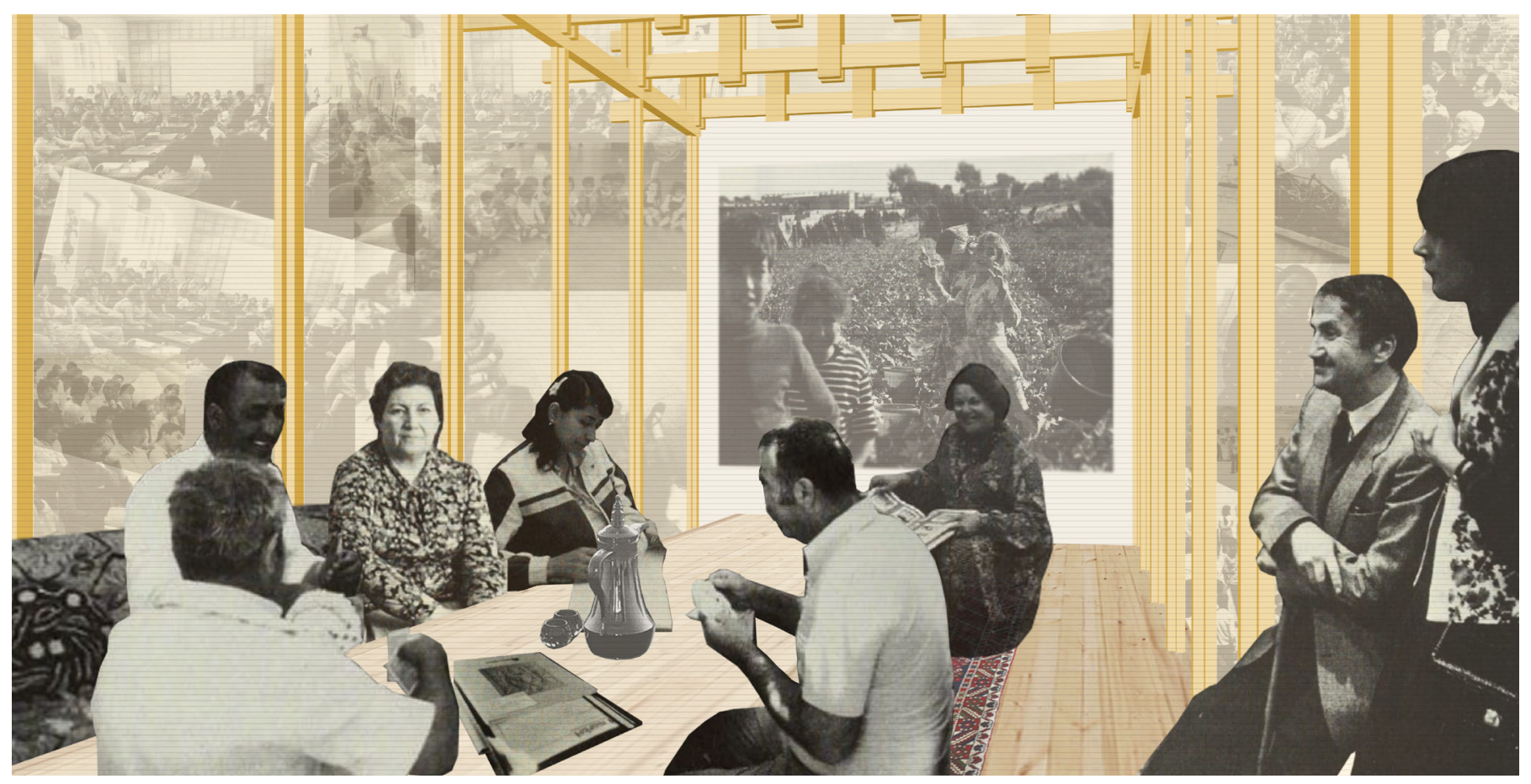

Figure 6.5 - The Living Room 
He's never without her picture when he comes to drink our tea but he forgets to tell us about her nightly chores about a horse of ancient melodies abandoned on a hilltop.

Palestinian poet and author Mahmoud Darwish 


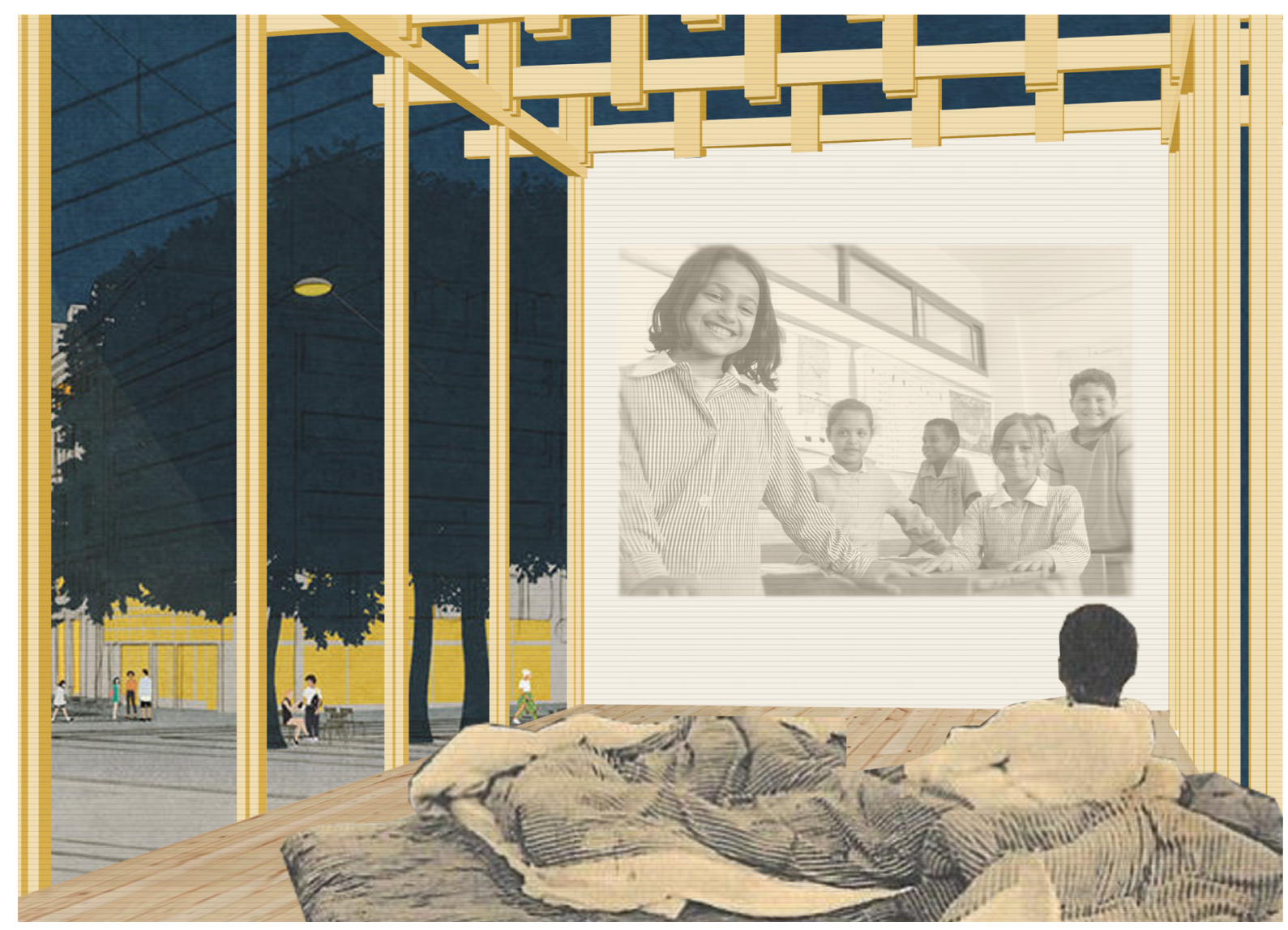

Figure 6.6 - A Nocturnal Visit to the Homeland 


\subsection{Tatreez}

Palestinian embroidery is more than a cultural artifact. The distinct stitches and patterns represented in the various items made through Tatreez symbolize a point of recognition, in which one can identify Palestine. The proposed Tatreez space in the mobile madafah aims to provide a platform for the teaching and collection of various stitches of Palestinian embroidery, a unique cultural heritage composed of various patterns shared among Palestinian families. In a casual setting, the space is intended to offer group embroidery sessions. In the case of an event, it functions a as showroom where people can try on and buy clothes and artifacts produced in the pavilion. In exchange for using the space for learning, each user who has the knowledge of embroidery is expected to contribute to the madafah by providing a stitch or pattern inherited by their family.

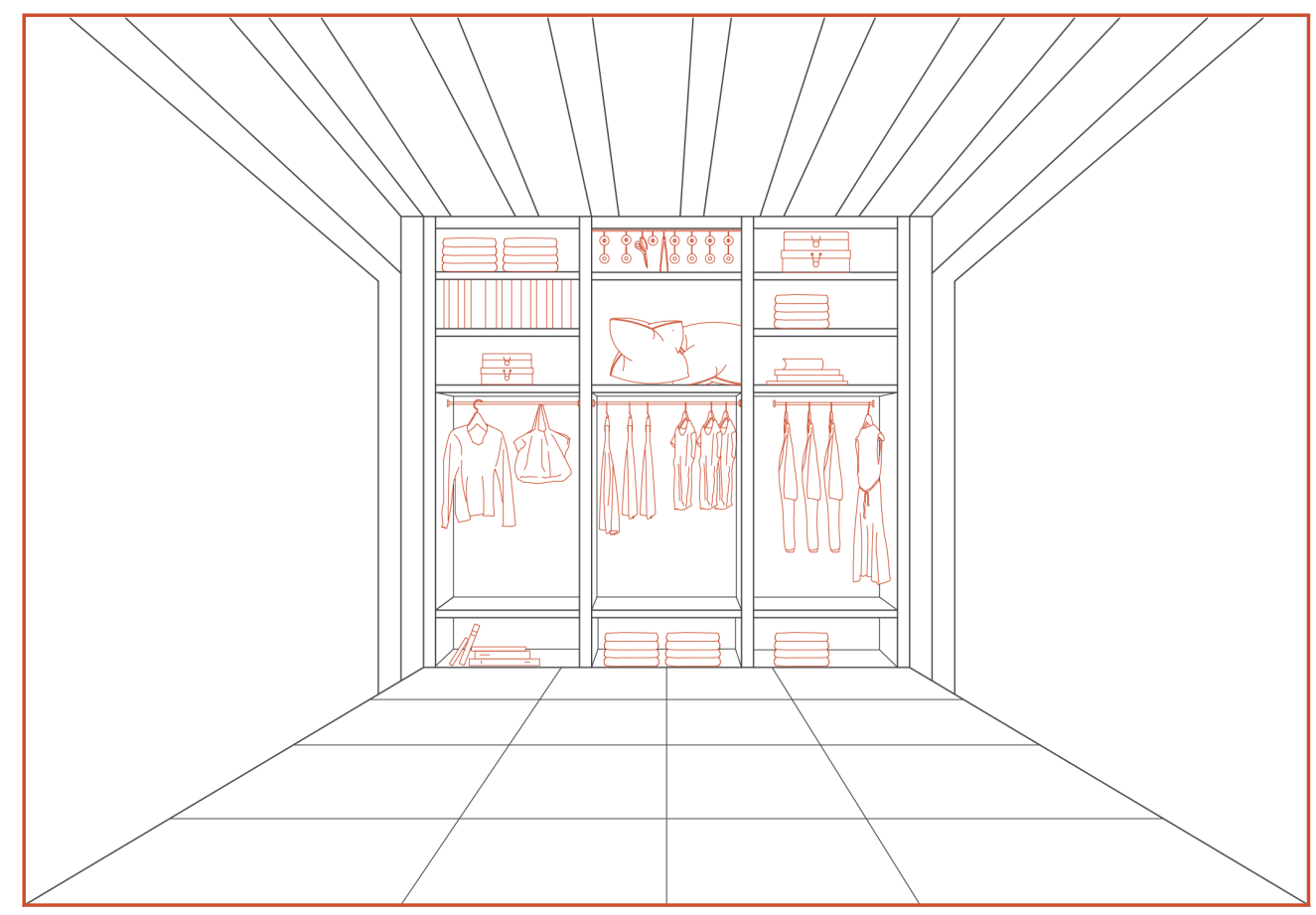

Figure 6.7 - Tatreez, Interior 


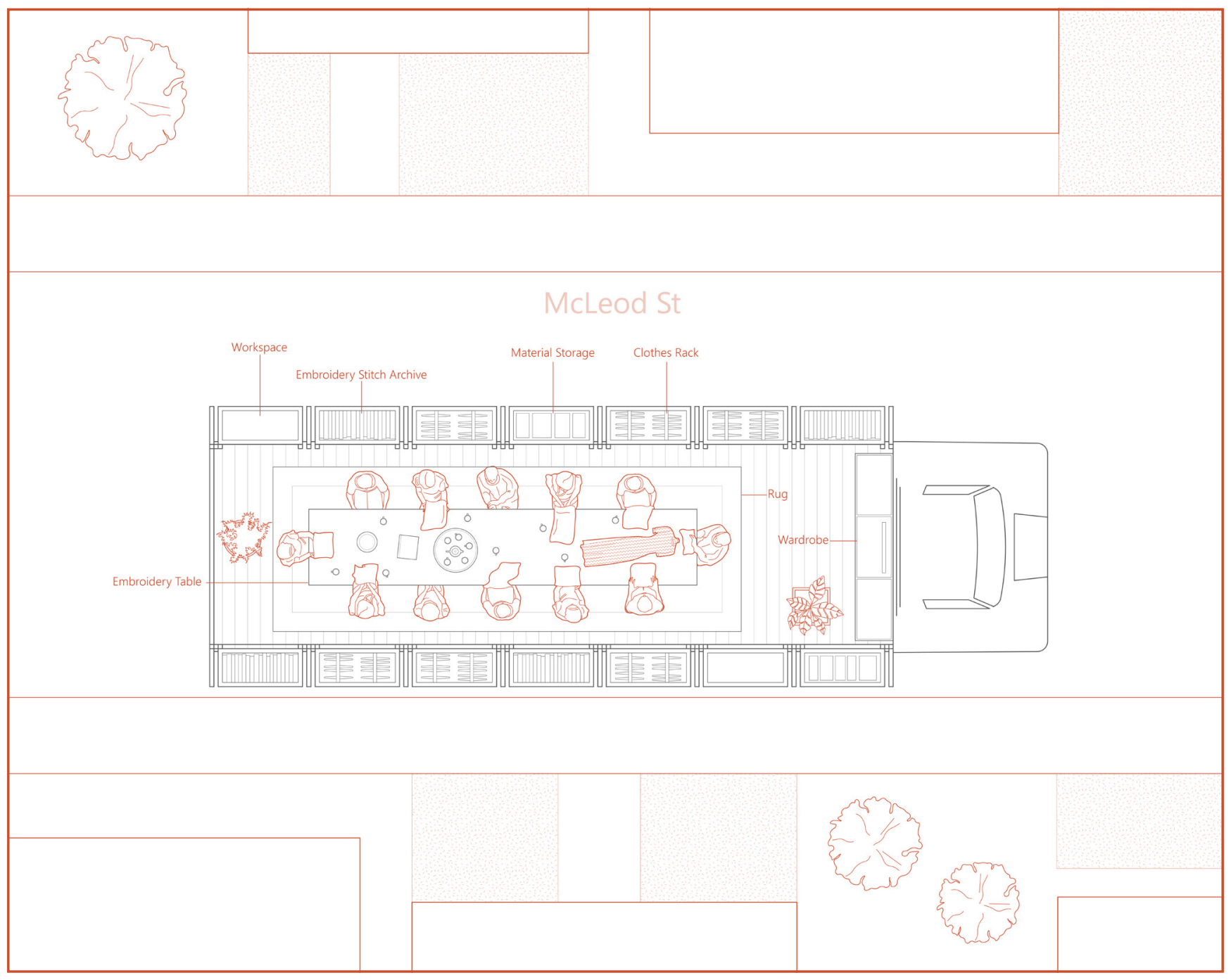

Figure 6.8 - Tatreez Casual Plan, McLeod Street

The madafah is shown in its possible configuration on McLeod Street in Ottawa, Canada. The truck is parked adjacent to a nearby lot, allowing the person in charge to host their community. The tatreez madafah is primarily used as a space for providing group embroidery lessons in the neighborhood in which the madafah is usually parked. Residents of the selected neighborhood are able to use the space as a lounge where there is coffee served at all times. In addition, the space serves as a workspace for working on their personal embroidery projects. 


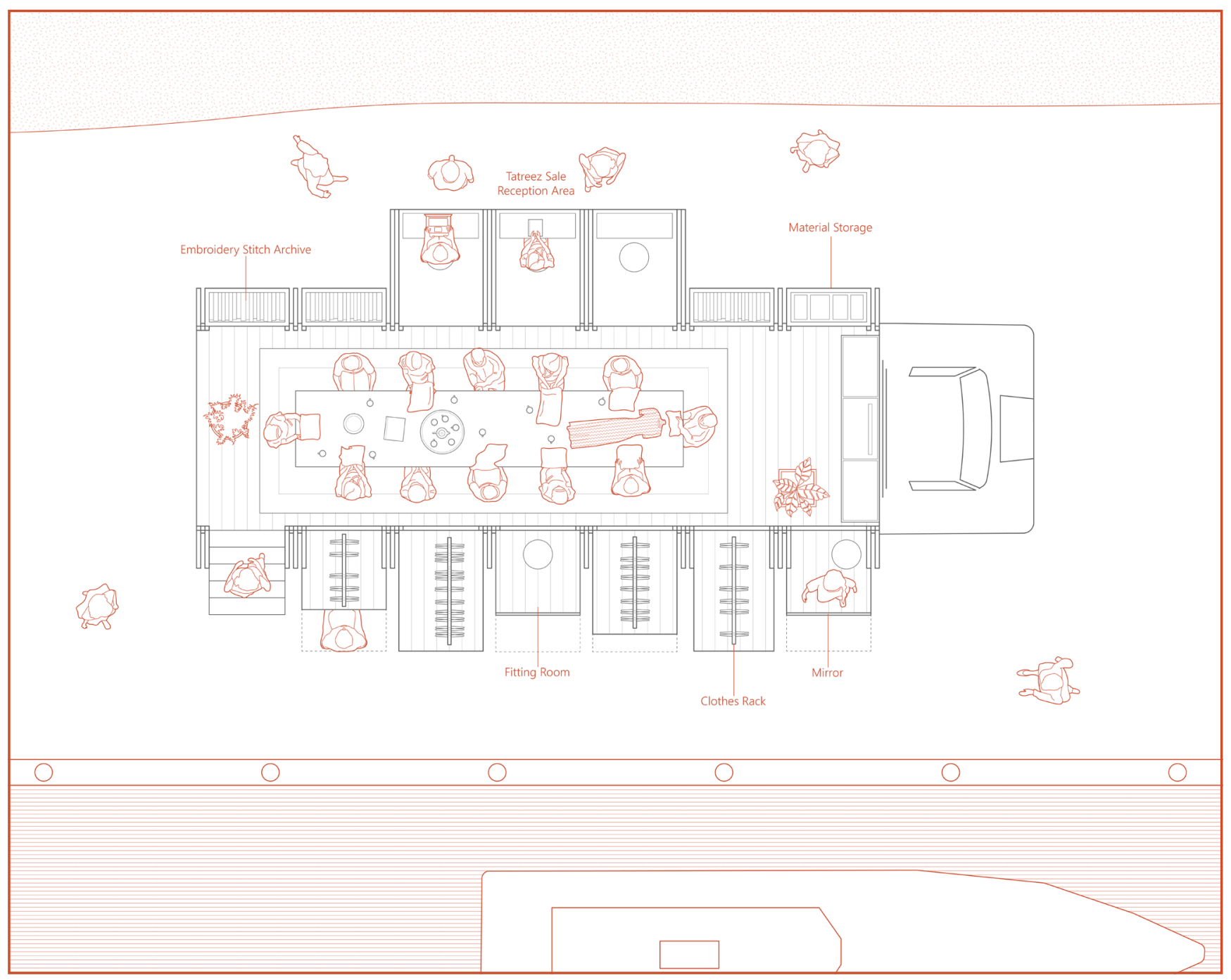

Figure 6.9 - Tatreez Event Plan, Ottawa Canal

The madafah is shown in a configuration that serves to host an event by the Ottawa canal. The space here serves a larger community in comparison to its neighborhood version. Similar to the former version, the interior is reserved for making embroidery in groups. However, the exterior serves as a place for presenting and selling the produced work. Each module is extruded out of the facade in order to accommodate a reception area and multiple fitting rooms for those who wish to try on the works that are showcased. 
In figures 6.7 and 6.9, the pavilion is shown as an example of how it might be set up by the Ottawa canal, near to The Palestinian General Delegation in Canada on Queen Elizabeth Driveway, a popular public space where people can be easily exposed to the pavilion as a mobile showroom. The proximity to the delegation as a political and cultural hub allows for such exposure and becomes a zone of interaction between Palestinians and non-Palestinians. The transient nature of the canal walkway is also a key contributor to bringing attention to the public and announcing the car's presence during the course of an event. Association of Palestinian Arab Canadians (APAC) is the potential host organization that would be responsible for organizing and promoting events. The madafah is divided into multiple bays that slide out of the car's perimeters during a public event to provide spaces for displaying the works produced. The showroom allows for the general population, whose pure interest may be limited to shopping and the material presented, to interact with active participants and get to know about the Palestinian embroidery. In the long run, there is an opportunity for such casual interactions and conversations to shift towards subjects that essentially create awareness about Palestinian culture and also allow the public to share their own cultural heritage with the Palestinian community. In fact, solidarity is expected to evolve in this manner. 


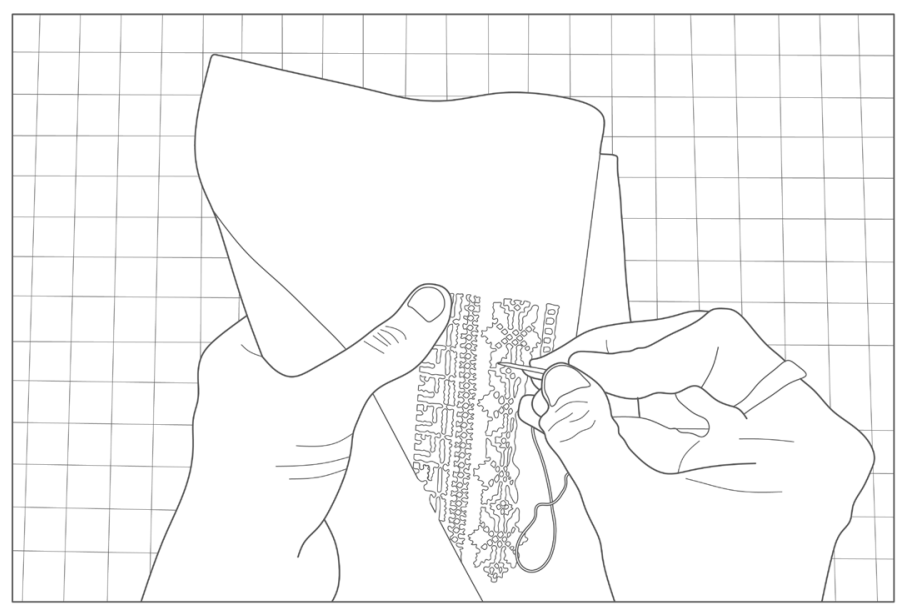

Each individual is welcomed to add their inherited tatreez pattern to the inventory in order to be shared with other guests.

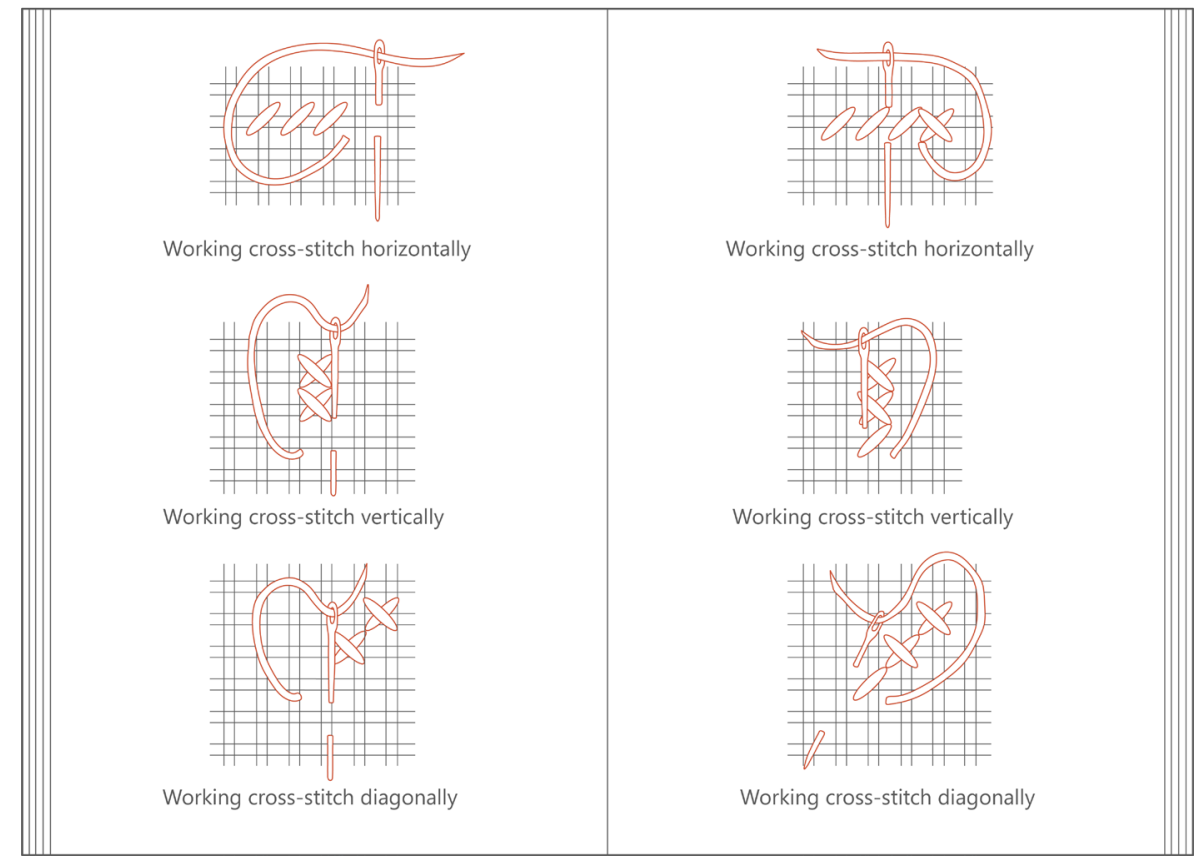

Figure 6.10 - An Instruction Guide on Tatreez 


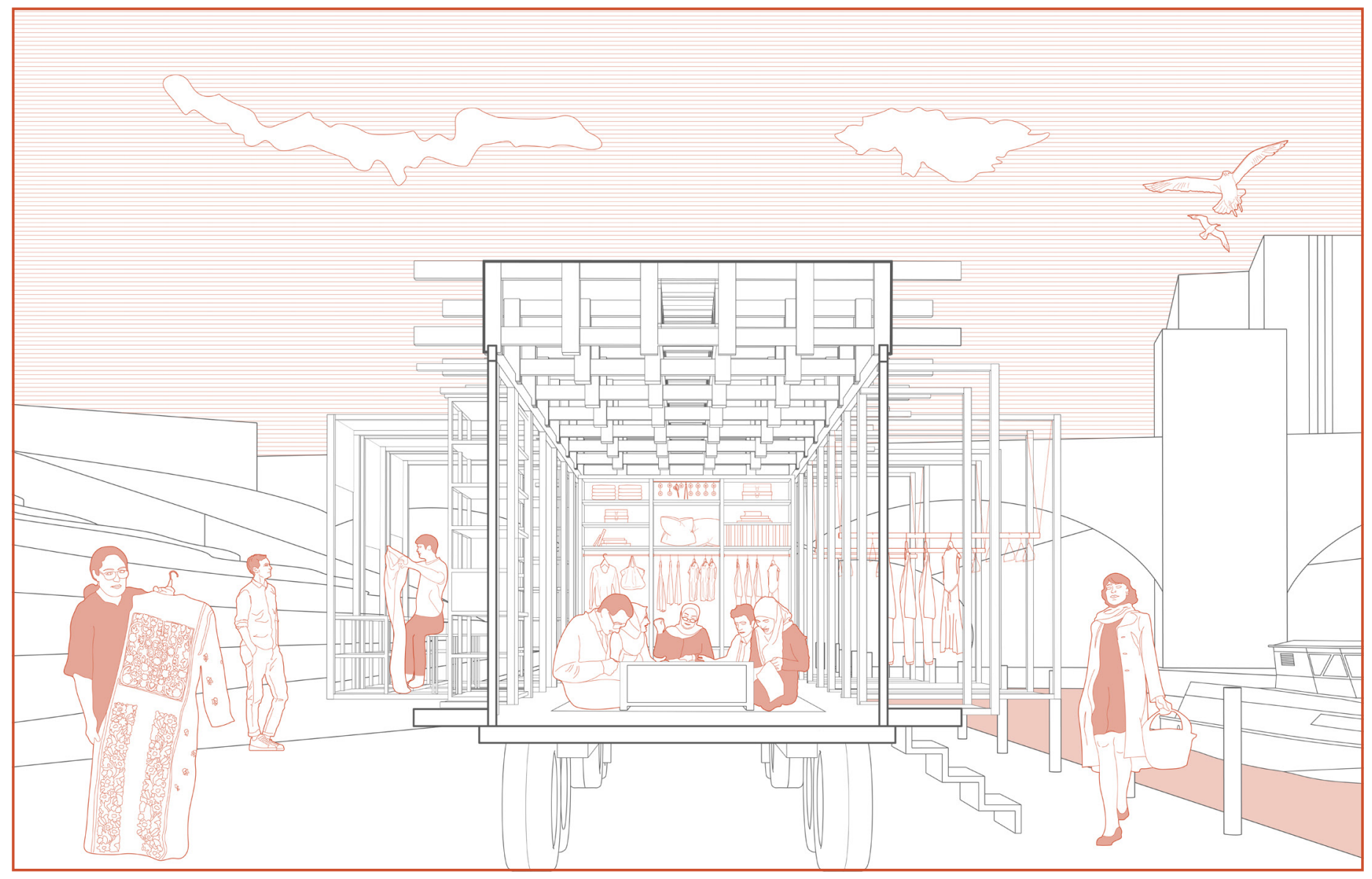

Figure 6.11 - Tatreez by the Canal, Ottawa 


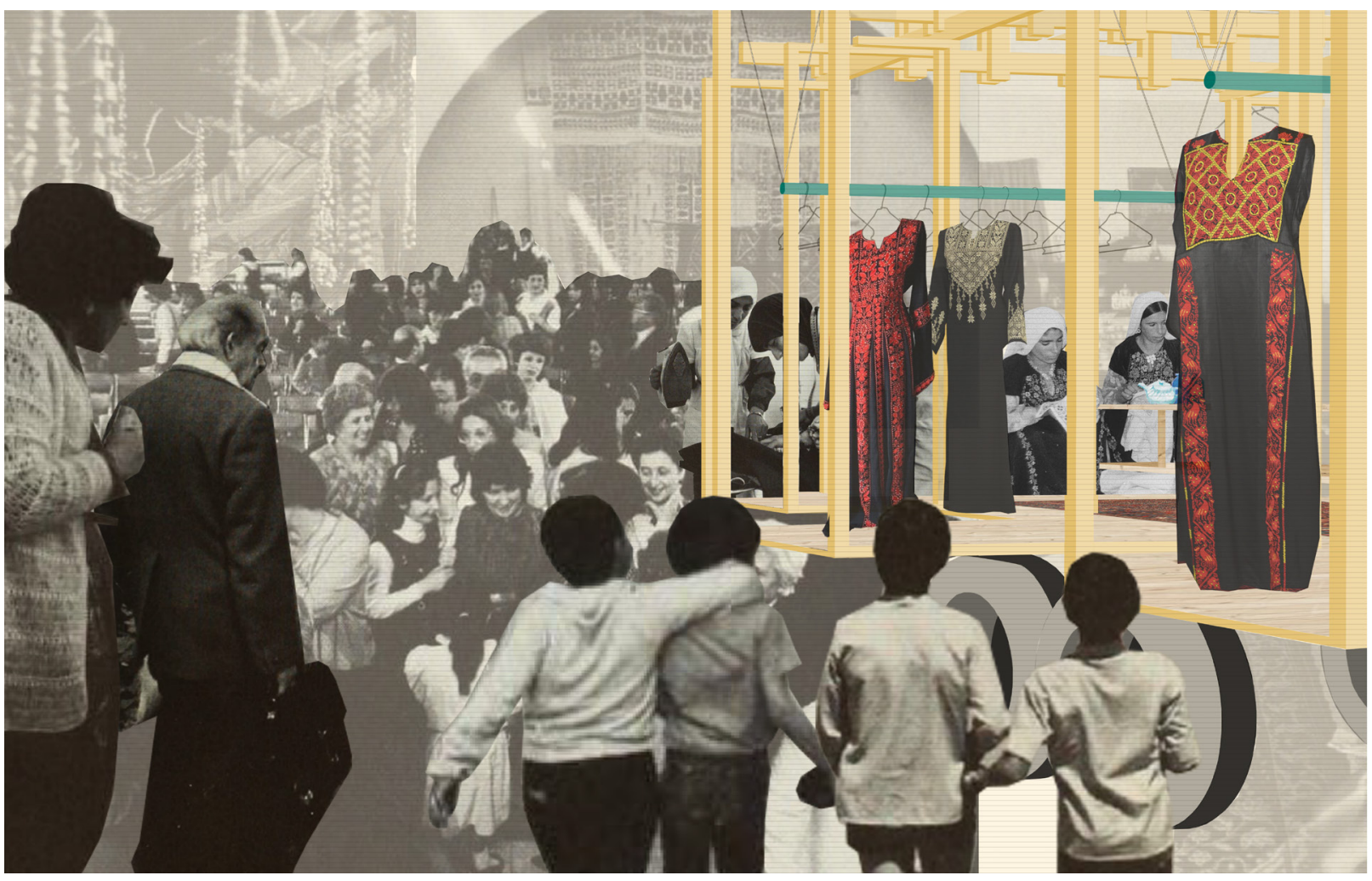

Figure 6.12 - Tatreez Showroom 


\subsection{Screening}

Given the physical disconnection to one's ancestral home for those in diaspora, images and films are effective media through which one can view and form a strong bond to places that they cannot visit in person. Palestinian communities in Canada already organize events to screen documentaries, films, and host lectures that engage Canadian society, helping people to become familiar with Palestine. This configuration of the mobile madafah serves to accommodate such programs in several public locations, both indoor and outdoor. The selected site for the screening pavilion is the Vancouver Art Gallery, one of the city's political arena where most protests and public events concerning Palestine take place. The possibility of screening in the plaza, adjacent to the gallery, puts forward the role of the space in diverting public attention to the events surrounding the pavilion. The informal use of the space may include connecting with friends and family who reside in Palestine. Aside from projecting visual media, the pavilion also serves as a digital archive for its users to store and eventually create a collection of images and films that depict Palestine from each user's perspective. Sharing this digital inventory with the public would allow individuals to have direct access to sources and contents that particularly belong to the space and cannot be found elsewhere. The potential host organization for screening would be the Solidarity for Palestinian Human Rights organization (SPHR) at University of British Columbia. The group regularly hosts events that involve screening documentaries and lectures about Palestine. As shown in figure 6.14, the madafah is equipped with a rear-projection system that allows the user to cast videos both on the inside and outside. The interior space deploys a conventional projection screen on the front wall. The outer surface of the madafah is covered with a projection screen that is installed on a mesh skin. In the case of an outdoor screening, the madafah becomes a device for bringing people together. 


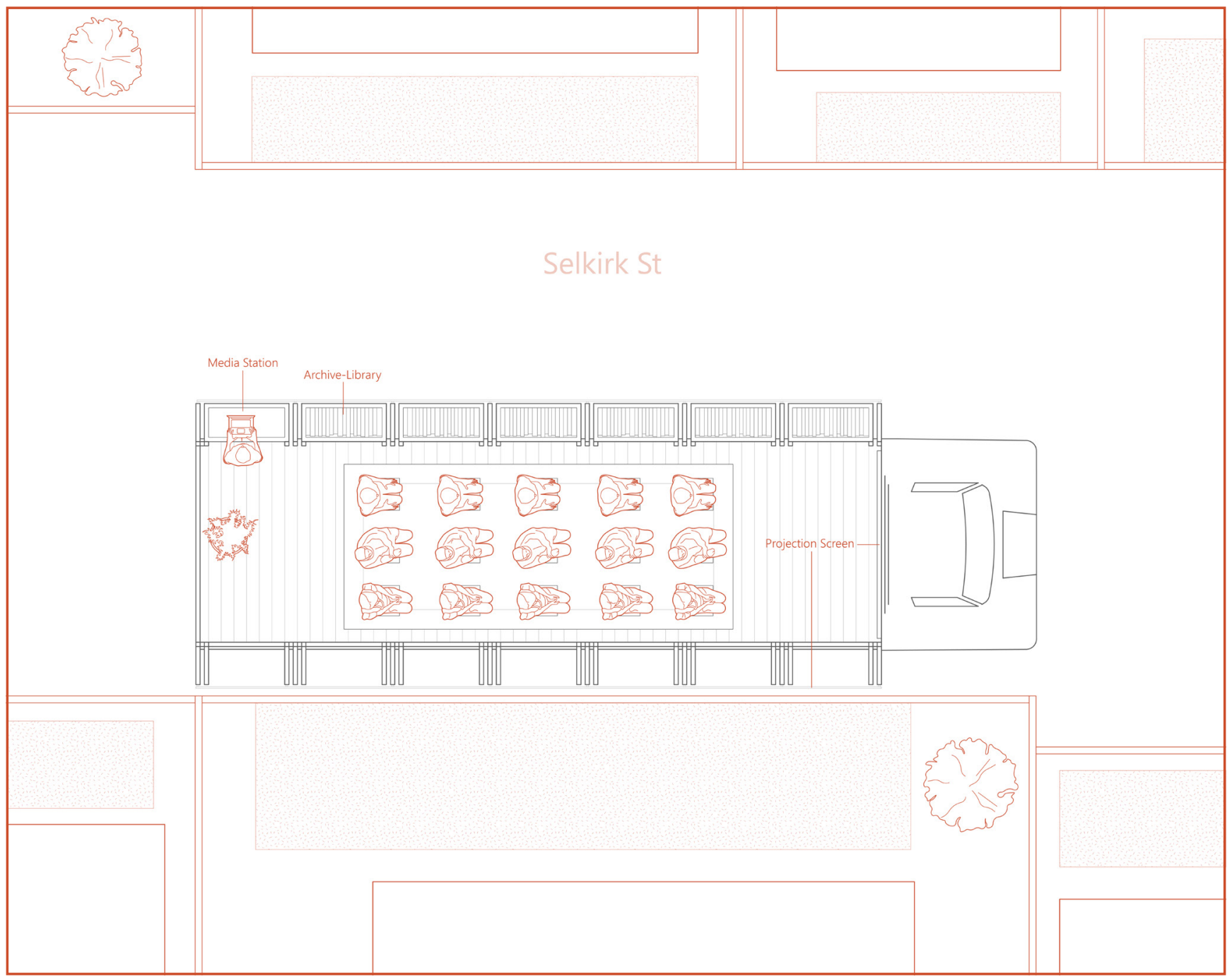

Figure 6.13 - Indoor Screening Plan, Selkirk Street

The madafah is shown in its possible configuration on Selkirk Street in Vancouver, Canada. The madafah is parked adjacent to a nearby lot, allowing the person in charge to host their community. The madafah is primarily reserved for screening films and images about Palestine to the residents of the selected neighborhood. The madafah contains a digital archive that is used for collecting Palestinian experiences through videos and images shared by its users. 


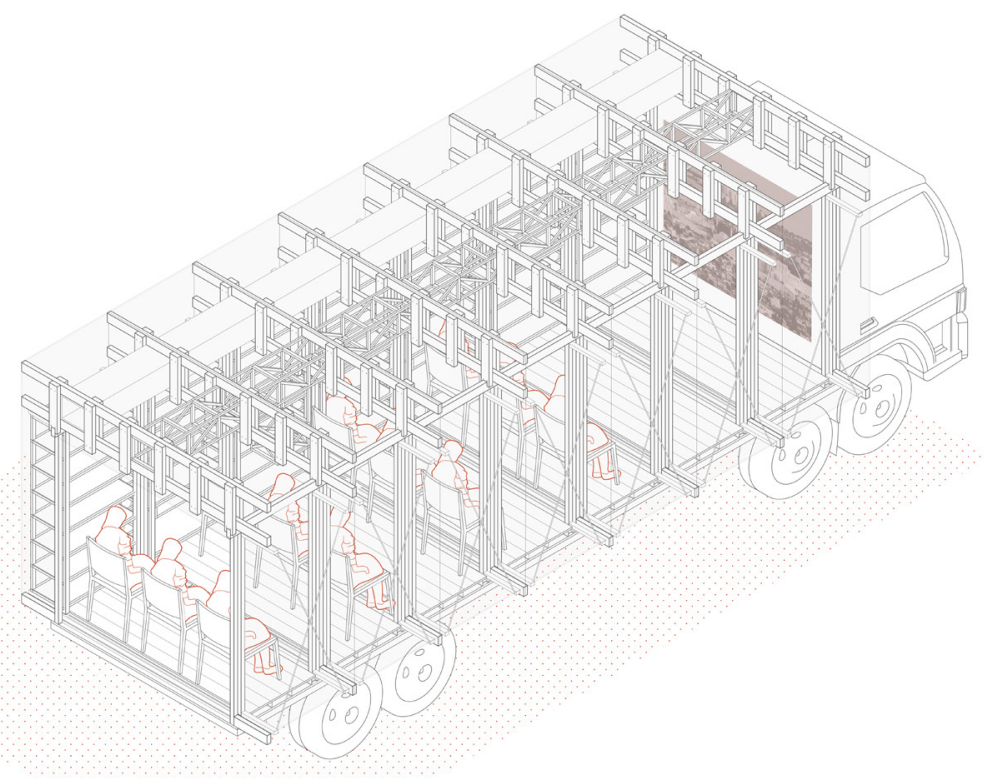

Figure 6.14 - Indoor Screening, Axonometric 


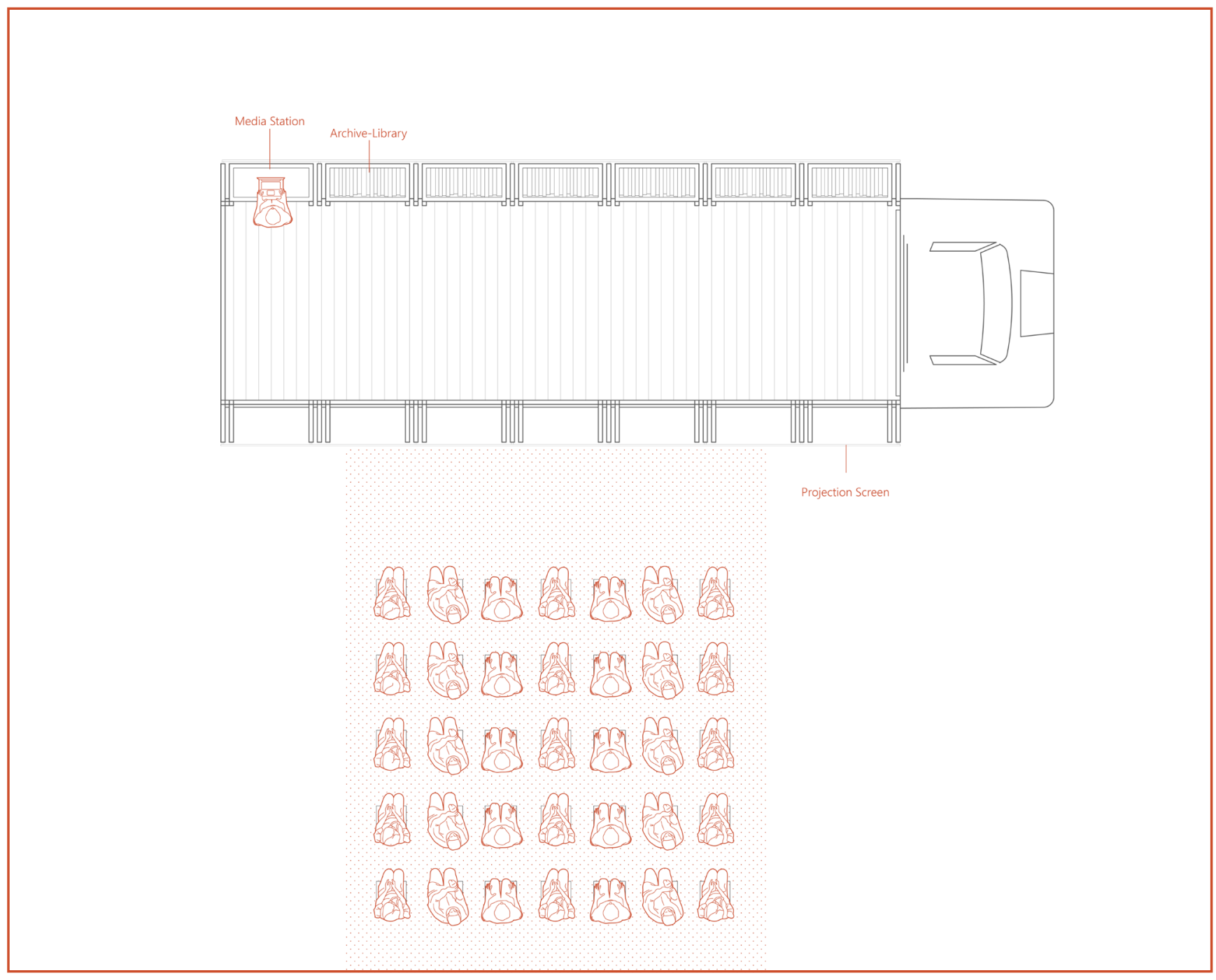

Figure 6.15 - Outdoor Screening Plan, Vancouver Art Gallery 


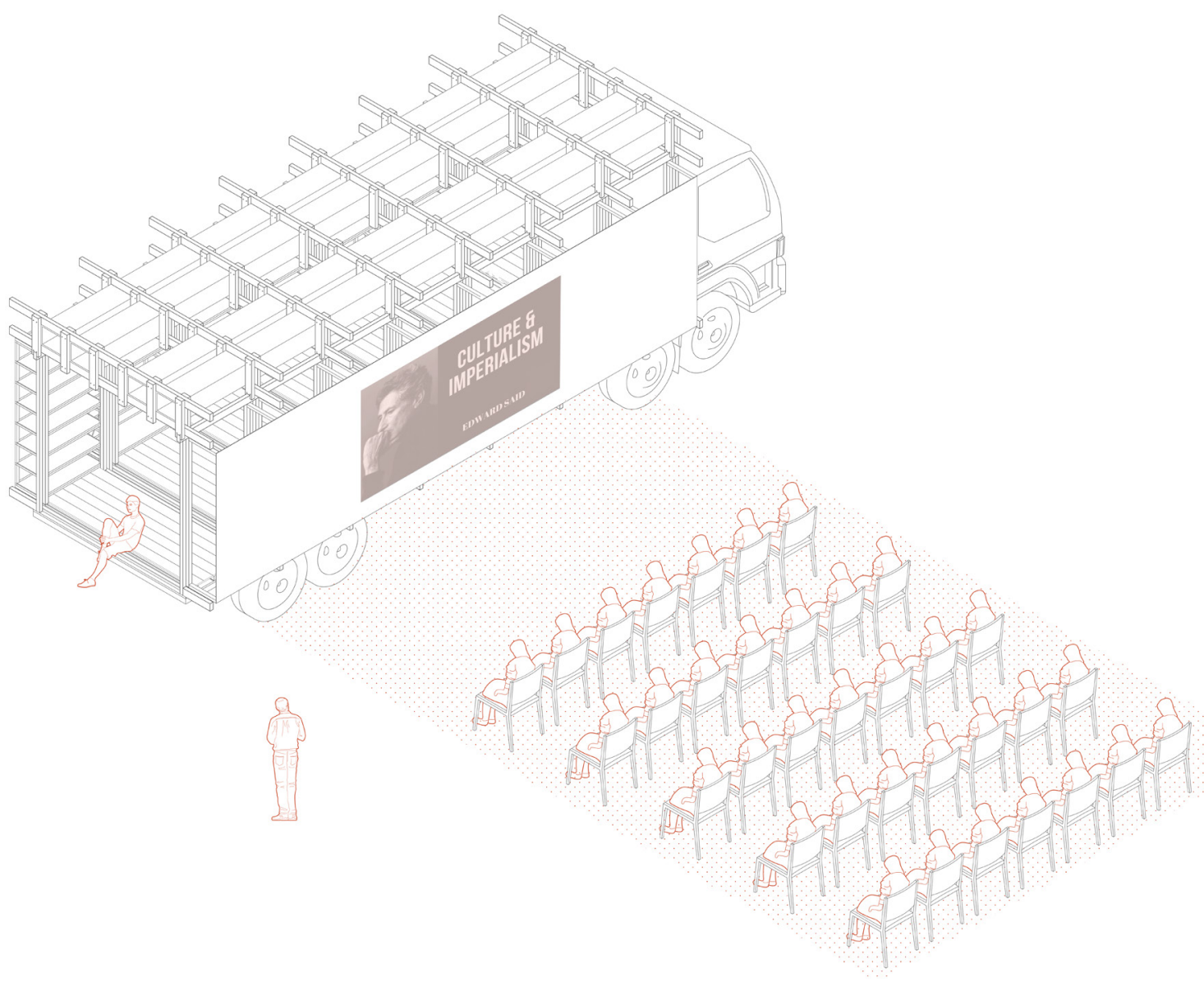

Figure 6.16 - Outdoor Screening, Axonometric 


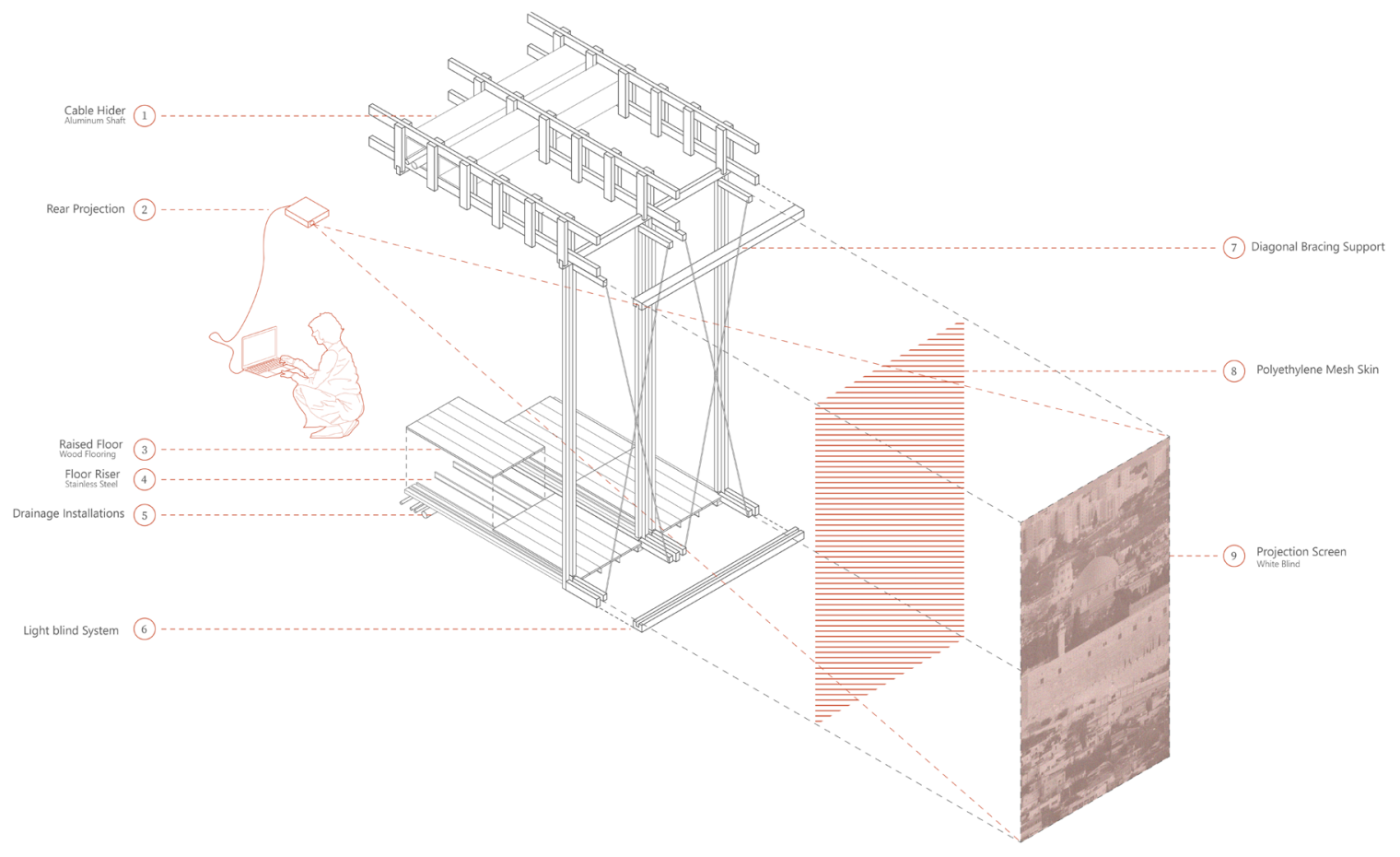

Figure 6.17 - Screening Detail, Exploded Axonometric 


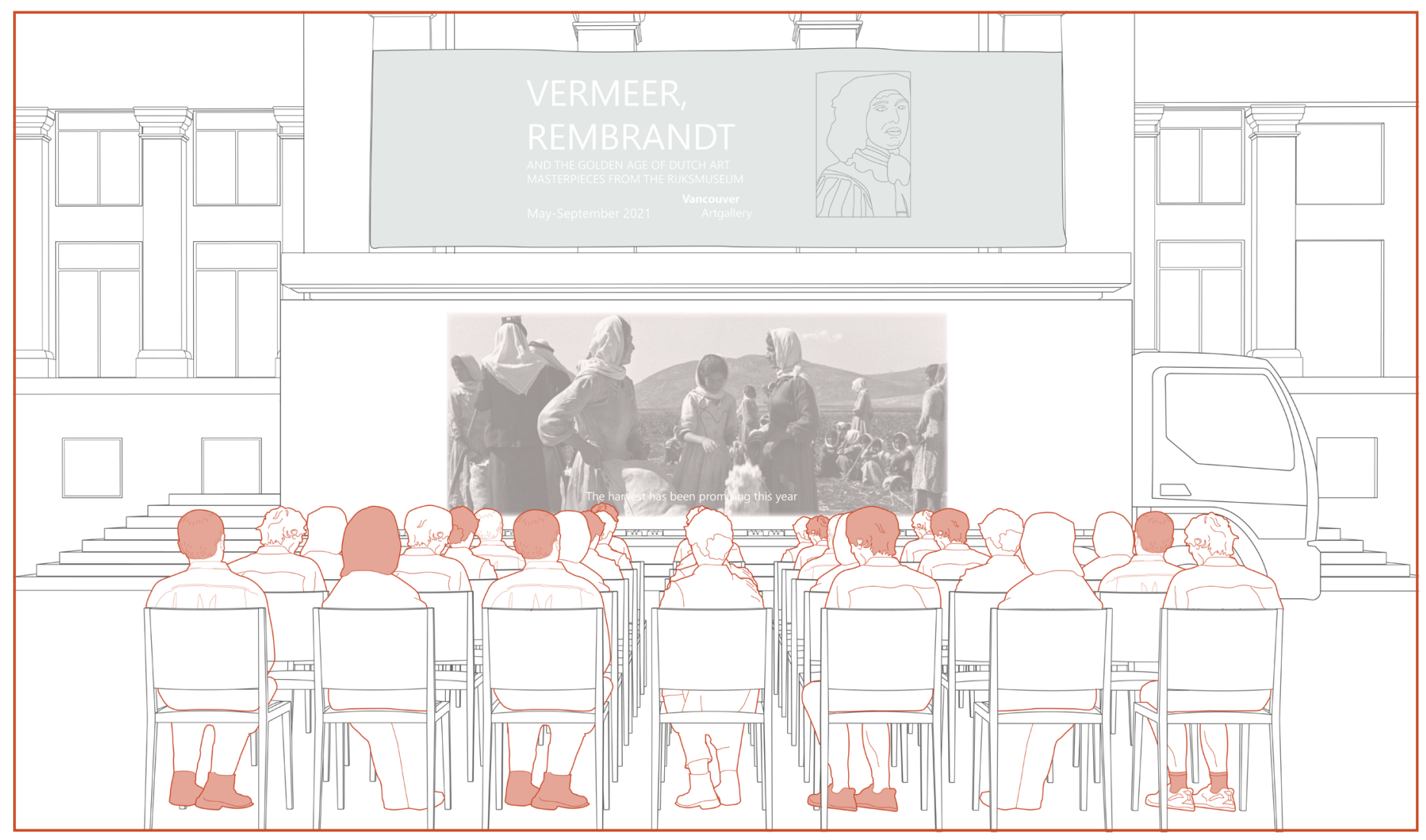

Figure 6.18 - Documentary Screening, Vancouver Art Gallery 


\subsection{Recipe Sharing}

The importance of cuisine in bringing people together has a critical place in the creation of the travelling kitchen pavilion. The opportunity to share and exchange recipes on the verge of vanishing aids in preserving and promoting Palestinian dishes. By doing so, not only the Palestinian user enjoys such an act of preservation, but also the public is provided with access to an extraordinary collection of unique recipes. The casual format of the pavilion is intended to host at a neighborhood scale, providing cooking sessions during which users are expected to share recipes and ingredients, and cook based on them. The recipes provided then get scanned and stored digitally. The eventual goal is to compile all recipes into a cookbook that could be housed in the pavilion and shared with the public.

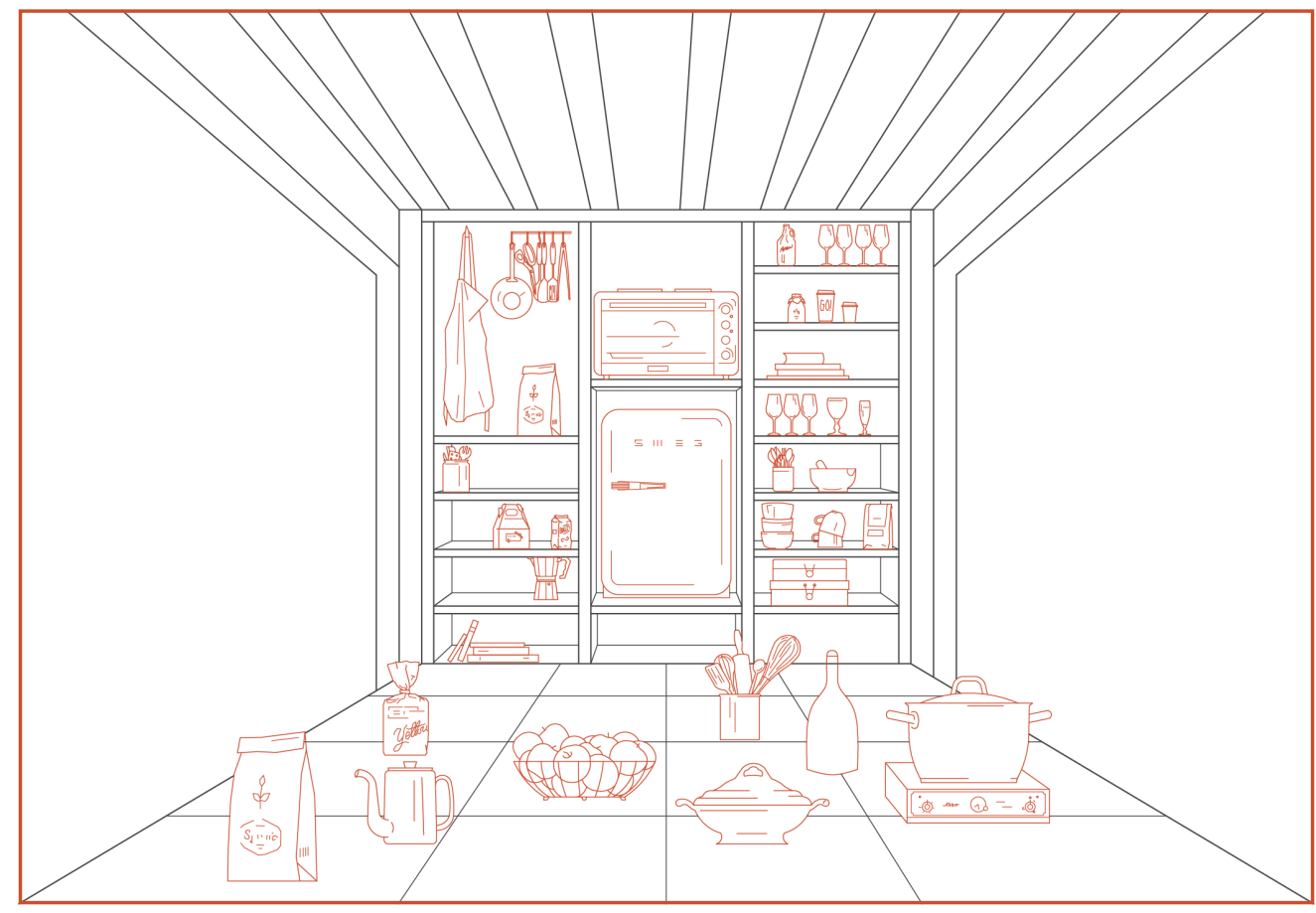

Figure 6.19 - Kitchen, Interior 


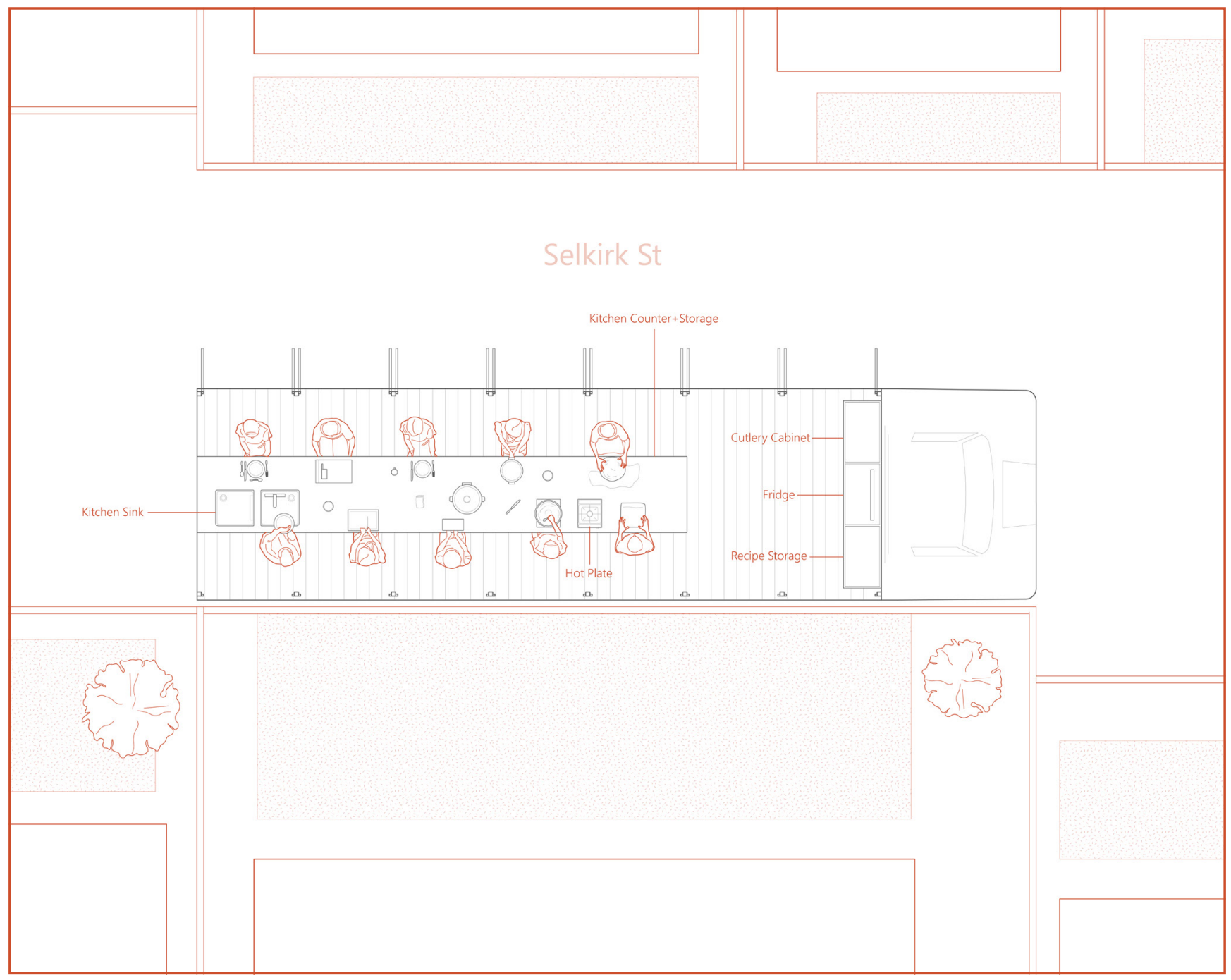

Figure 6.20 - Recipe Sharing Casual Plan, Selkirk Street

The madafah is shown in its possible configuration on Selkirk Street in Vancouver, Canada. The truck is parked adjacent to a nearby lot, allowing the person in charge to host their community. The madafah serves as a communal kitchen for the residents of the selected neighborhood. The madafah contains an archive that is used for collecting recipes from community members which are ultimately complied into a book. The space can also be used for providing cooking sessions based on the collected recipes. 


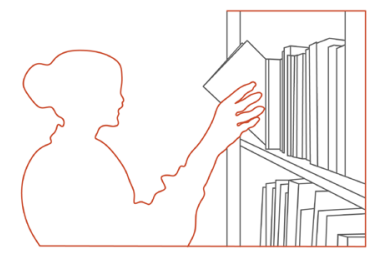

Access to a a recipe archive that is updated regularly by users and contributers to the Kitchen.

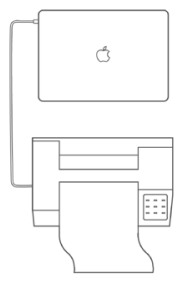

Recipes are stored digitally and available in print to be ready for use in the kitchen.

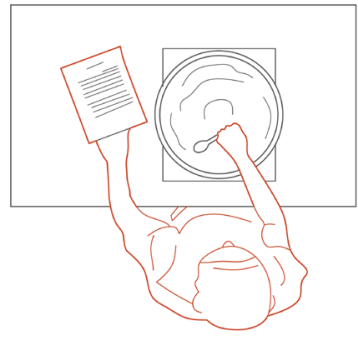

Stored recipes make their way into the kitchen to be put into use.

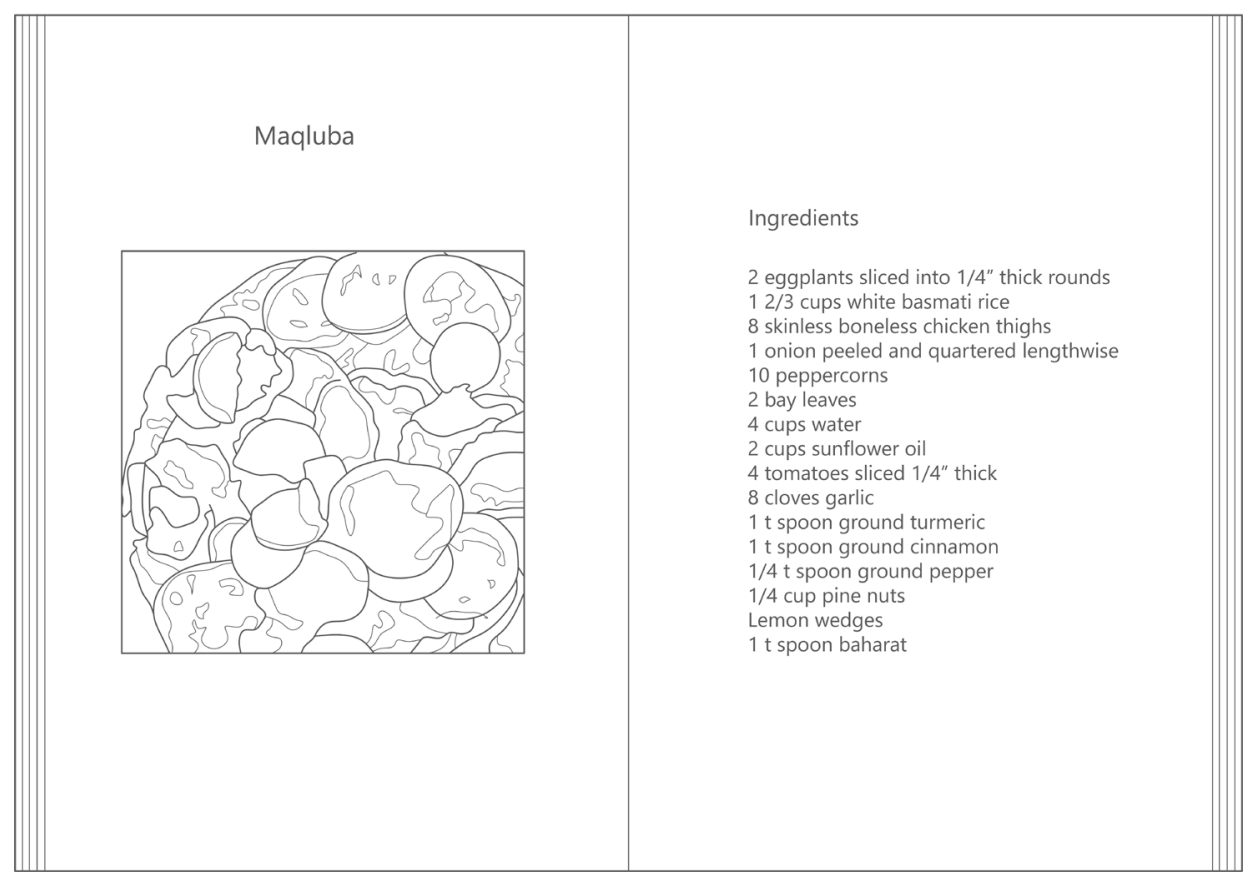

Figure 6.21 - Recipe Collection 

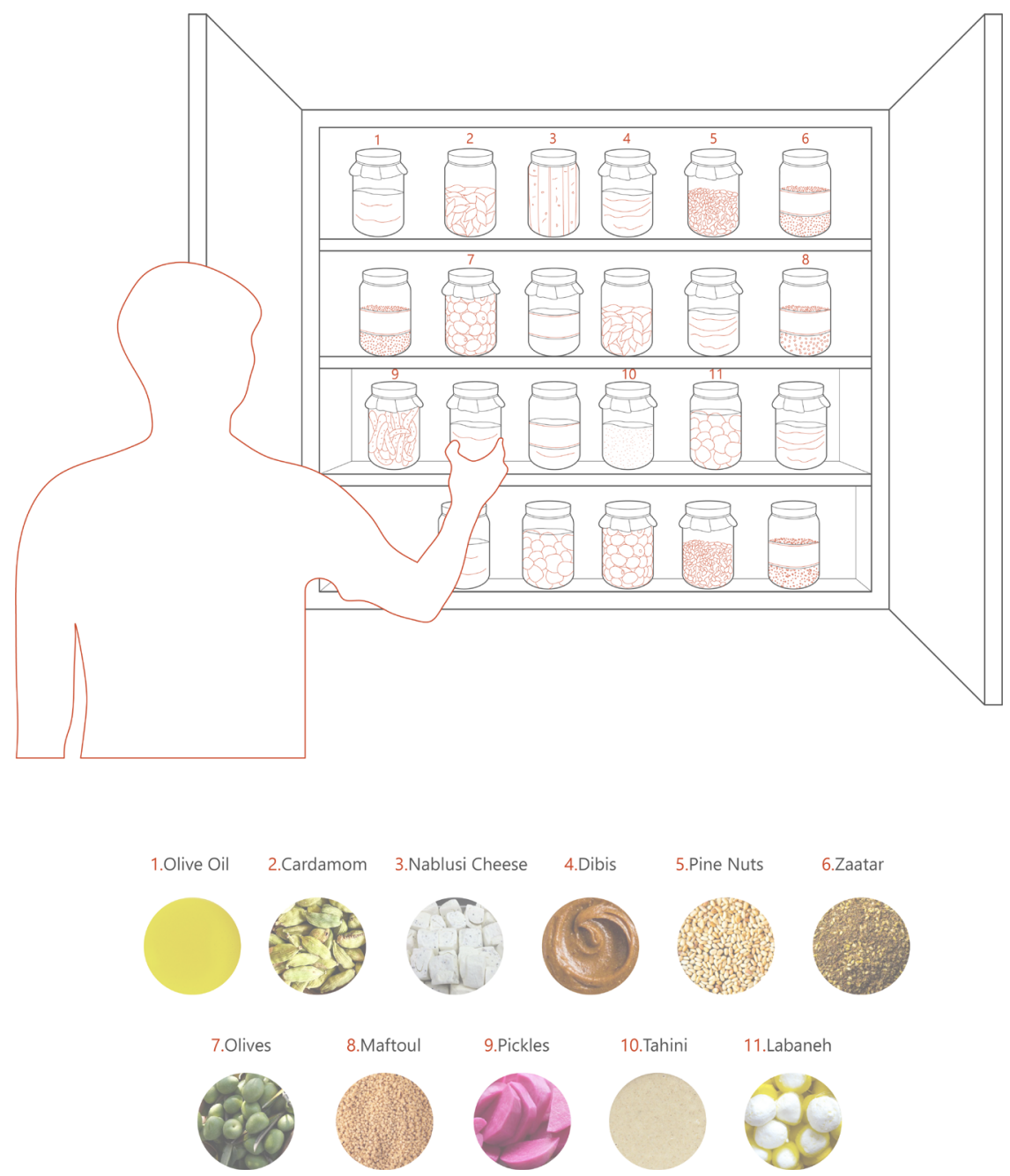

Figure 6.22 - Ingredient Repository 
The UBC SPHR organization is considered a potential host for organizing recipe-sharing events. Over the past few years, the group has hosted and promoted events that aim to introduce Palestinian cuisine to the public. The large-scale scenario situates the madafah at Stanley park in Vancouver, which aims to serve the produced food to the public, where those who do not cook can participate and learn about the cooking process and the recipes. A series of removable panels can be unhinged to allow for the madafah to have a seamless connection to exterior. A sliding roof assembly allows for an extension of the space towards the exterior, creating a shelter over a public dining space. As a result, the interior is designated as a production zone and the exterior is reserved for serving the dishes prepared in the kitchen. By sliding out two stored surfaces that act as tables, the stage is set for a dining event that takes place outside the madafah, while cooking still takes place on the inside. The table remains a central element in every madafah around which people gather to perform a variety of activities. Here, the table serves as a platform for cooking and dining. 


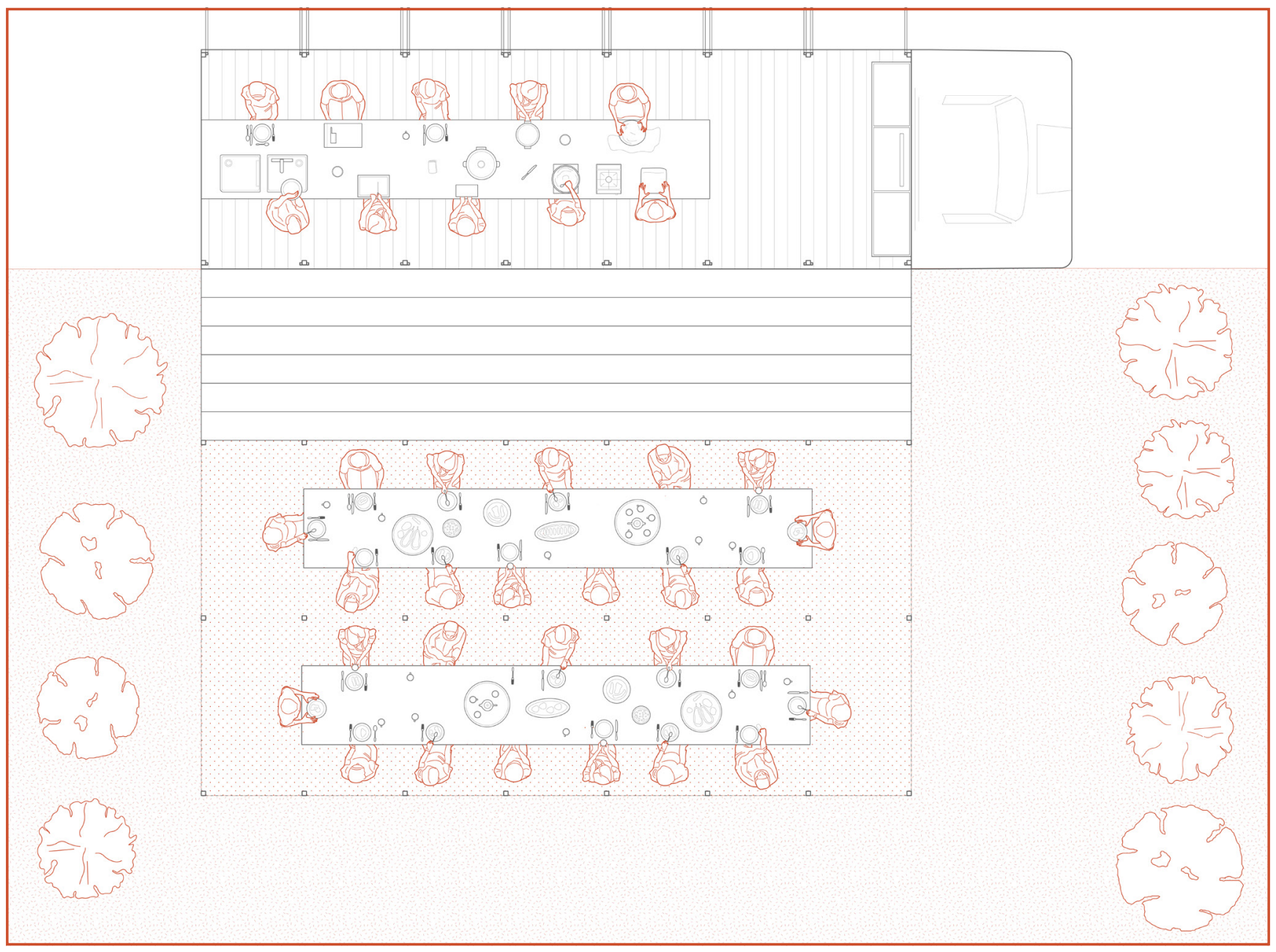

Figure 6.23 - Recipe Sharing Event Plan, Stanley Park

The madafah is shown in a configuration that serves to host a group dining event at Stanley Park in Vancouver, Canada. The space here serves a larger community in comparison to its neighborhood version. The interior serves as a community kitchen. The sliding roof extends outwards to create a sheltered area for hosting group dining. 


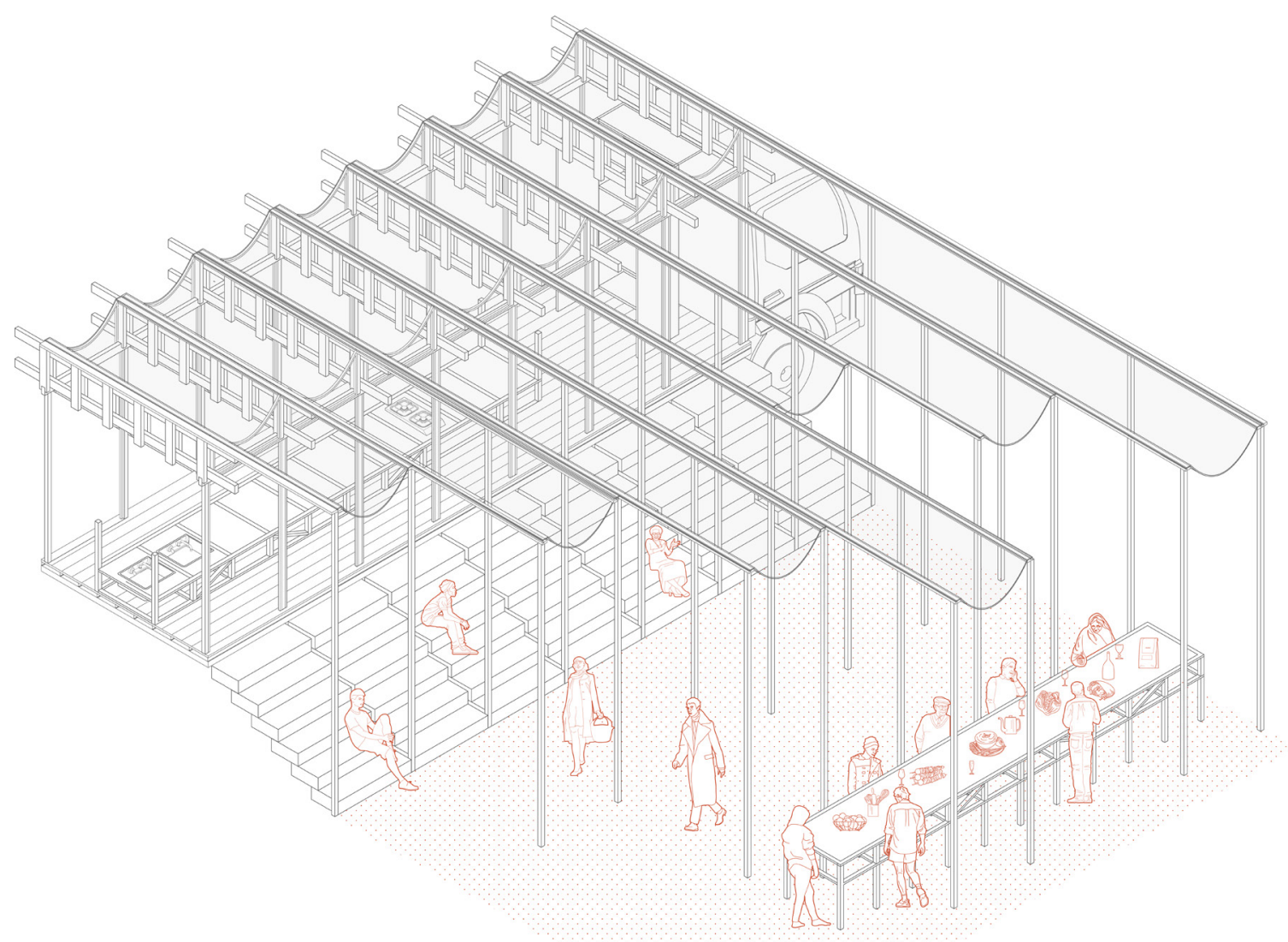

Figure 6.24 - Recipe Sharing Event, Axonometric 


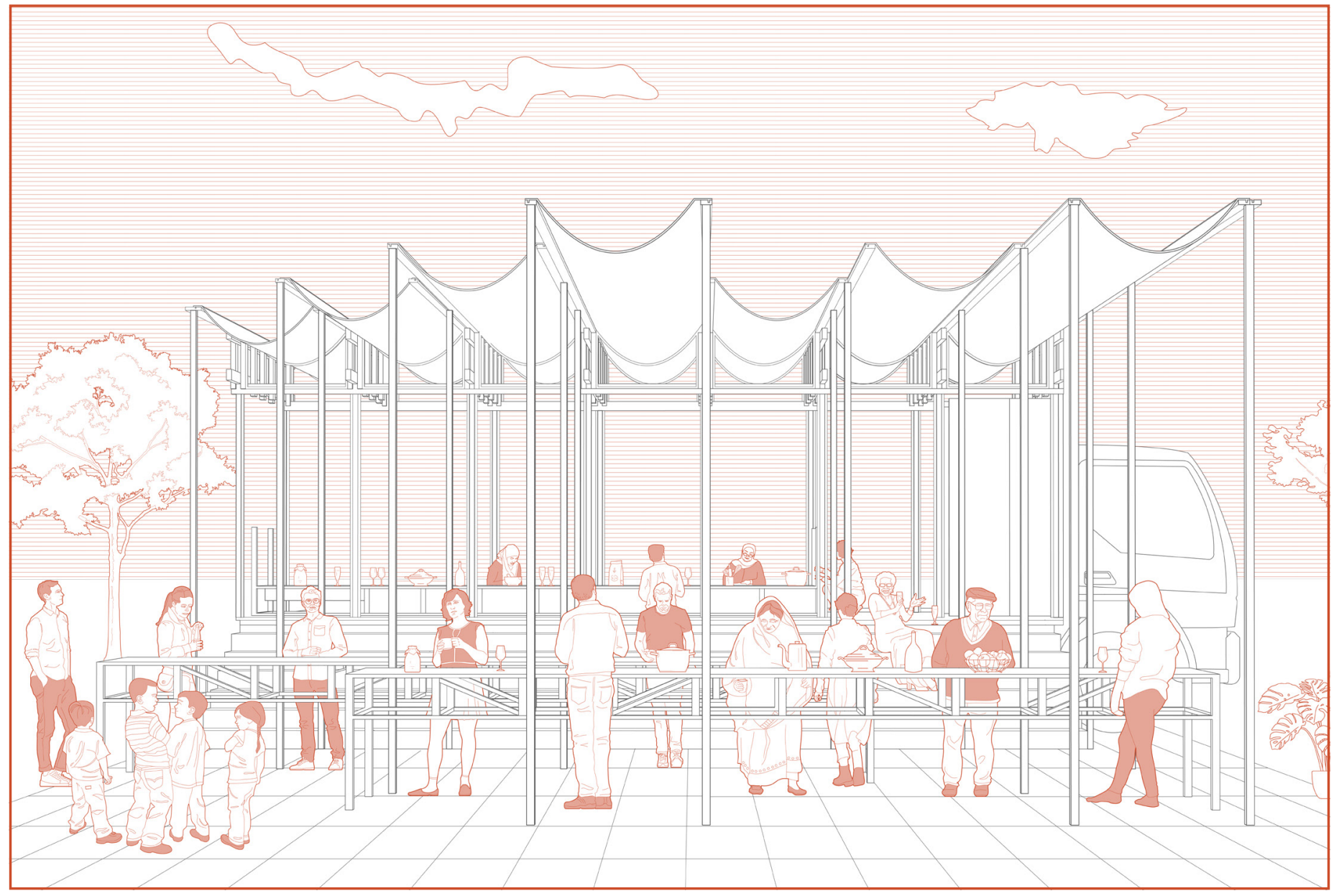

Figure 6.25 - Recipe Sharing Event, Stanley Park 


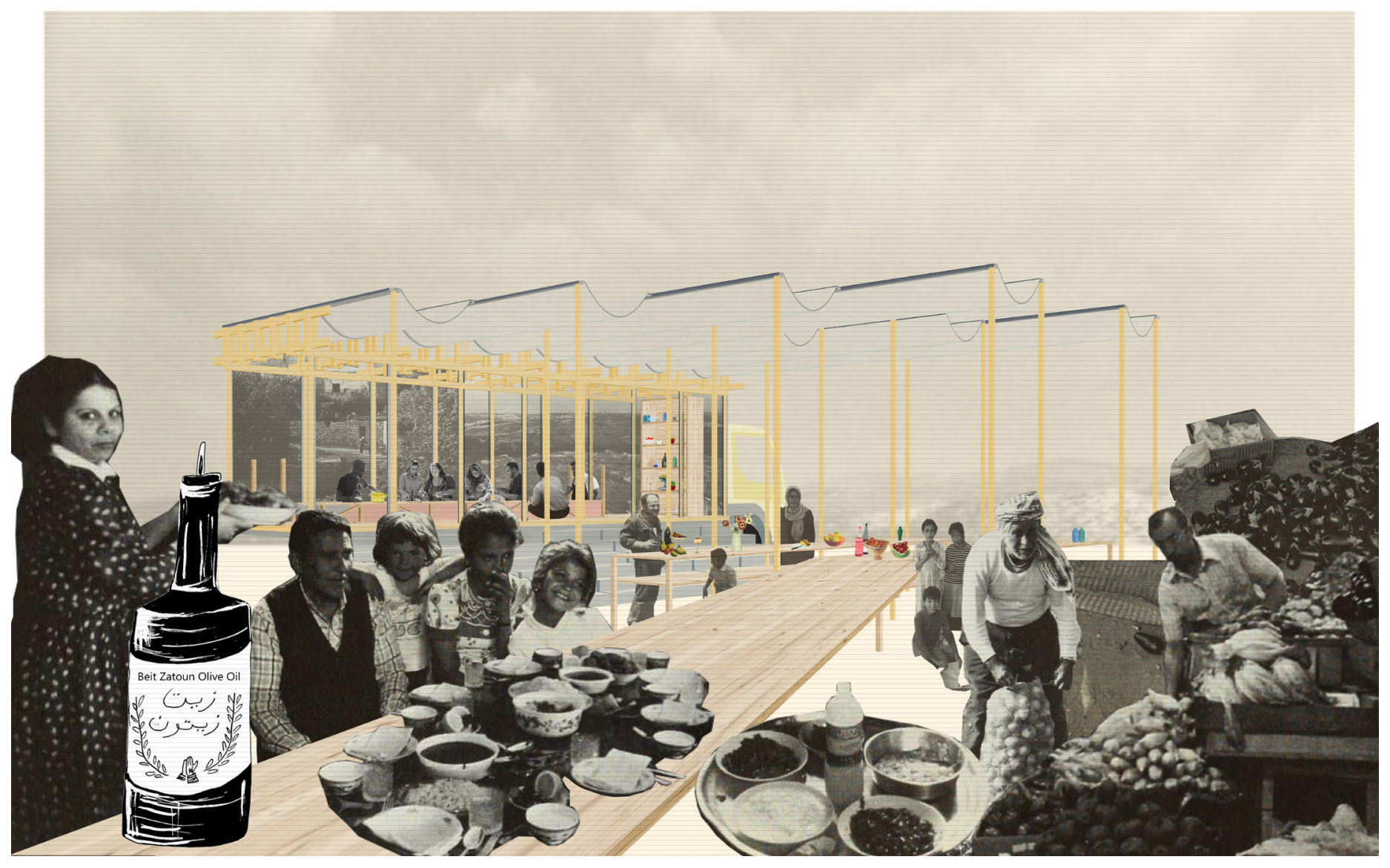

Figure 6.26 - Recipe Sharing and Memories 


\section{Conclusion}

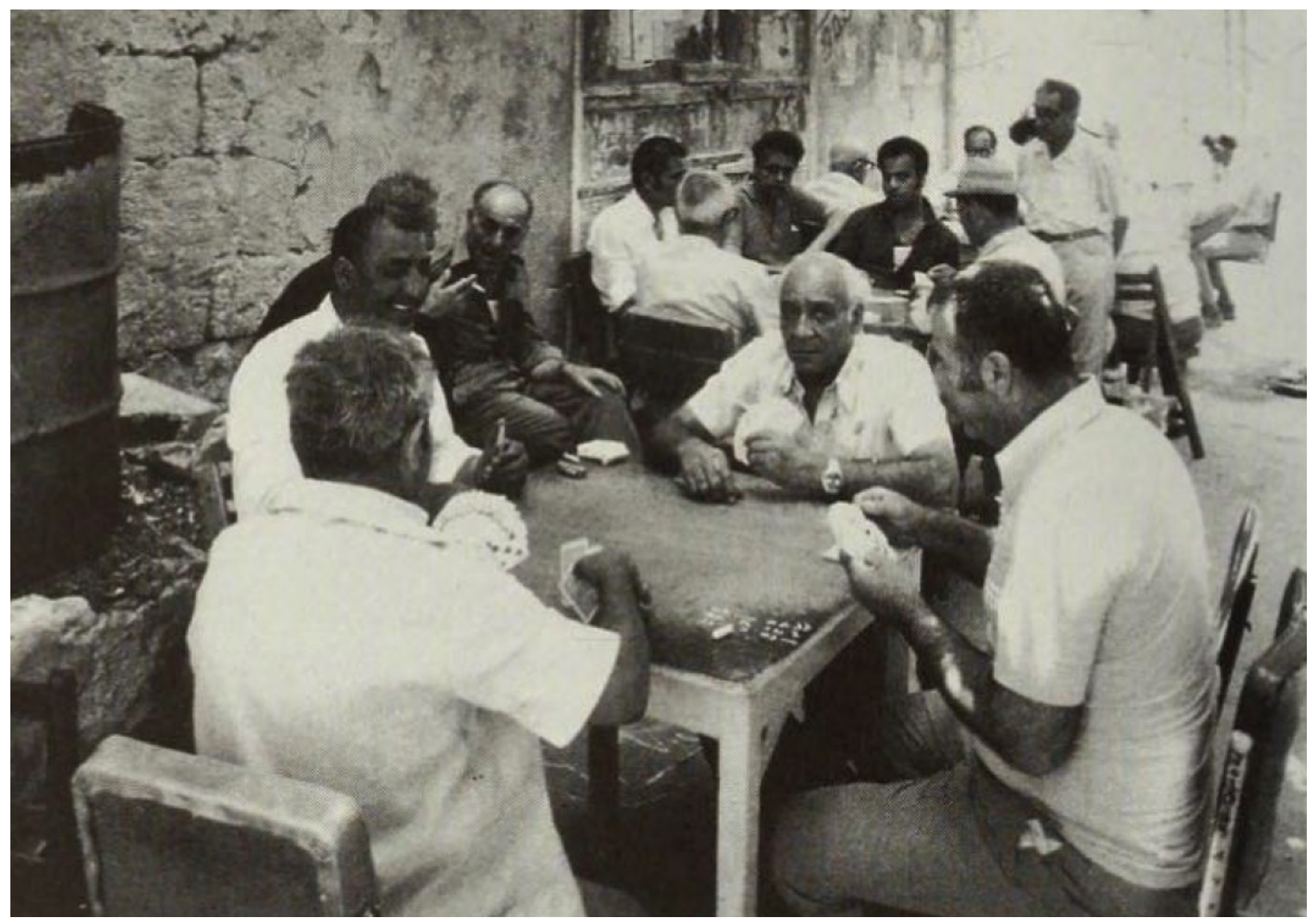

Figure 7.0 - Acre, 1979. A Café at the port. 


\subsection{Permanent Temporariness}

The subject of temporariness in this thesis is embedded in the mobility of the pavilions. The intent is to situate the debate regarding the madafah's mobility at the center of the controversy. The argument that Palestinians are always temporarily awaiting a return is put forward to be shown and problematized through the mobile madafah. The aspect of 'temporariness' is a critical part of Palestinian identity, prone to contradictory realities of the Israeli occupation. The temporary rejects the bitter taste of defeat, the everlasting future of exile, and challenges dispossession. The Palestinian temporary counters the Israeli side's temporary. Israel has exploited upon the unilateral excuse of labelling the occupation with a temporary status, one that provides a nullified justification over employing various means to reinforce and continue the occupation. Thus, temporary is a form of resistance to Palestinians; a firm belief in their identity and forced dislocation, and a clear rejection of becoming permanent Israeli subjects. If such status is granted, it would ultimately erase a Palestinian presence not only in demographic terms but also as a historical entity.

As various scholars such as Weizman ${ }^{1}$ and Frantzman² have shown, Israeli citizenship would not include the same equal rights to Palestinians as Israelis. Memories lost but not forgotten, houses destroyed but keys still kept; the vanishing visage of a forsaken past that has been deprived of men, women, and children, who once inhabited places that are no longer theirs, or erased off the ground. Palestinian architect Sandi Hilal and Alessandro Petti elaborate on the condition of 'permanent temporariness' in their book of the same title. ${ }^{3}$ The term alludes to the on-going and seamless situation in Palestinian refugee camps. The notions of alienation and non-belonging are the

1 Weizman, Eyal. Hollow Land Israels Architecture of Occupation. London: Verso, 2017.

2 Frantzman, Seth J. "The Power of Inclusive Exclusion: Anatomy of Israeli Rule in the Occupied Palestinian Territories - Edited

by Adi Ophir, Michal Givoni, and Sari Hanafi." Digest of Middle East Studies 19, no. 2 (2010)

3 Hilal, Sandi, and Alessandro Petti. Permanent Temporariness. Stockholm: Art and Theory Publishing, 2019. 
key principles that describe the permanent state of temporariness. The temporary state that comes as a result of displacement is deliberately explained by the Palestinian-Canadian architectural graduate, Reem Awad, in her thesis work. Awad states that the refugee's perception of space and status is essentially what really defines the temporary state. This is reflected through stories and memories that refugees often share from their villages to keep alive their narratives and establish a commitment to return. ${ }^{4}$

Refugee camps try to insist on their temporariness while, by contrast, those living in the West Bank (especially Area C) and Gaza fight to hold onto their permanence. Diasporic space is ambivalent and contested in its nature; not temporary, not permanent but both. The mobile madafah essentially captures such hybrid quality. The madafah which is studied as a conceptual and spatial precedent for the spatial intervention was known in the Arab world to be a space that was always about transience (people coming going at a guesthouse). It would function as a space that would be separate from the permanent family dwelling to become an arena of tense discussions and avoid disrupting the ordinary routine of home life. Similar to the old guest house, the mobile madafah aims to serve the community through social activities but the underlying purpose is to provoke in public arenas about the right of return. The mobile space acknowledges that community members have rooted houses, and rather stresses population flows and exchange of thoughts in a semi-public setting. The madafah could rather be viewed as an in-between space that retains qualities of both the domestic private home and the public realm. It offers some level of privacy and protection but also situates itself in a public setting.

4 Awad, Reem "The Palestinian Refugee Camps: From Crisis to Cultural Heritage." (2019). 


\subsection{Concluding Remarks}

The cultural dimension of the intervention, as well as its political force dictate a site of spatial production, where the user has a role in the formation of space through their contribution to the guest house. Archiving, in essence, is an active force of production. In the case of the programs hosted by each mobile madafah pavilion, each user is considered a spatial agent. Despite the speculative nature of this thesis, the research relies heavily on firsthand knowledge and testimonies from members of the community that reflect on real life-experiences in diaspora. The two parts of the thesis, the atlas and the intervention, complement each other in the formation of memory and space. The idea of the guest house was formed through the collected narratives from the atlas. At the same time, the proposed intervention seeks to produce archival documents similar to the atlas itself, which would be accessible to the public. In this case, the atlas becomes the product of the space, whereas for this thesis, the space is conceived through the atlas. Moving forward, both can work together iteratively to inform the role of design amidst an evolving sense of Palestinian diasporic identity.

The engagement of the public and their familiarity with unique Palestinian experiences opens up an opportunity to create solidarity among multiple ethno-cultural groups in the Canadian context. In the recipe sharing madafah, community members not only get exposed to unique traditional recipes of Palestinian cuisine, but also engage in conversations that allow for an exchange of knowledge. It is rather through identifying similarities and contrasts between cultures that a mutual understanding is formed. A difference or similarity in the use of ingredients for a particular recipe would allow a guest to share their own cuisine with the Palestinian community, and eventually reflect on other aspects of both cultures depending on the course of the conversation. The use of performance in the madafah as a medium for sharing expe- 
riences emphasizes the importance of human senses in reviving memories. A familiar smell from a dish can revive a memory from the past that can be shared with others. Likewise, a specific texture or subtle change in the stitch used in the practice of tatreez may call to one's mind a comparison with their own traditional embroidery. Images and films also contribute to share visual and auditory memories with the public. The intent here is not a full introduction of various customs but an exchange of glances through activities that reactivate memory. The circulation of words and the course of interactions are emphasized for their randomness, where there is no clear intention behind sharing memories and experiences. Indeed, the corresponding information is borne out of action.

The process of interviews was in essence a critical component of the thesis in terms of having real-life exposure to memories and experiences of the Palestinian community in Canada. Given that the intent behind the interviews was not to achieve a mere generalization, the rich diversity of experiences shared by community members allowed for capturing Palestinian diaspora from very distinct lenses. As an architectural research, the spatial indication of interviews was a key factor in understanding and documenting lived experiences in diaspora. The spatial dimension of each narrative helped elucidate certain aspects of the Palestinian diasporic experience that are best presented visually. In other words, the visual documentation served to depict instances where the verbal description came secondary as a mode of expression. The interviews were not only important as a guide for visual documentation but also as a conceptual framework for the development of the design intervention.

The premise of this thesis is to establish a point of connection to Palestinian life in diaspora through memory formation, where the exchange of knowledge and community narratives are treated with respect to their randomness and the ordinary nature. 
The sequence through which this thesis was developed is a reflection of reclaiming memories through social gestures. By giving this document back to the community, the thesis provides a starting point for them to discuss their spatial needs and orchestrate activities that best suit them. It is hoped that similar to the development of this thesis, the Palestinian community continues to expand such archival body of information as community members add their lived experiences to the atlas. In the same manner, the intervention would rely on the community for the items that they bring to each madafah and the activities in which they take part. 


\section{Bibliography}

Abdo-Zubi, Nahla, and Nur Masalha. An Oral History of the Palestinian Nakba. London: Zed Books, 2018: 17

"About Us." Beit Zatoun. January 21, 2014. Accessed February 27, 2021. http://beitzatoun.org/about/.

"ABOUT TPFF." Toronto Palestine Film Festival. Accessed February 27, 2021. https://www.tpff.ca/ about-tpff.

Agnew, Vijay. Diaspora, Memory and Identity: A Search for Home. Toronto: University of Toronto Press, 2013: 204

Al-Barghouti, Mureed. "Songs for a Country No Longer Known." Journal of Palestine Studies 27.2 (Winter 1998): 60-61

AlSayyad, Nezar. Hybrid Urbanism: On the Identity Discourse and the Built Environment. Westport, CT: Praeger, 2001: 5

Arjun Appadurai, Modernity at large: Cultural dimensions of globalisation (Minneapolis: University of Minnesota Press, (1996): 24

Atlas Al-'Ain: The Performativity of "return" and Common ..." Accessed September 20, 2020. http:// parsejournal.com/article/atlas-al-ain/.

Awad, Reem "The Palestinian Refugee Camps: From Crisis to Cultural Heritage." (2019).

Awan, Nishat, Tatjana Schneider, and Jeremy Till. Spatial Agency: Other Ways of Doing Architecture. London: Routledge, 2011: 29

Awan, Nishat. "Diasporic Urbanism: Concepts, Agencies \& Mapping Otherwise." PhD Dissertation: 9

Badil Resource Center for Palestinian Residency and Refugee Rights. Survey on Palestinian Refugees and Internally Displaced Persons 2008-2009. Bethlehem: Badil Resource Center for Palestinian Residency and Refugee Rights, 2009: 57-59

Bertman, Stephen. Cultural Amnesia: Americas Future and the Crisis of Memory. Westport, CT: Praeger, 2000: 31

Bhabha, Homi K. "Culture's In-Between." Questions of Cultural Identity Stuart Hall and Paul du Gay. London: Sage, 1996: 54

Bhabha, Homi K. Nation and Narration. London: Routledge, 1991: 314

Clifford, James. 1994. Diasporas. Cultural Anthropology 9(3): 307

Clifford, James. 1994. Diasporas. Cultural Anthropology 9(3): 305.

Frantzman, Seth J. "The Power of Inclusive Exclusion: Anatomy of Israeli Rule in the Occupied Palestinian Territories - Edited by Adi Ophir, Michal Givoni, and Sari Hanafi." Digest of Middle East Studies 19, no. 2 (2010) 
Gieseking, Jack Jen. "Where We Go From Here." Qualitative Inquiry 19, no. 9 (2013): 712-24. Hilal, Sandi, and Alessandro Petti. Permanent Temporariness. Stockholm: Art and Theory Publishing, 2019.

Hirsch, Marianne, and Valerie Smith. 2002. Feminism and Cultural Memory: An Introduction. Signs: Journal of Women in Culture and Society, 28(1): 9

"Hosting Is Power and by Having Power You Become Visible" - ArkDes - Swedens National Centre for Architecture and Design." ArkDes. September 18, 2020. Accessed November 26, 2020. https://arkdes. se/en/hosting-is-power-and-by-having-power-you-become-visible/.

"Introduction." DAAR, 25 Jan. 2016, www.decolonizing.ps/site/site3-returns/.

Kadman, Noga, and Dimi Reider. Erased from Space and Consciousness: Israel and the Depopulated Palestinian Villages of 1948. Bloomington, IN: Indiana University Press, 2015: 35

Khalidi, Rashid. Palestinian Identity. Columbia University Press, 1997.

Khouri, Rami G. "Saudi Aramco World : Room for Tradition." AramcoWorld. Accessed January 23, 2021. https://archive.aramcoworld.com/issue/199303/room.for.tradition.htm.

Molavi, Shourideh C. Stateless Citizenship: The Palestinian-Arab Citizens of Israel. Chicago, II.: Haymarket Books, 2014: 7

Knudsen, Are J., and Sari Hanafi. Palestinian Refugees: Identity, Space and Place in the Levant. London: Routledge, 2011.

Lefebvre, Henri. The Production of Space. Malden, MA: Blackwell, 2016: 31

Makdisi, Saree. Palestine inside Out: An Everyday Occupation. New York: W.W. Norton, 2010.

Mason, Victoria. "Children of the "Idea of Palestine"1: Negotiating Identity, Belonging and Home in the Palestinian Diaspora." Journal of Intercultural Studies 28, no. 3 (2007): 272.

Omar Salih-El-Barghuthi, "Rules of Hospitality ( Qanun Yd-Diyafeh)," Journal of the Palestine Oriental Society 4, no. 4 (1924): 178-79

"Palestine Heirloom Seed Library." Visibleproject. Accessed October 21, 2020. https://www.visibleproject.org/blog/project/palestine-heirloom-seed-library/.

Pappé, Ilan. A History of Modern Palestine One Land, Two Peoples. Cambridge: Cambridge University Press, 2014: 141

"Present State of Conservation." E. Accessed March 24, 2021. https://www.e-flux.com/architecture/ refugee-heritage/100716/present-state-of-conservation/.

Safran, William. "Diasporas in Modern Societies: Myths of Homeland and Return." Diaspora: A Journal of Transnational Studies 1, no. 1 (1991): 83-88

Said, Edward W. Reflections on Exile and Other Essays. London: Granta Books, 2012.

Slyomovics, Susan. The Object of Memory: Arab and Jew Narrate the Palestinian Village. Philadelphia: University of Pennsylvania Press, 1998: 137 
Suad Amiry, "Space, Kinship and Gender: The Social Dimensions of Peasant Architecture in Palestine" (Ph.D. diss., University of Edinburgh, 1987): 3

"The Right to Host." E. Accessed November 26, 2020. https://www.e-flux.com/architecture/overgrowth/287384/the-right-to-host/.

Weizman, Eyal. Hollow Land Israels Architecture of Occupation. London: Verso, 2017. 